




\section{PEARLS and PEARLING}




\author{
COPYRIGHT 1913.
}

BY FUR NEWS PUBLISHING CO. 



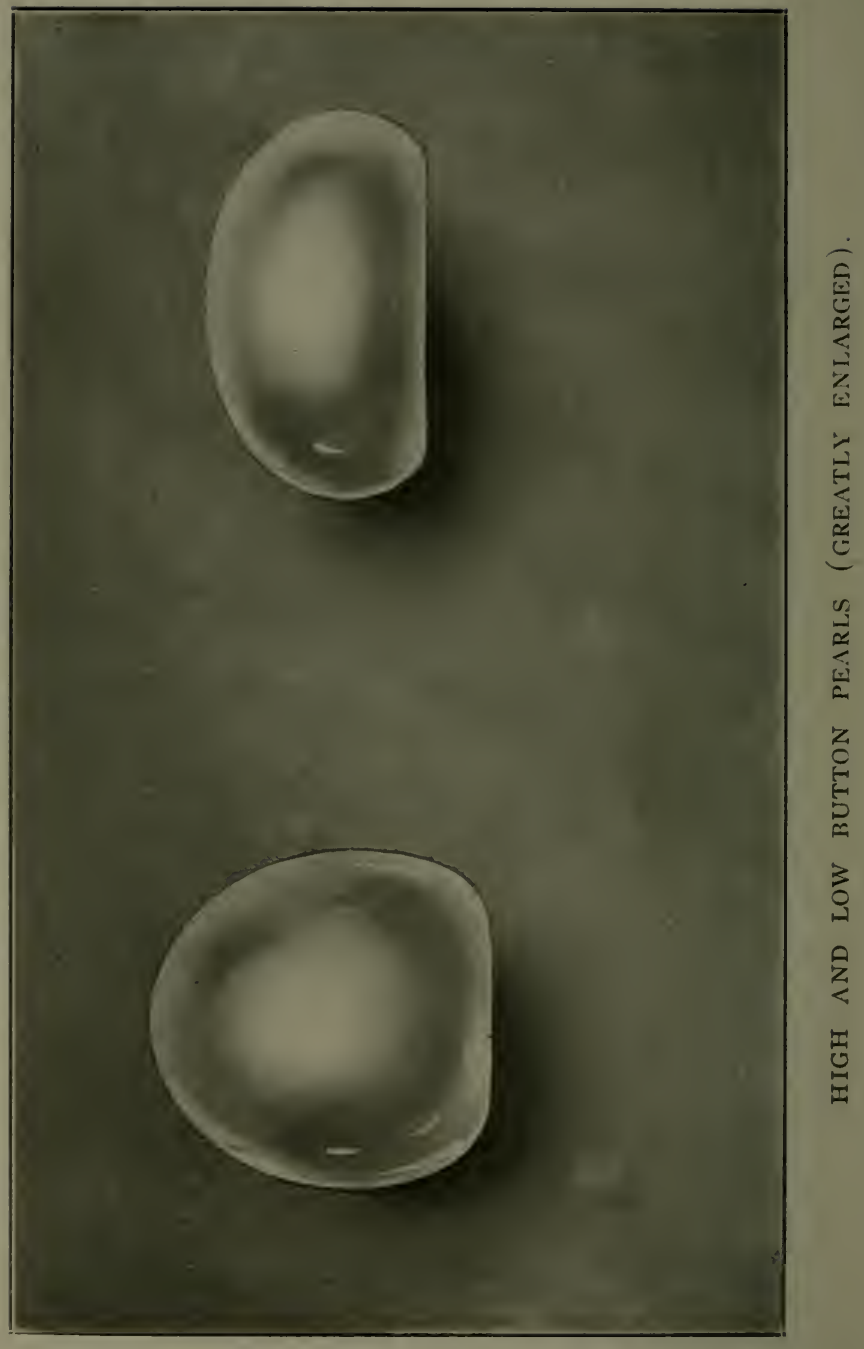




\section{Pearls and Pearling}

BY

HERBERT H. VERTREES

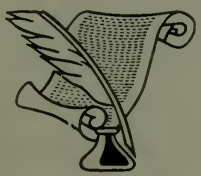

FUR NEWS PUBLISHING CO.

71 West 23rd Street

NEW YORK 


\section{PREFACE.}

FEIV years ago I temporarily set aside my work
as a salesman to hunt for pearls on the lllinois
River.

The work in the pure air and sunshine; and the ever present hope of finding valuable pearls, were so fascinating I did not like to leave the occupation, so I continued with the work and studied most of the subjects relating to it.

Desiring to prepare for the business in a very thorough manner I tried to purchase a book upon the subject, but none was printed. There has been a general demand for information on pearl hunting and, at the request of the Fur News Publishing Company, I have written this book, which I hope will prove of value to my fellow-men.

It is intended especially for pearl hunters and those who contemplate entering the profession, although I shall be pleased if it is of.interest to jewelers and lovers of pearls in general.

My aim has been to explain all parts of the work so thoroughly that one entirely unacquainted will after reading this book, not only understand the methods and appliances, but be able to hunt for pearls successfully. I 
earnestly hope that all who read this book may be so fortunate as to find valuable pearls.

I am pleased to thank the friends who have supplied photographs, and am especially grateful to Messrs. Combes \& Van Roden, of Philadelphia, for the loan of the original photographs of members of the English nobility.

\section{Herbert H. Vertrees.}

Pittsfield, Illinois, May 23, I9I3. 


\section{CONTENTS}

Chapter

Page

I The Fresh-IVater Pearl............ I3

II The Origin of the Pearl............ I9

III The History of the Pearl........... 29

IV Pearls are Found in Most Rivers of the

United States and Canada.......... 39

$\checkmark$ The Life of the Unio............. 49

VI Perils and Enemies of Mussels......... 60

VII The Need of Laws for the Benefit of Pearl

Hunters .................. $6_{5}$

VIII Various Kinds of Unio Shells........ 72

IX Value of Uses of Shells........... 87

X How to Prospect for Pearls........... 99

XI How to Make a Crow-foot Dredge Outfit. . Io8

XII How to L'se the Crow-foot Dredge Outfit. . I2I

XIII The Dip Net and Its Use.......... I30

XIV Other Methods of Pearl Fishing....... I37

XV Methods of Opening Shells and Extracting

Pearls .................. $\mathbf{4} 45$

XVI Why Trappers Make Good Pearl Hunters. I5I 
Chapter

XVII The Particular Kind of "Crippled" Shell that Yields the Pearl ............ I55

XVIII The Influence of Local Conditions upon the Color of Shells and Pearls......... I $6_{5}$

XIX The Luster of the Pearl-Its Cause Explained ................ I73

XX The Care, Value and Sale of Pearls...... I78 XXI Imperfect Pearls and How to Improve Them ................ I90

XXII Imitations and Tests for Detecting Them.. I94 XXIII An Interesting Exhibit of Pearls....... 20I 


\section{LIST OF ILLUSTRATIONS}

Page

High and Low Button Pearls................ Frontispiece

Ball Pearl and Pear Pearl....................... 12

Japanese Culture Pearls......................... 28

H. M. Queen Alexandra......................... 32

Lady Howard de WValden........................ 43

Interior view of Quadrula heros, or "Washboard" shell... 51

Quadrula heros, or "Washboard" mussel exposed........ 53

Lampsilis rectus, or "Black Sand Shell".............. 56

Rock bass infected with glochidia................... 59

The Quadrula heros, or "Washboard" ............... 73

The Quadrula ebena, or "Niggerhead" ................ 73

The Lampsilis rectus, or "Black Sand Shell"............ 76

The Lampsilis anodontoides, or "Yellow Sand Shell"...... 76

The Lampsilis fallaciosus, or "Slough Sand Shell"........ 76

The Quadrula undulata, or "Three Ridge"............. 78

The Lampsilis ligamentinus, or "Mucket".............. 78

The Quadrula pustulosa, or "Warty-luack," or "Pimple-

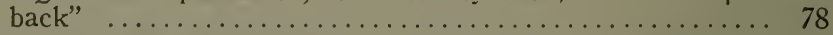

The Tritogonia tuberculata, or "Buckhorn," or "Deerhorn" 81

The Quadrula lachrymosa, or "Stranger," or "Maple-leaf" 81

The Plagiola securis, or "Butter-fly"............... 81

The Lampsilis ventricosus, or "Pocket-book"............. 83

The Symphonota complanata, or "Razor-back," or "Hatchet-

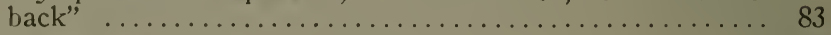

The Quadrula obliqua, or "Pigtoe"................ 85

The Quadrula metanevra, or "Monkey-face"............ 85

The Unio gibbosus, or "Ladyfinger," or "Spectacle-case"... 85

Gatlin's Landing........................... 90

"Washboard" shell from which button blanks have been cut. 93 
The Marchioness of Londonderry................ 98

View of Illinois River, showing method of locating nussel beds

"Crowfoot" Dredge Outfits......................... 109

The "Mule" .................................... 111

"Crow-foot" hook . . . . . . . . . . . . . . . . . . . . . 112

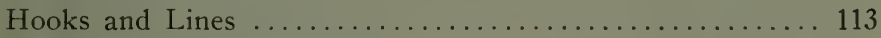

Outline Shape of "Crow-foot"..................... 114

Machine for Making Twisted Hooks................. 116

The "Crow-foot" Dredge Outfit in Use............... 127

The Dip Net............................. 131

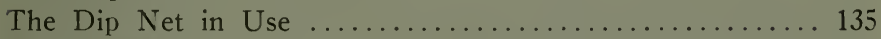

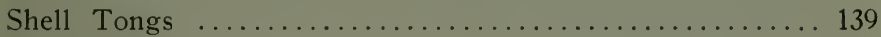

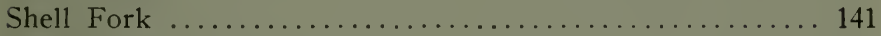

Eagle Claw Clam Rake........................... 143

Vat and Table for "Cooking Out" and Sorting Shells.... 149

Exterior View of the Worthless "Cripple" ............ 156

Exterior View of the Valuable "Cripple".............. 157

Interior View of the Worthless "Cripple" ............. 158

Interior View of the Valuable "Cripple," which Yields the Pearl

Plate I. Typical Pearl Shapes, Natural Size.......168 and 169 The Countess of Stradbroke ..................... 175

Cross Section View of Pearl and Onion.............. 177

The Marchioness of Lansdowne................... 180

Various Forms of Pearls..................... 183

Plate II. Typical Pearl Shapes, Natural Size........184 and 185

Some Average Run Slugs ...................... 18

Japanese Culture Pearl Attached to Shell............... 195 


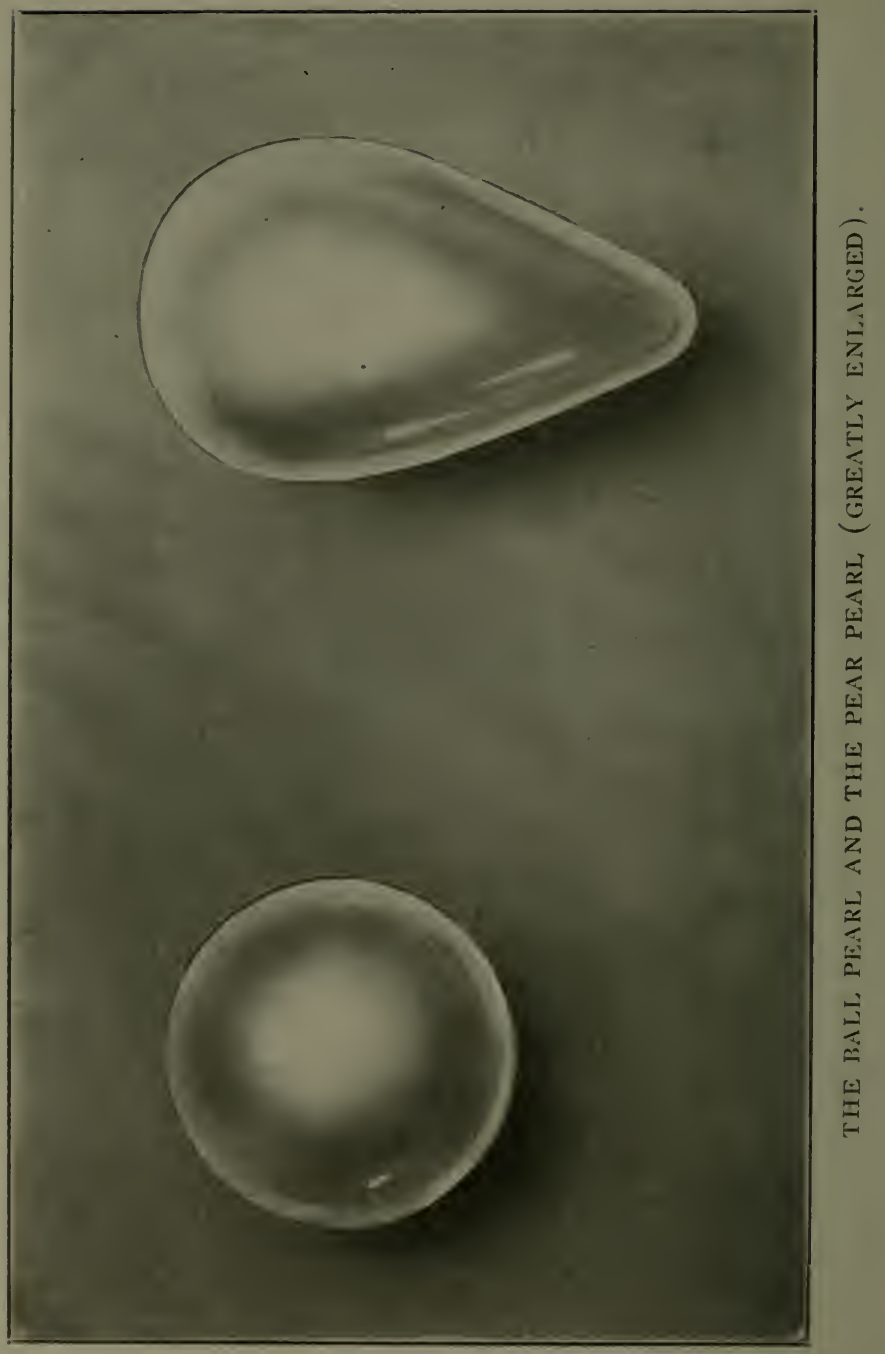




\section{CHAPTER I.}

\section{The Fresh-Water Pearl.}

$P$

EARLS are lustrous gems produced by certain Mollusks. They consist of thin concentric layers of carbonate of lime interstratified with animal membrane, and are the result of an unusual secretion, primarily caused by the introduction of a parasite or some other object within the mantle.

The exact composition of a pearl is as follows:

Carbonate of lime........... 91.72\%

Organic matter $\ldots \ldots \ldots \ldots \ldots \ldots .5 .94 \%$

Water ................... $2.34 \%$

These gems are clivided into two classes, known as Oriental and Fresh-Water Pearls.

The Oriental, or Ocean Pearl, is produced by the Avicula Margaritifera, or Pearl Oyster. Of this bivalve there are many varieties all differing in size, color, weight and quality of the shell.

The most important Oriental Pearl Fisheries are the following: Ceylon, Australia, Gambier, South Sea Islands, Arabian Sea, Bands, Costa Rica, Aroe, Haiti, Manilla, Venezuela, Panama and Lower California.

The Fresh-Water Pearl is produced by a mussel known as Unio Margaritifera. This name is applied to the mussels of our country. The name Naiades is a more gen- 
eral term and includes all fresh-water mussels, which are distributed over the entire globe and are found throughout the streams and lakes of all continents, as well as all the larger islands and some smaller islands.

The Unio Margaritifera is very common in North America and especially in the United States. These have a large variety of species also, and there are known to be living in North America nearly 600 different species of them. Most of these are found in the Mississippi drainage area and other streams emptying into the Gulf of Mexico from the north.

Many Mollusks are found in the streams emptying into the Great Lakes and St. Lawrence River. Many are also found in rivers that flow into the Atlantic Ocean. The rivers emptying into the Pacific Ocean do not contain many Mollusks and are not known as pearl streams. Most of the Fresh-Water Pearls come from the United States. In this book we shall give our attention almost entirely to subjects relating to Fresh-Water Pearls. Most of the Unionidae are Margaritiferous, or pearl bearing, although many of these varieties are uncommon and so we get most of our pearls from the varieties that are most abundant. Although these are very plentiful, the pearls are very scarce and one has no assurance of finding a pearl in a given number of shells. In some localities there are more pearls than other places; yet they are scarce, everywhere. This is not a bad feature after all as the scarcity of the pearls increases the value of the few that are found.

In Europe the Fresh-Water Pearls have held an im- 
portant place among the gems of the world since ancient times. They were used as articles of trade and barter with the Romans, and it is said that Cæsar undertook his British expedition partly for the purpose of finding pearls, and Pliny reports his bringing home a shield of British pearls, which he dedicated to Venus Genetrix. and hung up in her temple. An account of the pearl fisheries of Ireland was published describing the way the mussels lived in the swift rivers there. The men would find about one good pearl in 10,000 mussels.

Between 176 I and 1764 the Conway River, in Scotland, supplied the London market with about $\$ 50,000$.00 worth of pearls. The rivers of Cumberland, Conway and Tay. in Scotland, have in the past yielded fine pearls, and these gems are still found there.

Ireland still places pearls on the European market. These are from the Armagh River, in County Tyrone, and the Slavey River, in County Wexford. Some small pearls are found in the lakes in Finland. These are bluish white in color and resemble the Scotch pearls. Many beautiful pearls have been found in the rivers of France, Germany, Austria, Bavaria and many other countries.

In the United States fresh-water pearls were found several hundred years previous to the visit of Columbus. In the prehistoric times the Mound Builders who used to inhabit this country used these gems as ornaments, and archaeologists have unearthened large collections of pearls from the mounds in Ohio.

These pearls, however, were of no value because they 
had been pierced by a hot wire and also partly decayed by lying in the earth for such a long period of time.

When Columbus discovered America, he found the Indians wearing numbers of fresh-ivater pearls.

Upon his return to Spain, he presented to Queen Isabella a magnificent necklace of these American freshwater pearls. Other discoverers also found the natives with these pearls and prized them very highly, and some were so disrespectful as to rob the graves of Indian chiefs, while the Indian relatives of the dead monarchs were compelled to allow the depredations.

The first great "find" of our American people occurred in 1857 at Notch Brook, near Paterson, N. J. It weighed 93 grains and was sold to the Empress Eugenie, of France. It became known as the Queen Pearl. This event created great excitement and pearl hunting began throughout the country, and Unios at Notch Brook and elsewhere were destroyed by the million, but without much success. The experience at Notch Brook is only one of many "pearl fevers." In almost any locality where some good pearls have been found, many people leave good positions and nearly every one goes to the river to hunt for the very elusive pearl. The wholesale destruction of the mussels soon exhausts the local supply and the excitement subsides, and very few are rewarded for their work.

After a period of from five to ten years, during which interval the mussels have an opportunity to increase in size and numbers, the pearl fever is sometimes repeated with the same results. In the experiences just mentioned, 
the methods and appliances usually employed in the pearl hunts were very crude and primitive, and the people were without knowledge or skill in their work. It is quite likely that a man who has a good knowledge of the business, and who is skillful in the use of some of our modern appliances for pearl hunting. can now go into the same localities and work with a reasonable degree of success.

At the present time the industry known as pearl hunting differs widely from what it was many years ago. There is now in most instances a market for the shells and the appliances and methods used were not thought of twenty-five years ago.

The pearl hunting industry, or profession, as we may rightfully speak of it, is supported and elevated by many thousands of our best citizens who depend on this line of work for the necessities and comforts of life.

These men add continuously to the wealth of our land by raising from the watery depths the shells for many economic uses and the lustrous fresh-water pearls for adornment.

As a result of the efforts of pearl hunters the markets are supplied with thousands of American fresh-water pearls which are now the pride and delight of many ladies in America and Europe.

Among these American pearls are many of extraordinary size and beauty. Some of the large white pearls are so irridescent and clear that they possess great radiance and luster and are used in centers of very famous necklaces. 
Another important feature of the American freshwater pearls is the great variety of tints and colors found among them. This is not found in pearls of other lands, excepting ocean fisheries of Lower California, Colombia, Mexico and Panama, Gambier, and several unimportant fisheries. In our fresh-water pearls we find sky blue, peacock green, lavender, ruby, maroon, cherry, salmon, rose, bronze, purple, pink, gold, wine, gray, green, silver, black, bright yellow, red, blue, lead and brown. In fact, all shades of the rainbow are duplicated in these gems.

In addition to their color and sheen they are very irridescent. On account of their radiant layers some are more lustrous than the Ceylon pearls, and many of the lighter colored irridescent ones are nearly translucent.

For a long time the American fresh-water pearls were not fully appreciated by the European aristocracy and had to be offered under the name of oriental pearls to be sold; but now they are offered under their real name and stand on their own merits and reputation, and have nearly reached their deserved economic position among the gems of the world. Four rare American fresh-water pearls are very artistically portrayed in this book. The ball pearl, pear pearl, high-button pearl and low-button are well displayed in the illustrations. 


\section{CHAPTER II. \\ The Origin of the Pearl.}

NE may examine many thousands of mussels without finding a pearl. This fact often induces people to wonder why all mussels do not contain gems; or why any of the mollusks produce them; or what really causes the pearl to form. Many interested people have studied the origin of pearls and many theories have been advanced by noted scientists, but until the last few years there seemed to be no solution of the problem.

In order that we may consider this subject properly it will be necessary to first show the difference between the fine pearls and the various other nacreous formations. The fine pearls are found in the posterior part of the mussel, usually loose within the mantle of the mollusk. Sometimes these become attached to the shell near the mantle, and in very rare instances they go astray into some other part of the shell. The other nacreous formations are the common, irregularly shaped pearls which are not to be compared with the fine pearls in value. These are baroques and slugs and are not formed in the same manner as the fine pearls.

They seem to originate from a number of causes. Sometimes the shell of a mollusk is injured in an accident and some parts are broken off from the linge or others parts of the shell. Occasionally they seen to be 
small lumps of mother-of-pearl covered by the secretions of the mollusk. Then again they appear to be due to an irritation caused by the introduction of some foreign object. All these objects gradually become coated with layers of nacre.

These are found in a large variety of forms; but never assume the perfect shape of any of the styles of the fine pearls.

In this chapter, therefore, we shall give our attention mostly to the study of the formations that are only found in or near the mantle at the posterior or thin end of the shell.

As the pearl has been known for so many centuries, it is quite probable that its origin was a much debated question in ancient times; yet the old historians have not recorded anything more than a few far-fetched stories that are referred to as legends and that do not offer any reasonable theories as to the origin of this brilliant jewel.

For more than 350 years the best scientists have been studying the origin of the pearl. Their efforts have resulted in many theories which differ widely and all are interesting. Our first record is that of the experience of Rondelet in I554. He considered pearls to be concretions due to disease, like the calculi of mammals. In the sixteenth and seventeenth centuries some writers regarded pearls as the eggs of the mollusk. In 1826 a scientist named Home advanced a similar theory, stating that pearls were formed around eggs that had failed to be expelled by the ovicluct. 
The scientist Diguet, who studied this question in the pearl oyster of the Gulf of California, said there were three stages in the development of the pearl. In the first stage there is a sack filled with a translucent, serous liquicl, the effusion of which is due probably to irritation caused by a parasite. In the second stage the liquicl gradually thickens and assumes the appearance of jelly. Then it changes into conchyolin and the mass divides into concentric layers separated by interstices. The third stage is the petrification or calcination of the pearl by the filling of these interstices with a crystallized calcareous deposit.

The famous German naturalist, Von Baer, in 1830 macle the statement that the central nucleus of a pearl was a small animalcule or worm. The Italian naturalist De Filippi, in 1852 again brought out the theory of the parasitical origin of pearls. He attributed the frequency of pearls in the Anodonta cygnea of the Lake of Racconigi in the royal park to the presence of a parasitic worm, Distonium duplicatum in the mantle of the mollusk.

In 18,66 Kuchenmeister stated that the pearls of the rivers in Saxony, had as their nuclei small ticks, or mites.

Mobias devoted considerable time to the pearl oyster on the western coast of America. It was his opinion that the formation of pearls in these mollusks was due to a parasitical worm. Two famous scientists. Kelaart and Humbert, announced that the Cercaria, Filaria, and three other helminths which they found in the pearl oyster of Cerlon, acterl an important part in the formation of the 
pearls of this mollusk. The views of these men were confirmed by M. Edgar Thurston in 1894 .

In 1897 M. A. Giard noticed that mollusks produced irregular deposits of conchiolin and lime around the parasite.

In IgO2 Jameson, of London, explained that the formation of pearls in the edible mussel, Mytilus edulis, is due to irritation caused by the Distoma.

Two noted English naturalists, Herdman and Hornell, after three inspections of the oyster banks, made a statement to the effect that they had examined many hundreds of oysters and had finally concluded that grains of sand and other inorganic particles did not form the nuclei of pearls, except in unusual instances, such as injury to the mollusk by breaking the shell which would allow sand to enter. According to these English naturalists, the nucleus of the fine pearl of Margaratifera vulgaris is the embryo of a worm of the genus Tetrarhynchus.

The famous scientist, Dr. L. G. Seurat, in examining the Margaratifera cumingi, or pearl oyster of the Gambier Islands found that the formation of pearls is due to irritation caused by the embryo of a worm of the Tylocephalum.

Investigations of American fresh-water mussels for the purpose of learning the origin of pearls have also been carried on by our scientists.

It has only been in recent years, however, that the subject has engaged their attention.

The United States Bureau of Fisheries, in charge of Hnn. George M. Bowers, Commissioner, has accom- 
plished some very wonderful feats in the various tasks that concern the fresh-water mussels of our country.

Among the scientists in the Government service who have contributed much valuatle information are: Dr. Barton, IV. Everman, Chief of the Division of Scientific Inquiry of the Bureau of Fisheries; George Lefevre. Winterton C. Curtis, H. Walton Clark, Charles B. Wilson, S. E. Meek, Ernest Danglade and R. E. Coker, Ph. D. All of these men have proved by the results of their efforts that they are well qualified for this kind of work for their country. It is to be hoped that all of them may continue in the service in which they have proved themselves so valuable.

While their work has been largely in the investigations of the Unionidae, with reference to the various economic questions relating to these mollusks, yet they have also studied the origin of the fresh-water pearl. One of the most important of these investigations will be mentioned, viz: The report entitled, "The Mussel Fauna of the Maumee River," by H. WValton Clark and Charles B. IVilson. In this record eleven pages are devoted to the parasites of mussels. These men found nine parasites which will be described briefly:

I. Cotylaspus insignis, Leidy. A small organism which to the naked eye resembles a pale leech. The body is trumpet shaped and the ventral surface has a large ovate disk cut up by partitions. By this disk the animal adlheres to the mussel and lives in the axils of the inner gills.

It was most common in Anadonta grandis and was also 
found in most of the other mussels. One example of Lampsilis rectus contained sixty-seven of these parasites. They do not seem to harm the mussels.

2. Aspidogaster conchicola, Von Paer is similar to the one just mentioned, but much larger and has a larger arlhering clisk. This parasite affects various species of mussels, but prefers Anadonta, Sympliynota Complanata and Lampsilis Alatus, in which many are found. It usually lives in the pericardial cavity of the host. It is possible these may occasionally form hinge pearls, as tice shape of the two are quite similar.

3. The Marginal C l'st Distomid. This distomid forms spherical cysts and is fairly common, especially in Lam/silis ligamentinus and L. icntricosus. Some were fuunci in one Indrula undulate and one Symphynota costatu. It is probably the species discovered by H. M. Kelly, who noticed it in four examples of L. ligancntinus. The cysts were usually found along the edge of the mantle. generally in the muscular portion below the pallial line. They are also frequently found in the adductor muscle: and especially in the lower part of the foot where occasionally many are found. They seem to prefer muscuiar tissue. Sometimes cysts of various ages are found in the same mussels. The scientists carefully broke the crust surrounding one of the younger cysts, and the released distomid crawled about slowly. It was necessary to use the miscroscope to sturly the minute distomid. This parasite often causes irregular blisters and stains the shell a steel blue color, where the cysts are near the outer surface of the mantle. Then, too, as the cysts increase in 
size, they form nodules in the mantle and cause the shell to be built out around them, so that they leave pits in the nacre similar to pearls. The marginal cy'st distomid is of especial interest on account of its connection with pearl formation. Suspicion that this distomid concerned the formation of the pearls was aroused when the object. were first found, as their form and position in the mantle were especially suggestive. This suspicion was intensified by frequently finding small round pearls in the mantle of mussels, closely associated with the cysts. Finally one of these pearls was examined and a cyst was found to be the nucleus of the pearl.

The marginal cy'st distomid is very widely distributed. being found in the Mississippi. Illinois, and many other rivers.

4. The Distomid of Osborm.-Anadonta was often affected with small white sporocysts, which covered the outsicle surface of the mantle next to the nacre. The nacre of these mussels was often raised into a number of sharp, pearly blisters conforming with the size and shape of the sporocysts, and indicate that the sporocysts had been actually covered with nacre. Some sporocysts were carefully examined. The skin of the sporocysts was transparent enough to reveal, in the interior, the cercarial. It has been learned that the cercarial later come out from their sporocysts and pass through varinus changes until it has the typical form of a Distomum, when it moves up into the umbonal region of the mussel and acquires a pinkish color. There it remains and stains the nacre a salmon color. The distomid of Osborn is said to form dorsal baroque pearls in the anadonta. 
5. The Distomid of Kelly is very similar to the Dis. tomid of Osborn. However, they are not so common anil are not usually associated with sporocysts or cercariae. It does not produce a salmon colored stain or any other stain usually. This distomid is frequently found in the thicker shelled mussels such as Lampsilis ventricosus, $L$. ligamcntimus, Obozaria circulus, and especially in Quadrula tuberculata and Unio gibbosus.

It is said that most of the dorsal baroques which are found by pearl hunters are formed through the activities of this parasite.

6. Bucephalus polymorphus, von Baer is a common parasite which affects many mussels. It has been found to be very dangerous to mussels, and is probably to be regarded as a parasite.

8. Leeches were found quite frequently on the inside of the shells of the anadonta, and are probably parasites.

9. Atax ypsilophorus was a common parasite and was particularly common on anadonta. It has been suggested that the eggs of the Ata.x may lead to the formation of pearls : but this has not been proved.

As a rule the anadontas and other thin shelled mussels are more heavily parasited than the thick shells, and parasites are more abundant in shallow, warm and quiet pools than in rivers.

There has been a theory in regard to the origin of pearls in which a grain of sand or small pebble was saicl to be the nucleus of a pearl. In some localities this theory is accepted as a fact, yet from the experiences 
of the scientists recorded we are unable to find any who advance the sand or pebble theory. Some admit that this may be the cause of fine pearls in rare instances or that such foreign particles may be the cause of the formation of baroques or slugs very frequently, yet practically all of these learned men have returned a verdict in favor of the parasitical origin of fine pearls. The author has also given considerable attention to the origin of pearls, and in his various experiences as a pearl hunter on different rivers, has found a large variety of conditions, and he is a firm believer in the parasitical origin of fine pearls in most instances, and in the parasitical origin of baroques and slugs in many instances, although he has found many baroques and slugs which were undoubtedly formations due to accidents in which the shells were broken.

At present, pearls are being produced artifically by the Japanese. These are called culture pearls. A small porcelain dome is attached to the inside of the shell and cemented in place, this becomes covered with layers of nacre and, when taken from the shell, is joined to another dome of mother of pearl and placed upon the market. These are culture pearls and cannot be sold as rea! pearls.

The Chinese have also made some progress in the production of artificial pearls and their method is similar to that of the Japanese.

It will be seen that pearls can be formed in several ways, and the old, old problem regarding the origin of the pearl is now almost solved. 


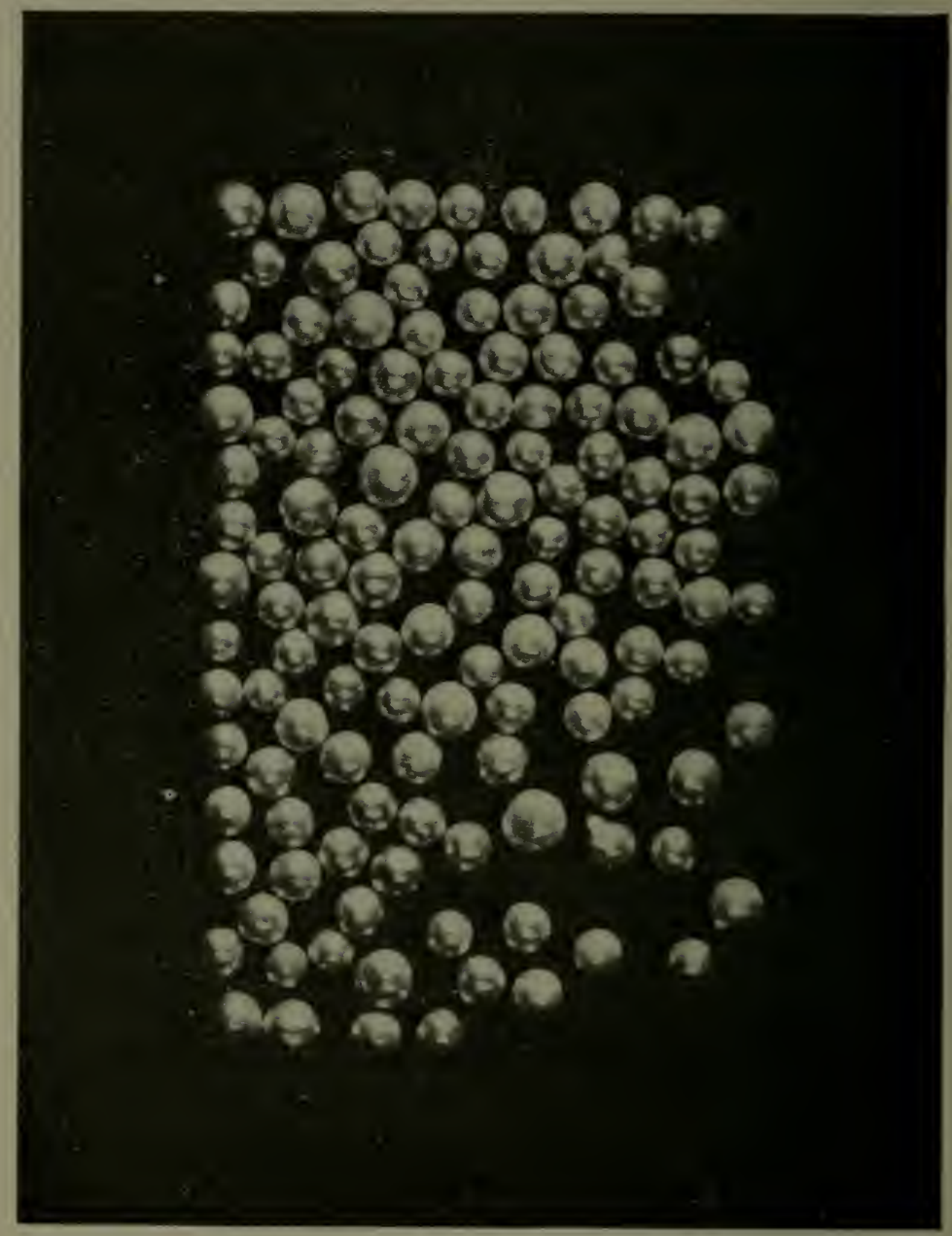

J.AP.NESE CLLTURE PE.IRLS. NATURAL SIZE. (From Bulletin Inited sitates Burran of Fisherifs) 


\section{CHAPTER III.}

The History of the Peirl.

I

$\mathrm{N}$ turning the pages of ancient, medieval and modern history we find recorded the deeds of the people of all nations, and always, even as far back as the earliest dawn of civilization we can see the tender light of the lustrous pearl shining softly and radiantly, from the crowns of kings in nearly all lands.

The glimmering, shimmering light of the wondrous pearl has attracted and charmed the rulers and people of all nations. Chinese. Japanese. Hindu, Egyptian, Roman, Greek, Macedonian. Italian, Persia, Austrian, German, French, English. Spanish, Australian, Polynesian, African, Turk, Arab, Indian, American and many others have been won by the subdued splendor of this precious gem.

About 350 B. C. a writer of Myteline, in the Island of Lesbos, mentioned pearls that were found in the oysters near the shores of Armenia, Persia, Susiana, and Babylonia. This was just before Alexander the Great crossed the Hellespont with his magnificent Macedonian army and won his triumphant victories in Persia. Then the store houses and treasures of Babylon and Susa were opened to him. It is also recorded that pearls were found in Egypt and, as that country had been under 
Persian rule, it and its treasures were acquired by the great Alexander.

In 55 B. C. Julius Casar, with his mighty Roman army, invaded Britain and in his conquest secured valuable treasures among which pearls were mentioned. It is also known that Cæsar presented a pearl of great value to the mother of Brutus in the year 54 B. C.

The famous Cleopatra was born in the year 69 B. C., and was the daughter of the Egyptian king Ptolemy Auletes. It is on record that on the occasion of a great feast she dissolved a pearl of fabulous size and value in wine or vinegar, and drank it. The density of pearls and the value of vinegar as a solvent, however, both tend to weaken the account, and the reader is not expected to believe the story.

Claudia, the glutton, is said to have also consumed a valuable pearl in imitation of the noted Cleopatra. The Bible mentions the pearl in several places. The Saviour enthroned the pearl in a celestial sheen, when (Matt. I3: 45-46) He likened the kingdom of Heaven unto it. In His similitude, the pearl was crowned with the highest compliment of all ages. He was the greatest of all teachers and from His use of the pearl as an object in the lesson we observe that not only $\mathrm{He}$ recognized the great worth of the gem, but that his audience also esteemed it highly as $\mathrm{He}$ always used objects that were known by all.

In the revelation of St. John the Divine, in the twentyfirst verse of the twenty-first chapter occurs a description of the gates of Heaven: 
"And the twelve gates were twelve pearls, each one of the several gates was of one pearl; and the street of the city was pure gold, as it were transparent glass." The use of pearls in describing the heavenly gates, shows the sublime and sacred respect with which John thought of the radiant pearl.

The great historian Pliny, who was born in Italy in 23 A. D., mentioned the pearl in his writings.

In 37 A. D. the wife of Caius Caligula possessed a collection of pearls valued at $\$ 3,000,000.00$.

From the earliest history pearls were found in Britain.

From the reign of Francis I. to Louis XIII. the pearl was prominent in France. It is said that there was a law in France about 1355 which prohibited the goldsmiths in Paris from setting Scotch pearls with the oriental.

Mary, Queen of Scots, wore pendant pearls in her ears when she went to chapel and possessed a magnificent rosary of pearls which were greatly coveted by other queens at that time.

Sir Thomas Gresham, of London, was a wealthy subject and is said to have ground a large pearl to powder and mixed it in wine, which he drank to the health of the queen to show a prodigal loyalty to her.

At the time of Columbus, Spain and other European nations considered pearls as among the most valuable jewels, and the early discoverers were required to give a part of the treasures which they found to the king.

On October 12, I492, when the valiant hero Columbus landed at San Salvador another addition was made to the history of pearls. The natives possessed large quanti- 


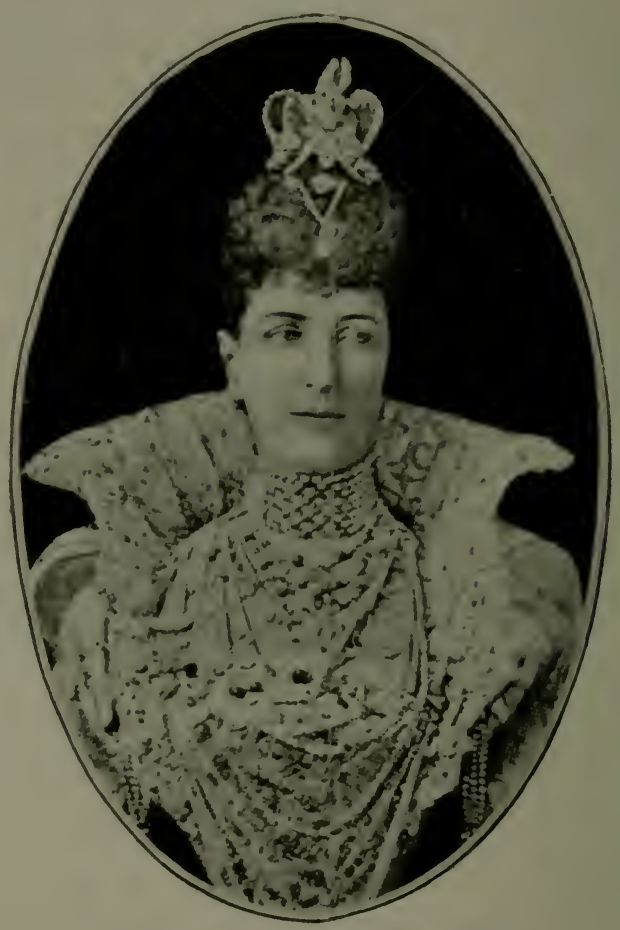

H. M. QLEEN .ILEX.INDKA 
ties of these gems, which were probably from the pearl oyster.

In a letter to Pier Soderini, Amerigo Vespucci related the account of his first voyage and mentioned that the Indians did not realize the worth of their gold, jewels, pearls and other riches, and were liberal with their gifts.

In the year I499 Sebastian Cabot made his third trip to America, visiting the lands bordering the Gulf of Mexico. He also found the Indians with large quantities of pearls.

Pamfilo de Narvaez, in I50I, found pearls in Santo Domingo, and later found them on the American continent.

In 1512 the aged Juan Ponce de Leon came to Florida and found pearls among the natives.

When Vasco Nunez de Balboa crossed the Isthmus of Panama in I 5 13 , he found the Indians along the shore of what is now the Bay of Panama taking pearls from oysters which had been washed ashore during storms and also diving for them near the shore.

In I 526 Hernando Cortez discovered Lower California, where he found the natives wearing lustrous pearls, gathered from the Gulf of Lower California. History also relates that when Montezuma, the Emperor of Mexico, stepped from his royal palanquin, "blazing with burnished gold and overshadowed by a canopy of gaudy feather work powdered with jewels and fringed with silver," to grant audience to Cortez, his cloak and golden 
soled sandals were sprinkled with pearls and other precious gems. At the time of Cortez the Aztecs of Mexico and the Incas of Peru valued their precious pearls as highly as European monarchs. When the king of Spain made Ferdinando De Soto conqueror of Florida in 1538 , his concession provided that one-fifth of all the gold and silver, precious stones and pearls won in battle, on entering towns or obtained by barter with the Indians, be reserved to the crown. It was stipulated that the gold and silver, gems, pearls, and other treasures which might be found and taken as well as stolen from the graves, sepulchers, or temples of the Indians "should be equally divided between the king and the party making the discovery." From this we know that the Spanish king confidently expected his discoverers to find valuable pearls.

None of these men were disappointed in this respect, for when De Soto landed in Tampa Bay he found the Indians of Florida using pearls as ornaments. When the Indian Queen welcomed him she drew from her head a long rope of pearls which she placed around his neck and assured him of her friendship.

In the town of Ucita, the Indians, who feared the strange adventures, allowed De Soto to open some sepulchers, from which the Spaniards took a large quantity of pearls and baroques. In referring to the experience of De Soto, Garcilasso Inca de la Vega told that when De Soto was in the town of Ichiaha, near the place where Rome, Georgia, now stands, a cacique came to him, bringing him a present of a string of large pearls. De Soto received them with thanks and presented the 
Indian chief with pieces of velvet, colored cloth and other attractive articles.

As De Soto wished to know how they secured the pearls, the cacique sent out forty canoes to fish for the oysters during the night. The next morning the Indians made a large fire on the bank of the river and as the fire burned low the canoes came in and the mussels were laid upon the hot coals. These quickly opened and from some of the first that opened the Indians took ten or twelve pearls as large as peas, which they brought to De Soto and the cacique who were standing together looking on. The pearls were of fine quality, but injured by fire and smoke. Having gratified his curiosity, De Soto returned to his quarters for breakfast.

The English also noted the presence of pearls in America. History records the fact that Sir WTalter Raleigh collected from the Indians in Virginia, 5,000 pearls, "of which number he chose so many as made a fayre chaine, which, for their likeness and uniformity in roundness, orientnesse and pideness of many excellent colors, with equalitie in greatness, were very fayre and rare."

Father Louis Hennepin made the statement that the Indians along the Mississippi wore bracelets and earrings of fine pearls, which they spoiled, having nothing to bore them with but fire.

All the early explorers who came to America found the natives wearing pearls. It is evident that they were found in many rivers here at that time. The American Indian, however, was not the first to use pearls in this country as the prehistoric tribes of America used large 
quantities of pearls for adornment long before Columbus arrived. It is probable that they occupied the Scioto and Miami Valleys about I200 A. D. These mound builders have left a complete proof that they had a high regard for the fresh-water pearls of our rivers. The many mounds in Ohio have been explored and the archaeologists have found great stores of pearls. One of the greatest "finds" was made in the effigy of the Hopewell group, where more than a gallon of pearls were found with two skeletons. Some of these pearls were twothirds of an inch in diameter. They were usually placed around the neck, the wrists, and the ankles, and were often sewed on the garments. All the pearls had been drilled with a heated copper wire. They were also injured by lying in the graves.

Important "finds" were also made in the Turner group and the Porter mounds. The conditions were found to be similar to the Hopewell group.

Many pearls were found set in bear's teeth. No hinge pearls were found.

It is probable that the use of pearls was confined to a few individuals.

Appearances indicate that the mound builders had reached an advanced state of refinement.

Since the discovery of America, pearls have been found in the waters of other countries in fisheries that have been established for many hundreds of years and in some that have been found later. Among the oldest of these are the Indian, Ceylon, the Red Sea, the Persian Gulf and the Arabian Sea. 
The Ceylon fishery is the best known and produces a large amount of pearls. This fishery has been deserted many times for the reason that the oysters were said to have been gathered from the beds, but after a few years the work of fishing for the oysters would begin again and it is probable that pearls will come from Ceylon as long as there is a demand for the gems.

The noted French jeweler Tavernier should be mentioned. He was born in Paris in $\mathrm{I}_{60} 5$ and was the son of a Flemish engraver. At the age of fifteen he accompanied some French noblemen in a visit to eastern lands. Later he traveled through all the important countries and always went as dealer in pearls and other gems. On one occasion he returned from the Arabian Sea with \$500,000.00 worth of pearls. This event is said to have been the cause of the great popularity of pearls in France. He also sold some very valuable pearls to the Shah of Persia, and to other great rulers.

A recent ruler of India, the Rajah of Dholpur, possessed a collection of pearls valued at $\$ 7,500,000.00$. Many of the important historical facts concerning the pearl are included in this chapter, but in closing, it is well to observe that the pearl has exerted a great influence in extending boundary lines and in the advancement of civilization.

In the conquests of Alexander the Great, Macedonia gained a large area and increased its treasures. It is said that the treasures, among which the pearl was prominent, had something to do with the great conquests. We should also observe that Alexander the Great taught Eu- 
ropeans the road to India and gave them their first glimpse of that great treasure land.

Cæsar's conquests in Britain were also partly for the purpose of obtaining the fresh-water pearls of that country and he returned with many of these precious gems. All the early Spanish, French and English discoverers who came to America expected pearls and found them. In many cases there was an understanding that they were to be divided between the adventurerers and the king. So in these instances also the pearl has exerted a geographic and refining influence in our own country and in the other lands near us.

The "Pearl of Great Price" has occupied such an important place in the lives of men and their achievements, that if we had no historical records, except the ones that registered the events of the lives of those who prized the pearl we should still have a very elaborate history of the world. 


\section{CHAPTER IV.}

Pearls are Found in Most Rivers of the United States and Canada.

EARLS are found in nearly all of the rivers in the United States as well in many streams in Canada. There is no certain portion of our country that might be referred to as being our only source of pearls. While more pearls have been found in some rivers than in others, most of our rivers contain them and there are but few rivers in the United States that have not yielded these brilliant gems.

Eighty-five per cent. of our United States streams, however, are in the mighty Mississippi drainage system. The streams of this system drain a large area of land. Lake Chautauqua, in New York; Lake Itaska, in Minnesota, and Yellowstone Lake, in the Yellowstone Park. in far away Wyoming, belong to this system. A thousand streams, from the babbling brook up to the mighty Missouri, all pour their tribute of water into the great Mississippi. Altogether these connect thirty-four States and reach into Alberta, Canada.

Pearls have been found in streams in nearly all of the States that are in this great system.

Most of the rivers which empty into the Gulf of Mexico from the north have yielded pearls. 
These gems are found in the rivers which empty into the Atlantic Ocean, and are also found in the rivers that empty into the Great Lakes and St. Lawrence River.

Few pearls have been taken from the rivers that empty into the Pacific Ocean.

It is impossible to supply exact information in regard to all or even a small part of the pearls that have been found. In referring to the pearls from various rivers, we shall consider the States in which pearls have been found, taking the States separately in alphabetical order.

There has been some pearl hunting done in Alabama. Some fine round white and rose colored pearls were found in the Tennessee River. A letter from Demopolis states that some pearl hunting has been done near that city. The men worked while the river was low and used the crow-foot dredge and tongs. Some small but very pretty pearls were found there.

Arkansas has been one of the most prominent pearl States. The first "pearl fever" was in 1897 and extenderl into Indian Territory, Missouri, Georgia, and a part of Tennessee. Pearls were found in White, Black, St. Francis, Cache, Ouachita, Saline and Dorcheat Rivers; also in Murphy and Walker Lakes. Some of the "finds" were very valuable. Many of the pearls from the northeastern part of the State were pink.

One peculiar feature of the first experiences in the pearl fisheries of Arkansas was that many of the pearls found were not taken from the shells, but were found loose and alone on the ground near the shores of the rivers after the floods. There was a local belief that 
mussels "shed" the pearls. The exact cause of these peculiar circumstances is not really known and such conditions have not been reported from the pearl fisheries of other States.

Arkansas has been thoroughly worked and shells are scarce as compared with earlier times. Mr. George S. Glass, of Peoria, Illinois, who took his outfit to Arkansas last summer, said that 300 pounds of shells per day was a good catch now in the locality where he worked. Some nice pearls are still found there, however. A letter from Mr. John Risley, of Peel, Arkansas, dated February 26th, I9I3, stated that he found a Co-grain pearl in White River last summer. He said the pearl was imperfect and he sold it to an Arkansas pearl buyer. for \$500.00. Possibly the defect was a very serious one. It is impossible to tell the value of a pearl without seeing it, but it is to be hoped that he got all the pearl was worth. This is only one of the very many valuable "finds" of the Arkansas pearl fisheries.

All things considered, Arkansas has Deen, is now and will probably always be one of the best pearl States.

Connecticut is not prominent as a pearl State, although about fifteen years ago there was a "pearl fever" near the headwaters of the Mystic River, where a few pearls were found.

Florida has not been worked. A letter from Mr. I. H. Holmes, a large dealer in marine shells, in Clearwater, Florida, stated that he did not know of any pearl hunting having been carried on in that State. He said the Unios there were small and there were no beds of 
them in the rivers. It has been learned from other sourees, however, that the Ocklocknee River has yielded some small pearls. History records that the Spaniards had a pearl fishery on one of the islands in Lake Okeechobee in early times.

Most of the rivers near the Gulf Coast are very difficult to work because of brush, snags and vegetation.

The mussels are small, so no large pearls can be expected from them.

Georgia has had some "pearl fevers." One of these was in I897 and the other in I9II. Some nice pearls were found.

At the time De Soto was in Georgia, the Indians secured some pearls for him from the Oostanula River near the place where Rome, Georgia, now stands.

Illinois is especially favored. The Mississippi River on the west, the Wabash River on the east, the Ohio River on the south, and the Illinois, Rock, Kankakee Rivers and many other smaller streams inside the State make it the most prominent pearl State.

No other State has produced as many fine pearls within the last few years as Illinois.

Some of the finest fresh-water pearls in the world to-day came from the rivers in and bordering this State.

The Illinois River is the most important pearl stream in the State. In I9Io there were 2,600 boats on this river engaged in pearl hunting, or "claming," as it is called in many places.

In I9I2 there were only about 400 mussel boats in use on the Illinois River. 


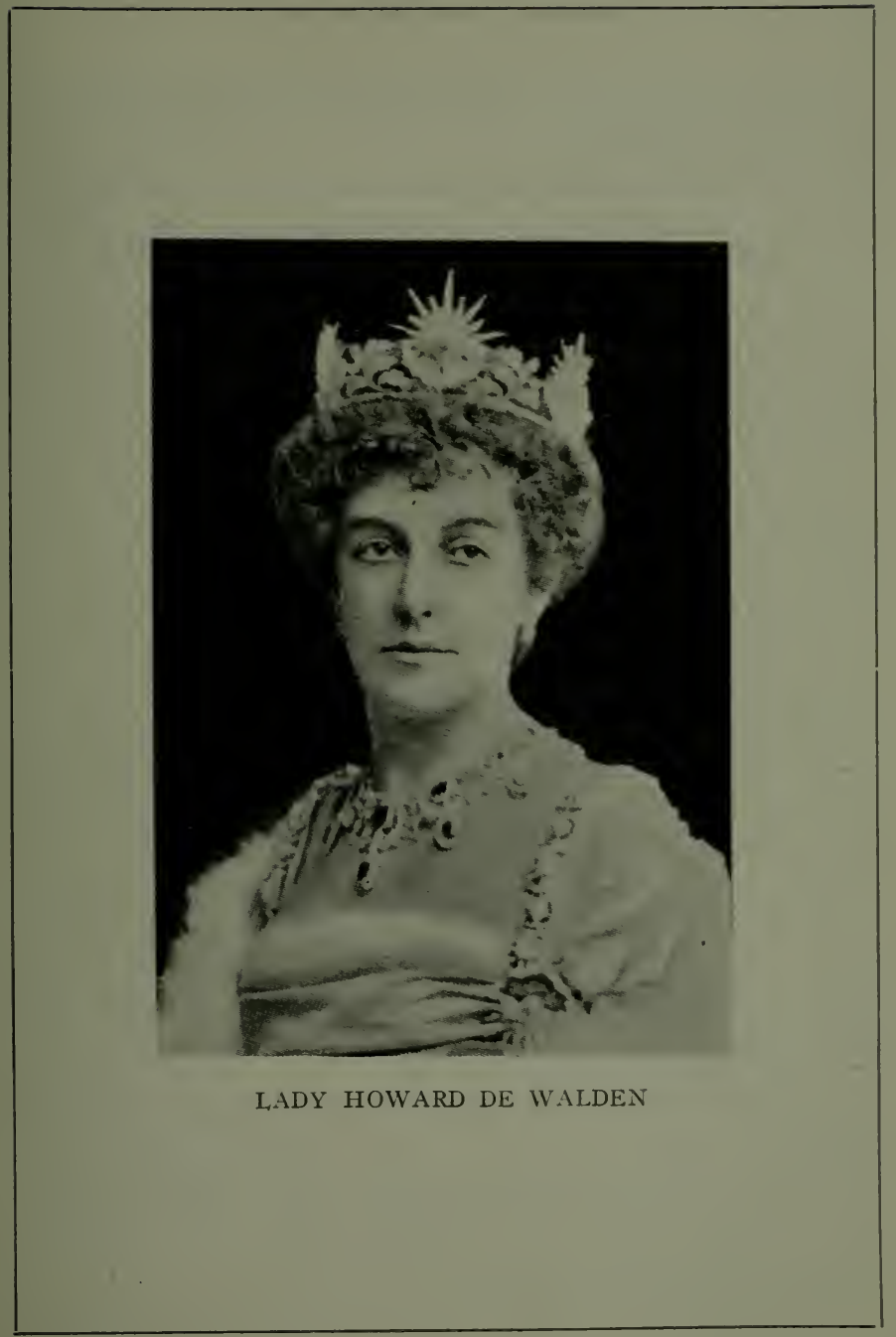


The new dip net is one of the most effective and profitable appliances.

It is now used in the Peoria district, but is not in common use in any other part of the State, or other States.

It will probably be used in many other places when its merits become better known by the pearl hunters.

Shells along the Illinois River are usually worth \$I 2.00 to $\$$ I5.00 per ton, although they have been known to reach the $\$ 20.00$ mark.

The shells from the Mississippi River are better for button material and the price generally ranges from $\$ 23.00$ to $\$ 30.00$ a ton at the Illinois towns near the Iowa button factories.

Where shells are plentiful, pearl hunters can make good wages in Illinois by gathering the shells.

Indiana has a good record as a pearl State, but its rivers have been so thoroughly worked that the yield of both shells and pearls is much less than it was a few years ago.

The Wabash and Ohio Rivers and other smaller streams have produced large quantities of the finest pearls and slugs. The shells from many localities are also very good. Like most of the older pearl rivers, the rivers need a rest in many places.

Indiana will probably always be one of our best pearl States.

Indian Territory has also had some "pearl fevers." during which some very beautiful pearls were found in Poggy and Kiamichi Rivers.

Iowa is one of the oldest pearl States and has the dis- 
tinction of being very prominent in the button manufacturing business.

Muscatine, Burlington and Davenport are the leading cities in the button business.

This State has some great advantages for the pearl hunter, or "clammer," as they insist upon calling a shell digger there. The great Mississippi and the smaller rivers are good pearl streams; and the shells, which are mostly niggerheads, bring a good price in the neighboring cities.

The people of the State of Iowa are especially progressive in regard to the study of the mussel supply. Some of them have formed an organization for the protection and artificial propagation of fresh-water mussels.

The United States Fisheries Bureau has a good biological station at Fairport, Iowa, which is a valuable aid in maintaining the mussel supply.

The many valuable pearls found in Iowa places it among the leading pearl States.

Kansas is not an important pearl State, although some nice lavender pearls have been found there.

Kentucky is known to have yielded some pearls. Some nice ones have been found in the Cumberland and Little Rivers. Two men reported that Green River and Barn River, near Metcalf county, have very large mussels in them. It is possible that some nice pearls may be found there.

Louisiana is now coming to the front as a pearl State. Many nice pearls have been found in the northern part 
of the State. and especially in Caddo Lake, which extends into Texas.

A few small pearls have been found in Massachusetts.

In Michigan a large number of pearls were said to have been found in mussels from the St. Joseph River, in the southeastern part of the State.

Some pearls have been found in Minnesota, but the number is very limited. This State will probably have a much better record later as the conditions there are apparently very favorable for both mussels and pearls.

A few small pearls have been found in Mississippi.

Missouri has several rivers in which pearls have been found.

In a letter from Mr. John Regelman, of Potts, Missouri, he stated that a man found a pearl worth $\$ 200.00$ while in bathing in the Gasconade River. PearIs have

New Jersey is not an important pearl State, although it has had several "pearl fevers," the most important one being in 1857 when the famous "Queen pearl" was found near Paterson.

Although New York is not a prominent pearl State, some nice pearls have been found in Frost Brook and Grass River in the northwestern part of the State.

Ohio should be mentioned as an important pearl State. Many pearls have been found in the Miami, Scioto and Ohio Rivers. The ancient mound builders used large quantities of pearls which probably came from the Miami and Scioto Rivers.

Tennessee has a fine record as a pearl State. Among 
the Rivers in which pearls have been found are the Tennessee, Cumberland, Caney Fork, Holston and Clinch. Also on the Calfkiller, Duck, Elk and other tributaries of the Cumberland Tennessee Rivers.

The famous "sky-blue" pearl from Caney Fork was sold for \$950.00. Another round pink pearl brought $\$ 650.00$, while another sold for \$I,000.00. Many of the pearls from the rivers in Tennessee are of fine quality and color.

The shells in many of the streams are also good. The pioneer button manufacturer, Mr. J. F. Boepple, who examined the shells in various rivers in Tennessee, made the following statement: "The Clinch and Holston Rivers have the best mussels for buttons that I have seen in all my experience in the button business."

Many of the other rivers contain good button material. There are some localities, though, where the percentage of small and colored shells is too high to consider them as button material.

Texas is now an important pearl State. Pearls have been found in several of the rivers, but Caddo Lake, in the northeastern part of the State has produced a large number of nice pearls and is considered one of the best pearl fisheries in the United States. The shells there are worthless. The pearls are not so large as the ones which are found in the northern rivers, but there are more of them, while many are perfect and very lustrous. They range in value up to $\$ 500.00$. although most of them are of less value. One man found $\$ 2000.00$ worth of pearls there last year. It is reported that 3,000 people hunted 
for pearls in Caddo Lake in I912. Many of these were teachers, clerks and others on a vacation. Only a part were regular pearl hunters. They secured the mussels by wading in and picking them up.

Virginia and West Virginia have both yielded a few fine pearls.

Wisconsin is another of our best pearl States. Most of the pearls were found in mussels taken from the Sugar River and other streams in the southern part of the State and from the Mississippi River. The first "pearl fever" was in I889 when some very valuable pearls were found. The pearls from Wisconsin were principally purplish red, copper red, and dark pink, although some were peacock green and other shades of green.

Canadian rivers also contain pearls. A fine round pink pearl weighing thirty grains was found near St. John, New Brunswick. Hunters and fishermen have also found them in other parts of Canada; but there has not been much pearl hunting done in that part of the continent.

In the accounts mentioned it will be observed that pearls are found in many rivers.

Mussels grow in practically all streams in which fish may be found. They are more abundant in districts where there is plenty of limestone.

Pearls are scarce every where. While many rivers have not been mentioned, it is probable that many contain both mussels and pearls, and later we shall learn of many important pearl streams that are not thought of now. 


\section{CHAPTER V. \\ ThF LifE of THE UNio.}

T $T$ has often been said that one-half of the world does not know how the other half lives. In speak-

1 ing of mussels this is especially true.

Although the author had done considerable pearl hunting he did not have a good knowledge of how the mussels lived until July and August, I9Io, when he began his investigations while hunting near Port Byron and Rapids City, Illinois. At that time the Mississippi River was lower than at any time since about 1865 , and he and many other men waded in and picked up the mussels with their hands. It was necessary to wear heavy, warm clothing on account of the cool water and winds. Many times the pearl hunters were in the water up to their necks for quite a while. By this method of getting shells, a person had an opportunity to learn just how the mussels lived in their colonies on the bottom of their river.

The mussel beds are nearly always in places where sand and gravel and rocks predominate. Large rocks were especially plentiful near Rapids City, and the anthor knows just how unpleasant it is to be wading along and strike his foot or shin against submerged sharp rocks. There is more prose than poetry in that kind of pearl 
hunting. Mussel beds are of various sizes. Some are several miles long, while the length of others may not be more than a few hundred yards.

In young colonies, the mussels have plenty of room, but in some of the old beds like those mentioned, the mussels are so large that they occupy more space and in many instances they are piled on top of each other, and a small area will contain a large number of shells. As many as sixty mussels of various sizes have been taken from an area of one square foot of river bottom.

There are over four hundred varieties of mussels in the United States streams, but of this large number there is only a small per cent. of them that are especially common in most of our rivers. Some thrive best in swift, deep water and have heavy strong shells and large hinges and teeth to protect against injury in accident. In this class the quadrula group is prominent.

Some mussels prefer to live in quiet, shallow water. Their shells are not so heavy and they do not have heavy hinges like the quadrula. Many of these are in the Lampsilis group.

Illustration No. 4 shows the interior of a Quadrula heros, or "washboard." In the living mussel the shells are joined together by a tough ligament which acts as a spring in opening the shell when the adductor muscles are cut. In front of the ligament on the outside of each shell are elevated portions callerl the beaks or umboes, and are the oldest part of the shell. The heavy, thick. rounded encl of the shell is the front or anterior part, and is always ahead when the mussel is moving. The thin 


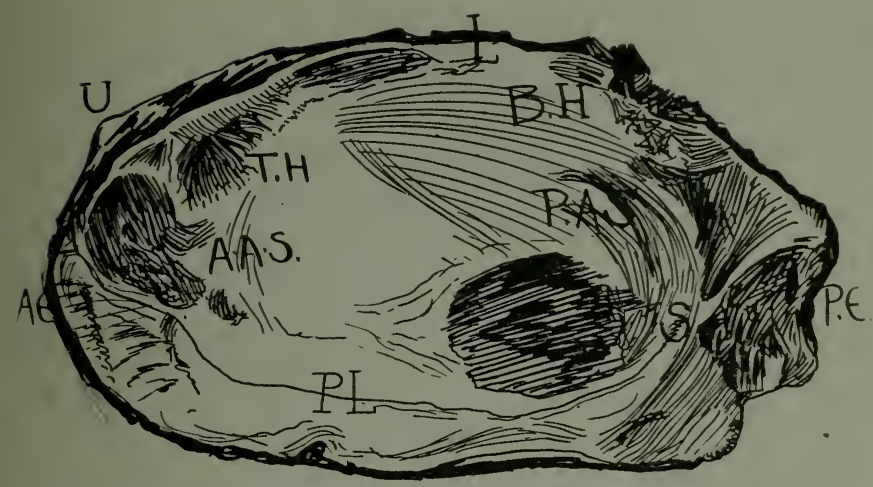

Fig. 4. Interior view of Quadrula heros, or "Washboard" shell.

U., Umboes, or Beak; L., Ligament ; B. H., Back Hinge ;

T. H., Tooth Hinge; A. A. S., Anterior Adductor Scar; P. A. S., Posterior Adductor Scar;

A. E., Anterior End; P. E., Posterior End; P. L., Pallial Line; S., Stains.

end of the shell is called the posterior end. The teeth are near the anterior end of the shell and are for the purpose of holding the shells together so they will not become misplaced in case of accident. The hinges are for the same purpose as the teeth and are rather long, elevated, nacreous formations at the top of the shell near the ligament. At each end of the shell there are rough scars where the adductor muscles are joined. One is called the anterior adductor scar and the other is called the posterior adductor scar. The pallial line is the name given to the rather distinct and slightly indented line near 
the border of the shell. In the living mussel the mantle is joined to this line and to the muscles at the upper part of the shell.

A living mussel can be opened by inserting a thin knife and cutting toward the hinge at both ends.

Illustration No. 5 shows a Quadrula heros, or "washboard" mussel exposed. A very soft thin tissue called the mantle covers the entire inside of both sheils, being joined together at the upper part of the shell, and is fastened to the shell at the pallial line and to muscles in the upper part.

The edge and outside of the mantle produces a sort of milky liquid, containing carbonate of lime and animal matter, which builds up the shell by thickening it from the inside and by adding to it at the edge, the pearly nacre near it, a layer of vertical prismatic cells outside this and over all, the protecting conchiolin epidermis. Ordinarily the growth of the shell is only such as to meet the needs of the growing animal and for its protection. After the mussel reaches maturity, the shell ceases to grow, excepting in some varieties which continue to lay on nacre only. The mantle is carried between the locking hinge teeth and fills the space between them like a cushion. In the illustration the mantle is folled back to show other parts of the animal. A mass of tough white muscular fibers will be found at each end of the shell on the inside near the back. These are the powerful arlductor muscles by which the animal closes the shell.

The muscles allow the shell to open but a short dis- 


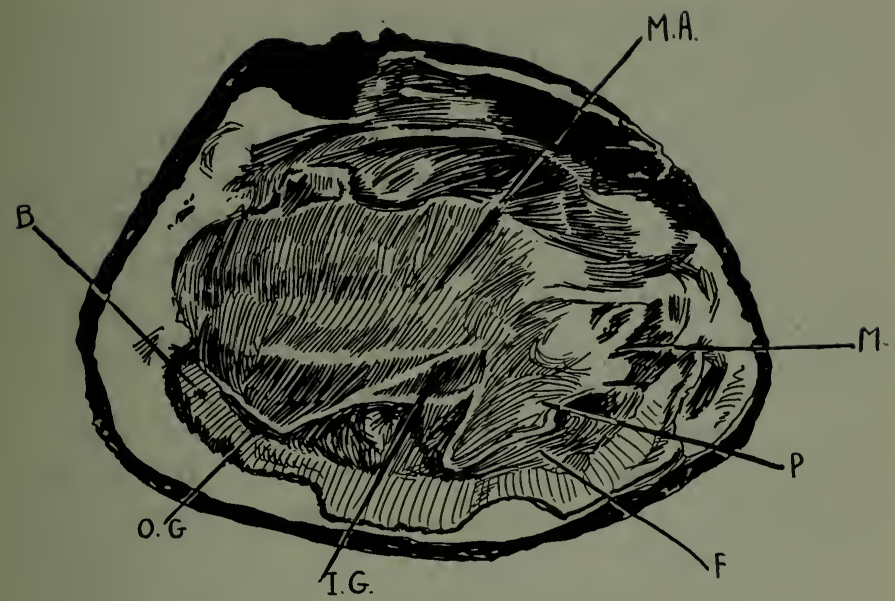

Fig. 5. Quadrula heros, or "Washboard" mussel exposed. MA., mantle folded back to show the other proportions; M., mouth; P., palpi; F., foot; I. G., inner gill; O. G., outergill; B., branchial opening.

tance so that the teeth always lock, and the mantle cushion swells when they are open and keeps them from slipping. Inside of the mantle and hung along the hinge line is a sort of bag which contains the vital organs. It takes up a large space in the shell and is called the abdominal sac. This extends below and in front into a tough muscular organ called the foot. The foot is shaped something like a tongue and can be projected from the shell and worked into the ground. A good idea of its use can be obtained by referring to Fig. 6, which shows a Lampsilis rectus, or black sand-shell mussel plow- 
ing its way through the mud or sand. The foot holds the mussel up while it is feeding and is used to move the animal from one place to another. By contracting and expanding the foot while it is in the ground the mussel is able to push forward and plow through the bottom of the river. The foot also holds the mussel from being swept away by the swift water in many cases. Although the shell may be almost closed, the foot which is expanded in the ground can hold so tightly that a great effort is required to lift the mussels.

The mouth is located under the anterior adductor muscle and opens into the abdominal sac. It is carried through the intestinal canal, and finally empties near the posterior addustor. The animal has a sort of a heart, surrounding the intestinal canal, which beats regularly.

Mussels have gills, or branchae, which separate the oxygen from the water and answer to the gills of the fishes or the lungs of land animals. They are fastened to the mantle and the top of the abdominal sac in some cases, and hang down between the two on both sides of the sac and reach from the posterior end of the shell almost to the anterior end. They are very delicate and beautiful and are of vital importance to the mussel.

The palpi are just in front of them on both sides of the abdominal sac and under the mantle.

This pair of smaller, triangular flaps, extending behind are constantly in motion when the animal is feeding. In the posterior part of the mussel the mantle shows two small openings, one above the other. One or both of these is fringed and may be seen expanded when the 
animal is feeding. The Branchial and Anal openings are expanded and the palpi flap rapidly, which draws the current of water through the branchial opening. The water goes through the gills and aerates the blook, then it passes into the mouth and through the intestinal canal, carrying in various microscopical organisms which are filtere from the water and constitute the food of the mussel, and the water passes out through theanal opening. The mussel also separates sufficient lime from the water to form its shell.

There is quite a difference in the length of lives of various mussels. Some of the Quadula group probably require ten or.twelve years to reach maturity and then continue to live for many years.

Some niggerheads have the appearance of being twenty-five years old. Some of the Lampsilis group attain a fair size in four or five years. In young shells of some varities such as the Lampsilis ventricosus, or pocketbook, and Lampsilis anadontoides, or yellow sand shell, the winter rest periods are very plainly marked. In most mussels, however, it is very difficult to determine the age.

The various kinds of mussels have different time: for spawning. Every month in the year is the spawning season of some variety. After ovulation the eggs pass into portions of the mussel's gills which are termed marsupium. These serve as brood pouches for the retention and maturity of embryos and glochidia until they leave the mussel. When the embryos have remained in the marsupium of the mussel for a period of time which 


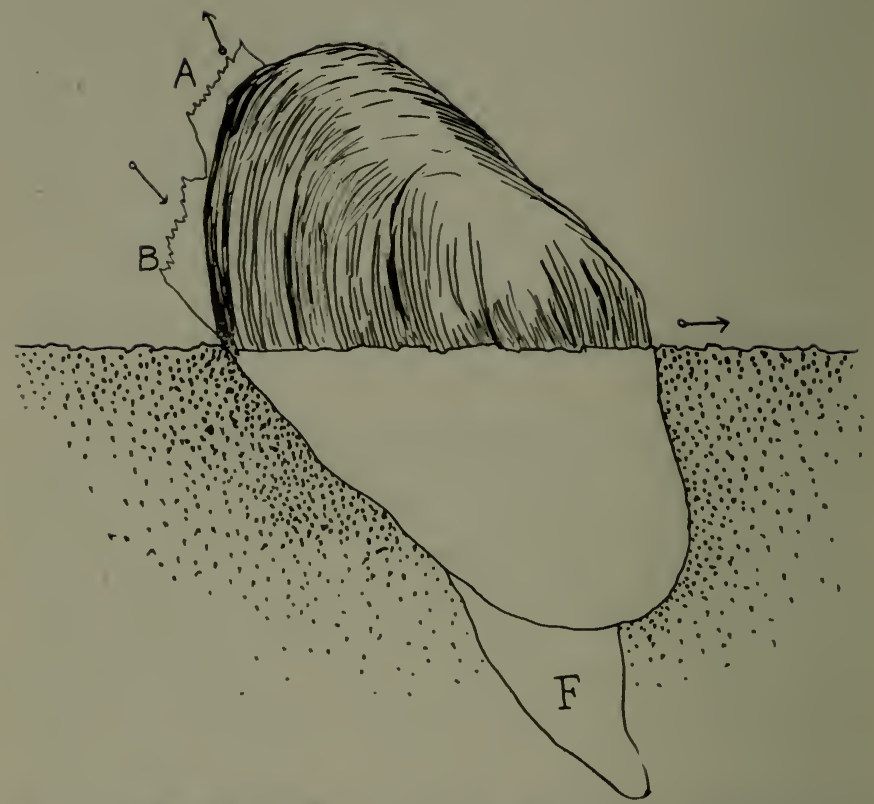

Fig. 6. Lampsilis rectus, or "Black Sand Shell" mussel plowing through the sand or mud at the bottom of a river.

A., anal opening; B., branchial opening; F., foot. Arrows indicate the direction in which the mussel is moving; also the direction of the river current.

varies in different kinds of mussels, they gradually pass into the water and are then called glochidia.

In the first stages of its development, the mussel lives as a parasite.

At the time of spawning the young glochidia fall to the bottom of the river and remain in a helpless condition 
until they die unless they are fortunate enough to become attached to a fish on which they pass through post-embryonic development as parasites. Multitudes of glochidia die by not being attached to the fishes. In most cases they attach themselves to the gills of fishes, although they also attach to the fins and tails of fishes. There are several types of glochidia. One is the hooked type which is provided with tiny hooks, which clasp the filaments of the fishes' gills and some times attach to the fins or tail.

Another kind is the hookless type and the tiny mussels cause the sharp edges of the shells to clasp the filaments of the gills and the edges of the fins and tail in about the same manner that the hooked type becomes aitached.

There is also another type called the Proptera or axhead type. The shape resembles that of an ax-head. This glochidium possesses hooks, but differs from the other hooked variety. It has four hooks which close toward each other and hold tightly wherever they attach. They seem to prefer to attach to the filaments of the fishes gills. A week after the attachment, the wall of the cyst becomes somewhat looser and later the valves open occasionally and the foot is extended and finally breaks out of the cyst and the free mussel falls to the bottom.

It is said that if these tiny mussels fall in muddy places they perish, while if they fall in sand and gravel they thrive and form colonies or beds.

Some of the fishes are much more susceptible to infection than others. The rock bass is especially susceptible, and according to the U. S. Bureau of Fisheries, 2,000 
to 2,500 glochidia have been known to attach themselves to the gills of one of these fish in forty minutes. The large mouth black bass is also well suited for some glochidia. From 500 to I,000 glochidia have attached themselves to the gills of a black bass in twenty minutes. A view of a rock bass infected with glochidia of Lampslis ligamentinus may be seen in Figure 7 .

Small mouth black bass, crappie, yellow perch, roach and blue gill sunfish are all very susceptible to infection with glochidia, and the parasites generally attach to the filaments of the gills.

The German carp is different. The glochidia do not attach to the gills, but 200 to 500 will attach to the fins in about forty minutes. It will be observed that the life of the mussel is not only a very interesting one, but also one that is in almost constant danger. The many changes that must be wrought throughout its life and the many dangers which it must pass through tend to make the life of a mussel a life of chance, and we wonder how so many of them happen to reach maturity. 


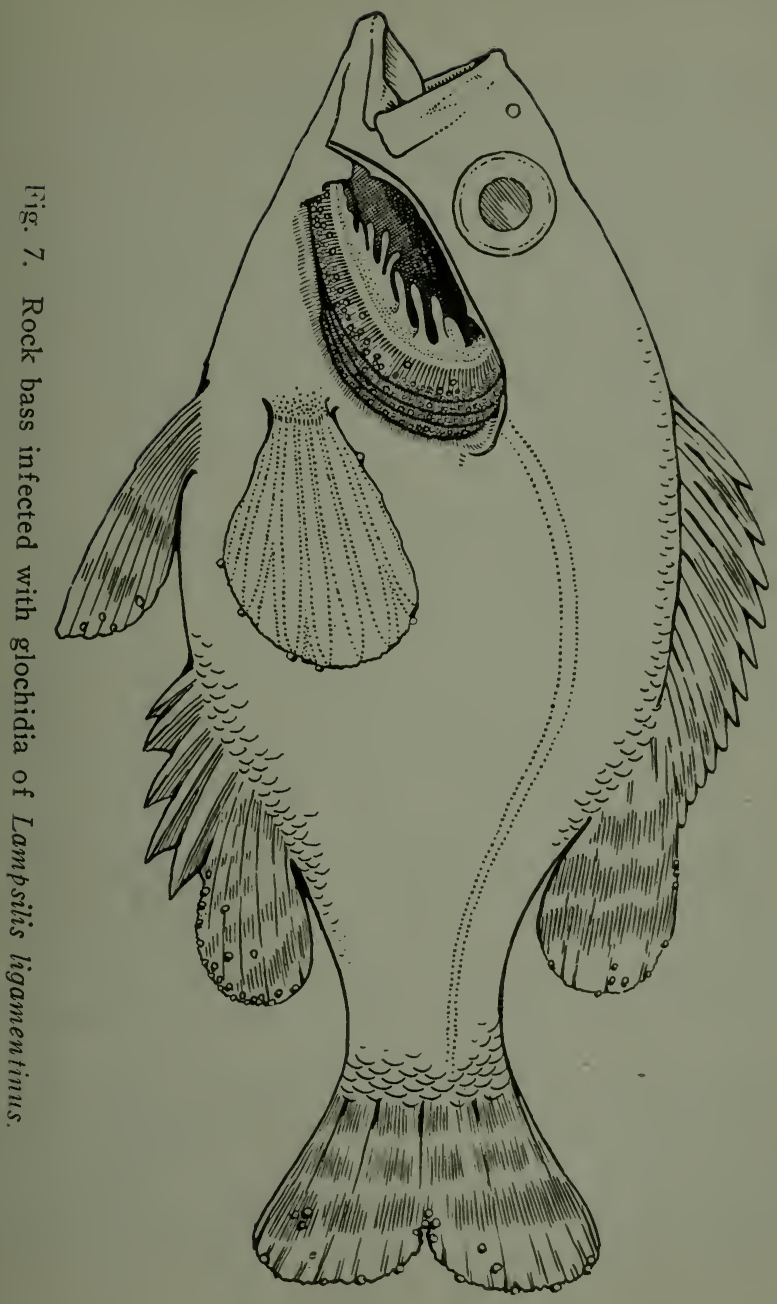




\section{CHAPTER VI.}

\section{Perils and Enemies of Mussel.s.}

$7 \mathrm{HE}$ very talented naturalist, Ernest Thompson Seton, has written many stories about the wild 1 animals of America. His stories are very interesting and are the result of a thorough study of the lives of the wild animals. It has been said that this famous naturalist maintains that no wild animal ever dies a natural death. There have been many instances in which wild animals were killed by other animals, or have met their death through some other disaster. Possibly the

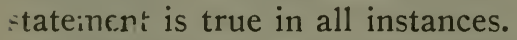

In the case of the mussel there are so many perils and enemies that the theory seems to apply very properly. As soon as the glochidia leaves the shell of the mollusk they are exposed to their greatest peril. At this time millions of glochidia perish by not becoming attached as parasites to the fishes. Even after clasping on the filaments of the gills or on the fins of the fishes, many lose their lives before the parasitic period is completed. Some attach themselves to a fish that becomes too heavily parasitized, and the infection is so great that the fish becomes swollen and diseased and death results, while the glochidia also lose their lives as a consequence. Others which are favorably attached to the gills or fins of a fish become brushed off or torn away. During this parasitic 
period, the glochidia are subjected to another danger. When fishermen take large numbers of infected fish from the water they destroy many millions of glochidia. At the end of the parasitic period, the tiny mussels fall to the bottom of the river; those which fall in mud are said to perish, while those which fall on sand or gravel have a chance to live. The small mussels, however, are constantly exposed to many hazards and dangerous enemies. When they reach maturity they are in less danger as they are strongly protected by their heavy shells. Their powerful adductor can hold the shells firmly closed and they are thus enabled to resist the attacks of many animals which are strong enough to open the shells of small young mussels.

Probably the chief natural enemy of mussels is the muskrat. These animals kill large numbers of them. They usually carry them to the bank, where they open the shells and eat the meats. Muskrats select the ladvfinger, pimple-back, monkey-face, or pig-toe varieties usually and always take the younger ones, as they can open them more easily. Sometimes the bank of a stream is a solid network of muskrat tracks where large quantities of shells are gathered by them and left empty on the shore.

When the water is low, hogs do very much damage to the mussel beds. They not only eat the ones that are loose, but also root up any that may be partially buried. A few hogs can destroy beds covering many acres in a short time. They eat mussels of all sizes, as they are able to break the strongest shells. 
Raccoons are very destructive in some localities. They seem to prefer the small mussels, although they also bring out some of the large ones and if they cannot open them they leave them to die in the sun and possibly they may eat them later if they happen to find them again. Other predacious animals that have been known to destroy the mussels for food are the mink, otter and bear.

Snakes also kill some of the smallest mussels. The author remembers an experience in Iowa when he saw a snake try to kill a large mussel. The water was shallow on the rocks so it was easy for the snake to find the mussel. The reptile bit into the body of the mussel while the shells were opened and immediately the mussel closed its shells. It was a very strange battle. The snake writhed and twisted about blindly, often letting the mussel fall upon the rocks, while the mussel held tightly to its enemy. Soon they disappeared into deep water and the result of the battle is not known. It is probable. however, that both lost their lives in the strange battle.

Catfish, crawfish, and mud turtles are also said to destroy mussels, but the extent of their damage is never known.

Cattle and horses often trample over beds in shallow water and kill large numbers of mussels. Aquatic birds kill and devour many of the smallest mussels and those having very thin shells. It has also been said that leeches and other parasites injure mussels, especially when these parasites are very numerous.

There are some physical cauces of destruction that are very disastrous. 
Among these the freshets are very prominent. During the freshets, entire beds of mussels sometimes become mudded over or covered with gravel or sand. Sometimes the erosion of the water causes large banks of earth to fall into the stream and cover the mussel beds. In other cases, the channel of the stream may be entirely changed leaving large areas of mussels exposed to the air and sun. Droughts are very disastrous in many instances, as the mussels, being nearly uncovered, are devoured by hogs, or, being entirely uncovered are exposed to the air and sun, so death results.

Another cause of injury is drift ice, which sometimes plows into the mussel beds and crushes the mussels. It is probable, however, that this is not a very destructive agent.

In some States the logging industry is a great menace to mussels. The large number of logs which pass down the rivers make it practically impossible for the mussels to live.

Water pollution is one of the worst causes of destruction. This is especially noticeable in the upper part of the Illinois River. The Chicago drainage canal has a very bad effect for many miles. The dissolved oxygen is drawn from the water by the organic matter in the sewage and mussels cannot live in it, especially during warm weather.

The refuse from factories which is turned into the rivers destroys the mussels. Along the Potomac and Shenandoah Rivers, and near Harper's Ferry are a number of mills which grind wood into pulp for making 
paper. The sawdust and waste is thrown into the streams and farther down where the water is rather quiet, the impure refuse settles to the bottom and is very destructive to the mussels.

In some of the streams of the Southern States the water contains a large amount of carbonic acid, which is very injurious to the mussels. It is very probable that the conchiolin epidermis is developed to protect the shell from the effects of acids. Where the epidermis is badly worn or broken off, as is often the case at the umboes or beaks of the shells of old mussels, the acid has an opportunity to eat into the shell and sometimes eats through the heavy portion of the shell and causes the death of the animal.

Another thing that is detrimental to mussels is the custom of cutting timber for various economic uses. While the timber remains standing, the water does not leave the soil rapidly and the brooks and creeks have many deep places where there is always plenty of water and the mussels thrive in such places. After the timber is cut, the rain water runs off rapidly and the streams become so dry that mussels cannot live in them.

The most dangerous enemy of the mussel has been man. His increasing activities in gathering shells and in pearl hunting have so depleted many rivers that it will require considerable time to replace the loss. Although man has been the enemy of the mussels, he is now becoming their friend, for he is learning and using methods which greatly assist in preserving their lives and increasing their numbers. 


\section{CHAPTER VII.}

The Need of Laws for the Benefit of Pearl HunTERS.

DARL hunting is an important industry. During its history it has grown from a few temporary "pearl fevers" to a well established business. Every home from the log cabin to the king's palace contains something which is the result of the efforts of pearl hunters.

The valuable pearl jewels, buttons for clothing, umbrella handles, knife handles, hat pins, penholders, and a hundred other articles in common use can all be traced back to the efforts of pearl hunters. The occupation is an honorable and necessary one. There are many of our best citizens engaged in this profession. Some of them follow the business of pearl hunting during the entire year, working in the northern streams in the summer and in the southern streams in the winter. Others hunt pearls in the summer and cut blanks in the button factories in the winter. The great value of this industry to our commonwealth is now recognized.

The pearl hunter's life is a strentous one. The work calls for great endurance and patience, and often the life of the pearl hunter is subjected to dangers in swift rivers, which other men would wish to avoid. The rush- 
ing water has no terror for him and he can be found in all kinds of weather gathering shells and hunting for pearls.

Laws are very helpful to other industries, and the time has arrived when the pearl hunting business, like other great industries, needs protection. In making laws for the benefit of this industry, it is to be hoped that the legislators will not think it is necessary for a person to purchase a license before entering upon this work. No man should have to buy the right to make an honest living. The pearl hunters have plenty of expenses without requiring the payment of ready cash for a license.

The sewage of the cities which is emptied into rivers is a very common cause of destruction to both mussels and fishes. The damage to aquatic life in the Illinois River, near Chicago, is an example of this great evil.

It is necessary for the cities to dispose of the sewage. but on account of the great damage done the cities should be required to pay a large license annually for the privilege of emptying the sewage and this revenue should be used by the States for the purpose of perpetuating the supply of mussels and fishes in other localities.

Laws should be enacted prohibiting factories from emptying refuse into the streams near them. Nearly all kinds of factories, from a small cider mill to a large chemical laboratory, when located near a river, find it convenient to empty refuse, acids and all kinds of filth into the water. As this pollution is the cause of death to mussels and fishes, the companies should be required to stop befouling the water or be made to pay fines, and the 
income from fines should be used in the work of maintaining the mussel and fish supply, where it is most neederl by the State.

As hogs are very destructive to whole beds of unios, the owners should be required by law to keep the animals out of the rivers during times of low water. In cases where the law would be disregarded and the inussel berls damaged, the owner should be fined about $\$ 3.00$ for every hog. This would have a good effect.

Legislation that will reduce the freight rates on cars of shells is needed very much in some localities. There is often considerable expense in moving shells to a railway station, but it can be done if the railroad companies' charges are favorable. But when the freight rate is high they cannot be moved. This difficulty is usually found in localities that are a long distance from the factories. As an example of the high prices charged by railroads, one case is mentioned here. Last year a railroad company charged $\$ 200.00$ for hauling a car of shells from Central Minnesota to the nearest button factory. A car usually contains about forty tons, so the rate was about $\$ 5.00$ per ton. This amount is about one-half the value of the shelis in some instances.

A high tariff placed on shells and all imported articles that are made of mother of pearl would raise the price of shells throughout the United States. There should also be a high tariff placed on pearls and pearl jewelry, and especially on the culture pearls which are coming so rapidly from Japan.

There is another thing that deserves the careful atten- 
tion of the lawmakers. Fishermen do not fully understand the unios and they destroy millions of mussels annually by killing fish that are infected with glochidia. There should be a law prohibiting fishermen from taking the varieties of fish that are the most susceptible to infection with glochidia at any time during the spawning season of the most common marketable variety of mussel, and also during the entire parasitic period of the same mussel in the locality where the fishermen are at work. If such fish are taken, they should be returned to the water immediately. Some States have made laws relating to the pearl hunting industry. The laws provide a few months a year as a closed season, during which time it is unlawful to fish for mussels. As far as the protection of the mussels are concerned, the laws are not valuable ones. They are based upon the theory that the mussels are spawning during the months that are named as the closed season. These laws were made by men who would not be able to distinguish between a "threericlge" and a "razor-back," to say nothing of the spawning season or the parasitic periods of the different commercial varieties of mussels. Any law which provides a few months in the year as a closed season is a failure. Every month in the year is the spawning season of some particular variety of mussel. If there is really to be a closed season at all, it would be better to divide a river into a number of small sections. Then leave one section open to the pearl liunters and close the other parts and restock them with fish infected with glochidia. At the end of a year, close the portion of the river that has 
been open and open another section to the pearl hunters for a year, allowing three or more years as a closed season for the sections that are to be rested and restocked. The duration of the closed seasons would necessarily depend upon the kinds of marketable mussels that are most common in the vicinity and the time required for such mussels to grow to marketable size. In restocking streams, the States should select a variety of unio that will thrive and mature rapidly in the locality, and that will be a good pearl producer, and have a lustrous white nacre and be good for button material without much waste. In this method of restocking streams it will be ilecessary to consider the interests of the pearl hunters. Many of them cannot go far from their homes without considerable inconvenience and expense, so the rivers should be divided into small sections in order to allow pearl hunters to work near their homes if it is possible to do so. In order to maintain this kind of a law, the States would probably need special mussel boats and men to restock the depleted streams, or portions of streams and attend to other things relating to the work.

In addition to the suggestions regarding the laws, there are some recommendations that might properly be in order here.

It seems that the Government should encourage mussel farming and pearl culture. There may be some who desire to raise mussels either for the market or for the pearls, and who have suitable lakes, ponds, or streams for the purpose. To such people the States should supply, free of all charges, fish that are infected with glo- 
chidia from mussels that usually thrive in such lakes, ponds or streams. By using this plan, many more bodies of water could be added to the mussel resources of our country.

Perhaps the National Government or some of the States will think pearl farming is of sufficient importance to justify a slight expense and effort in investigation and experiment. By selecting favorable locations for pearl farming in various rivers, and by careful scientific management, it is probable that valuable pearls of many fancy colors may be producerl. Such an investigation would require a number of years as it would be necessary to artificially cultivate various kinds of mussels under many different conditions, and would also probably involve the artificial propagation of various kinds of parasites that have been known to furnish the nuclei of pearls, and a study of methods of infecting the mussels with these parasites in the most sticcessful manner.

A good exhibit of valuable culture pearls and a booklet describing the methods used in the artificial production of the pearls would do much toward stimulating an interest in this untilled field of endeavor which should yield a large profit to labor, science and capitol.

Another thing would be very desirable. There is a need for a mussel that will mature quickly and that will be tender and suitable for food, and have pearly white shells that are valuable for button material without much waste, and that is a good pearl producer.

This is requiring a good many things from one variety of unio and possibly such a variety can never be clevel- 
oped, yet the various conditions of the business require the most favorable circumstances. If there is a man who is a sort of "mussel Burbank," and who wants a problem to solve, he can try to cultivate the kind of mussel just described. Such a mussel would be of special value to pearl hunters and an advantage to all.

The importance of proper legislation and a general public interest in the pearl hunting industry should not be under estimated. This industry yields products which are sold for cash and often when men cannot get employment in other lines, they can secure a good living for their families by hunting for pearls. The men should be protected in their work, and it is to be hoped that no legislation will in any way interfere with their rights. 


\section{CHAPTER VIII. \\ Virious Kinds of Unio Shells.}

F the hundreds of varieties of shells in the United States, there are only a few which provicle suitable material for the manufacture of buttons, and at the same time are plentiful enough to be depende:l upon for that purpose.

There are some varieties that possess a beautiful pearly white nacre and are especially suited to the needs of the button makers, but these shells are so scarce they cannot he secured for the purpose.

There are other kinds of shells that are very common in many rivers and can easily be secured in large quantities; yet they cannot be used for making buttons because they are colored.

Other varieties are very common, but the shells are too thin for this use.

Of the varieties that are usually considered of value there are instances in which they are found to be of little or no value.

A variety that may be large and heavy enough in one river may be too small or too thin to cut blanks from in another stream. Then, again, shells that are valuable in one river may be colored pink or lavender in another stream, and the color would render them worthless as 


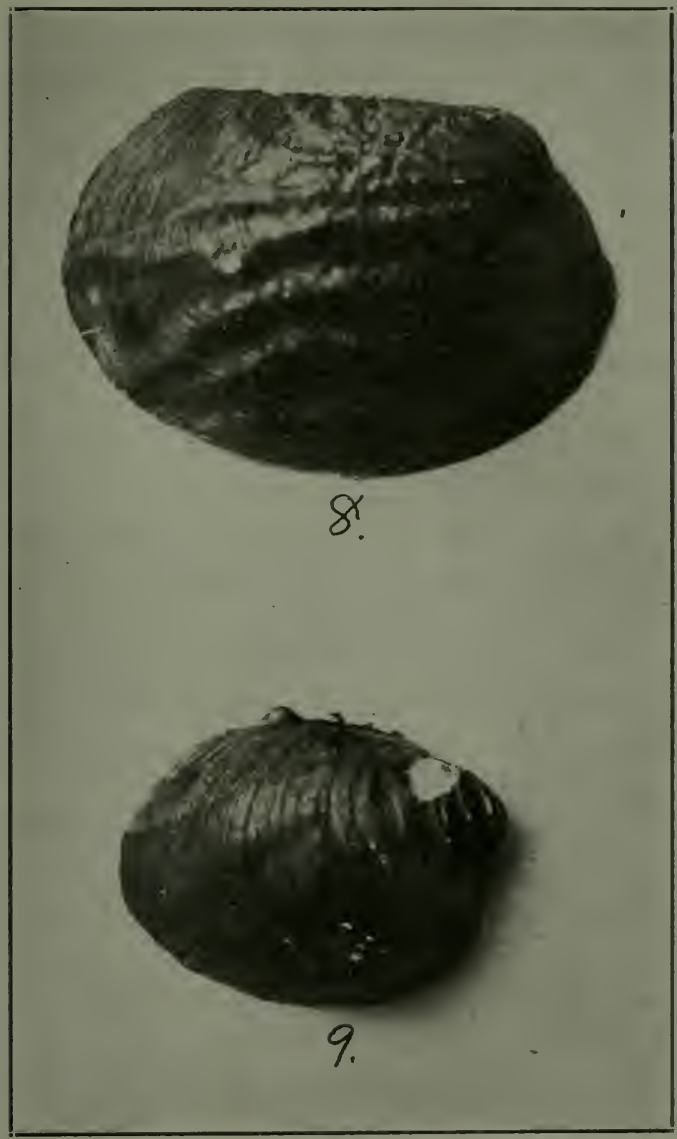

Fig. 8. The Quadrula heros, or "Washboard." Fig. 9. The Quadrula ebena, or "Niggerhead." 
button material. Other shells that are good material for making buttons in one river may be badly stained in another place, so their value would be reduced.

There are a few shells that can usually be depended upon in nearly all rivers in which they are found, but they are not all found in all rivers. In considering the various kinds of shells that are of value commercially it should be remembered that while only a few are of value for economic uses, practically all varieties are pearl bearing.

In some rivers, such as the Shell River in Minnesota. even the thin shells commonly known as "paper shells," or "floaters," are almost thick enough to cut button blanks from, so even they might possibly yield some pearls. As a rule pearl hunters do not separate the unsaleable shells from the valuable ones until after they have "cooked out" the mussels. In this way they secure all or most of the pearls. baroques and slugs that happen to be in the shells.

Each variety of mussels has a special scientific name by which it can be identified in all instances. Each variety of the mussels has also one or more common names in various localities, but the different localities often have different common names for the same mussel, so the common names can not always be depender upon to identify any particular variety of mussel.

For this reason it is necessary to use both scientific and common names in mentioning the different varieties.

Fig. 8 shows The Quadrula heros, or "washboard," and is about one-third natural size. This is found in 
many rivers, but is most abundant in the Illinois River. Near Peoria, these groly to be very large. Some of them are eight inches long and five inches wide. At Florence and Pearl, Illinois, they are about five or six inches long. while near Grafton, Illinois, they are very much smaller.

In the upper part of the Illinois River these shells are often stained or spotted, but in the lower part of the river they are not so badly injured. and are flatter and have a better luster.

In the Cumberland River, in Kentucky and Tennessee. the "washboards" are common, but are usually badly stained and are sold there as a second grade.

These are also found in IVabash, Mississippi and many. other rivers. The "washboards" vield many of our finest pearls. Those which are found in the washboards are often very large and therefore very valuable, if they are perfect or nearly so.

The most valuable fresh-water shell for the manufacture of buttons is The Quadrula ebena, or "niggerhead." This shell is shown in Fig. 9 in about one-fourth natural size. This shell is very common in most rivers, and especially in the Mississippi River. It was once plentiful in the Illinois River, but is scarce there now. It is a fine shell with a lustrous white nacre. The mussel delights in cieep waters and is not usually found near the headwaters of rivers. It is very important to perpetuate the supply of these mussels, yet the means of propagating them have not been found. Pearls which are found in "niggerhearls" are of fine luster and good value. 


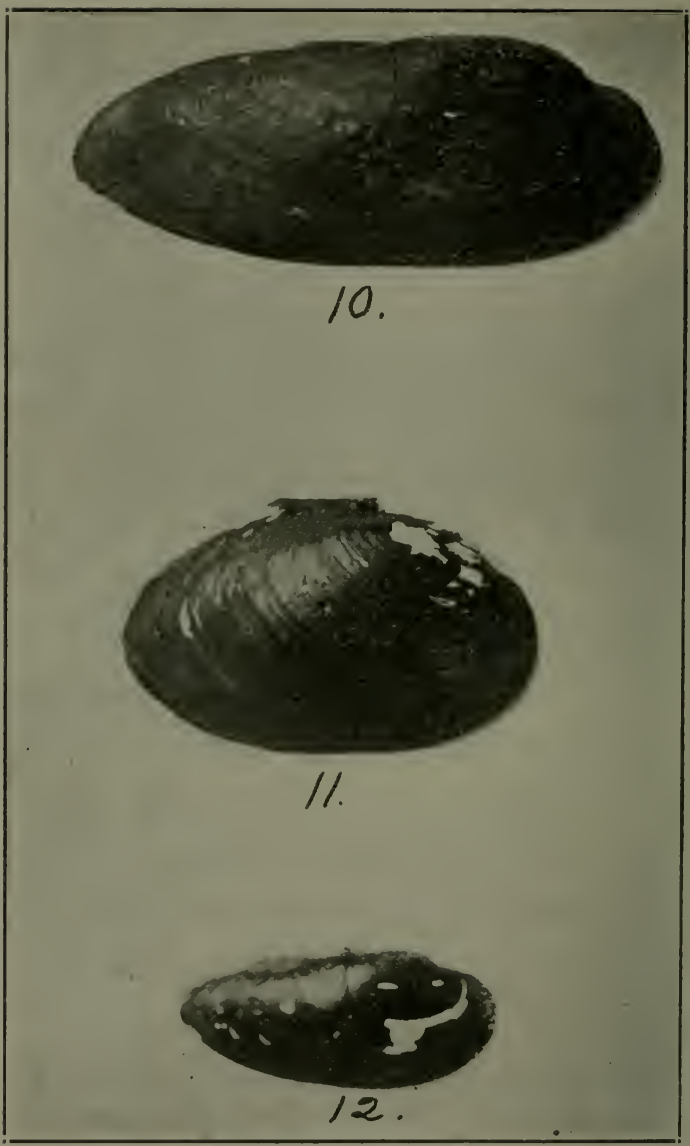

Fig. 10. The Lampsilis rectus, or "Black Sand Shell." Fig. 11. The Lampsilis anodontoides, or "Yellow Sand Shell."

Fig. 12. The Lampsilis fallaciosus, or "Slough Sand Shell." 
In Fig. Io a Lampsilis rectus, or "black sancl shell," is shown, about one-third natural size. This variety is scattered through most of our rivers, but is not especially plentiful in very many of them. It is usually mixed among other shells and not confined to colonies like some of the other varieties. The size and shape of the black sand shell is very much in its favor, but too often this shell is colored pink or purple. When the nacre is white it is valuable for both buttons and knife handles. Occasionally some very valuable pearls are found in this variety.

The Lampsilis anodontoides, or "Slough sand-shell," brings the highest price of all the fresh-ivater shells. It is usually exported to be used in making novelties and knife handles. This shell is shown in Fig. II, in about one-third natural size. The yellow sand shell is common in most of our rivers and prefers to live in sandy places. These shells are nearly always white and have a pearly nacre. When pearls are found in them they also have a high luster and good value.

The Lampsilis fallaciosus, or "slough sand-shell," is illustrated in Fig. 12, one-third natural size. It lives in slow currents near muddy banks. This shell is often too small to be valuable, although the larger and thicker ones are worth as much as the "yellow sand shells." Some of the shells are very beautiful. Pearls are found in this variety some times, but not often.

Fig. I3 shows The Quadrula undulata, or "three ridge," one-third natural size. This variety is very common in the Illinois River, and other deep rivers. It is a good 


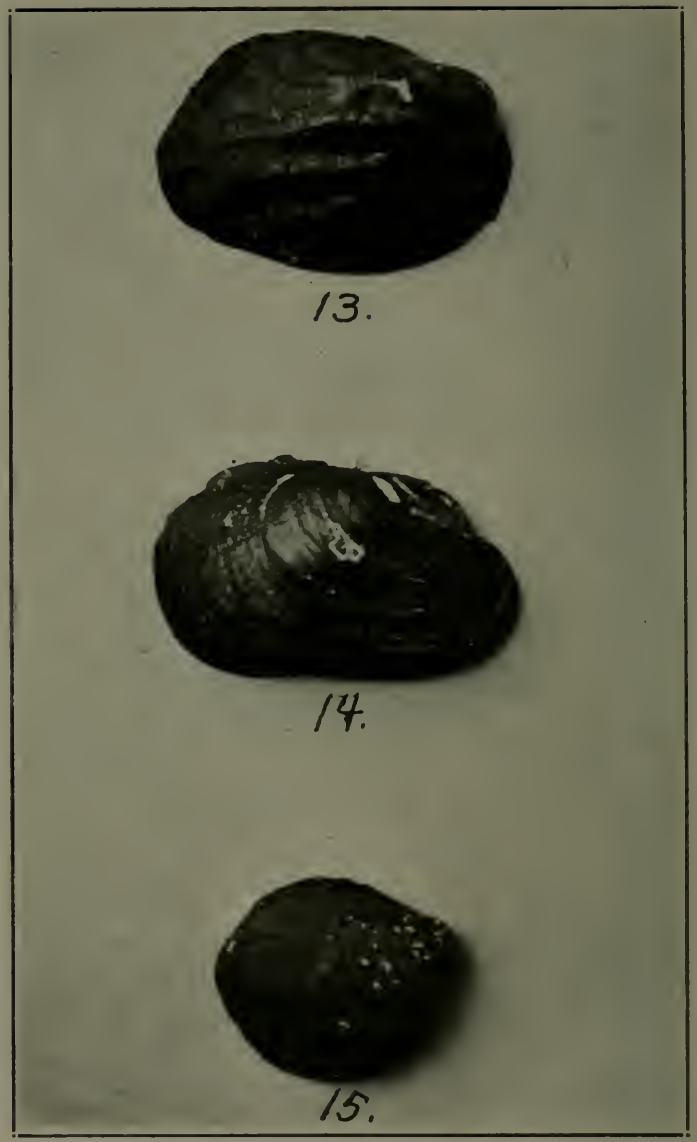

Fig. 13. The Quadrula undulata, or "Three Ridge."

Fig. 14. The Lampsilis ligamentinus, or "Mucket." Fig. 15. The Quadrula pustulosa, or "Wartyback," or "Pimple-back." 
shell for use as button material, but in some rivers these are not so valuable on account of the great depth of the ridges, which reduces their value as button material.

Another variety which is almost like tine "three ridge" is The Quadrula plicata, or "blue point." These two varieties are so similar that some do not realize that there is a difference between them. The "blue point" is a better shell for use in the manufacture of buttons, as it is flatter and does not have such heavy beaks. It is common in most places where the "three ridge" is found. Both varieties yield pearls, yet the pearl hunters expect more nice ones from the "blue points."

The Lampsilis ligamentinus, or "mucket," or "mougat," about one-third natural size, can be seen in Fig. If. In some rivers this shell is nearly equal to the "niggerhead" for use in the making of buttons. It has the advantage of being plentiful in most of our rivers. In some places a few have to be discarded on account of their pink nacre, but the shells are generally white. Being rather flat, smooth, and of uniform thickness, this shell can be worked up into button blanks without much waste. Probably more muckets are used in the manufacture of buttons than any other variety. This variety is not often found in lakes or small streams, but is the most common variety in rivers.

This species can be easily propagated. The glochidia fasten themselves quickly to bass, perch and sunfishes. It thrives well under many conditions and is better than any other species for restocking rivers. 
The "mucket" yields many slugs and baroques and some very fine pearls.

The Quadrula pustulosa, or "warty-back," or "pimple," is shown in Fig. I5, about one-third natural size. This shell is well known among the pearl hunters. It is found in most rivers, but not often found in lakes. This is a very good button shell, and in some instances is considered almost as good as the "niggerhead." The nacre is almost always white, with a good luster. It is variable, sometimes being very smooth and rather flat, while in other streams the shells are very rough and round and consequently of less value as button material.

Another shell which is very similar and is sometimes thought to be the same shell is The Quadrula tubcrculata, or "purple warty back." This variety often grows to be larger than The Quadrula pustulosa, but is not valuable for buttons on account of its dull purple nacre. It is not found in large beds like some varieties, but is usually mixed with other shells. This variety is mentioned because it is an important shell in the pearl hunting inlustry. The "purple warty-back" is the most liable to infection, by distomids, of all the heavy shelled varieties. It is a great producer of slugs and baroques and is very likely to produce fine pearls. All the slugs, baroques, or pearls found in this variety are purple and dark purple, corresponding to the color of the nacre of the shells.

The Tritogonia tuberculata is a very odd shell. It is commonly called "deerhorn," or "buck-horn," or "pistolgrip," or "fan-tail," and is shown in Fig. I6 about onethird natural size. The ones found in the upper portion 


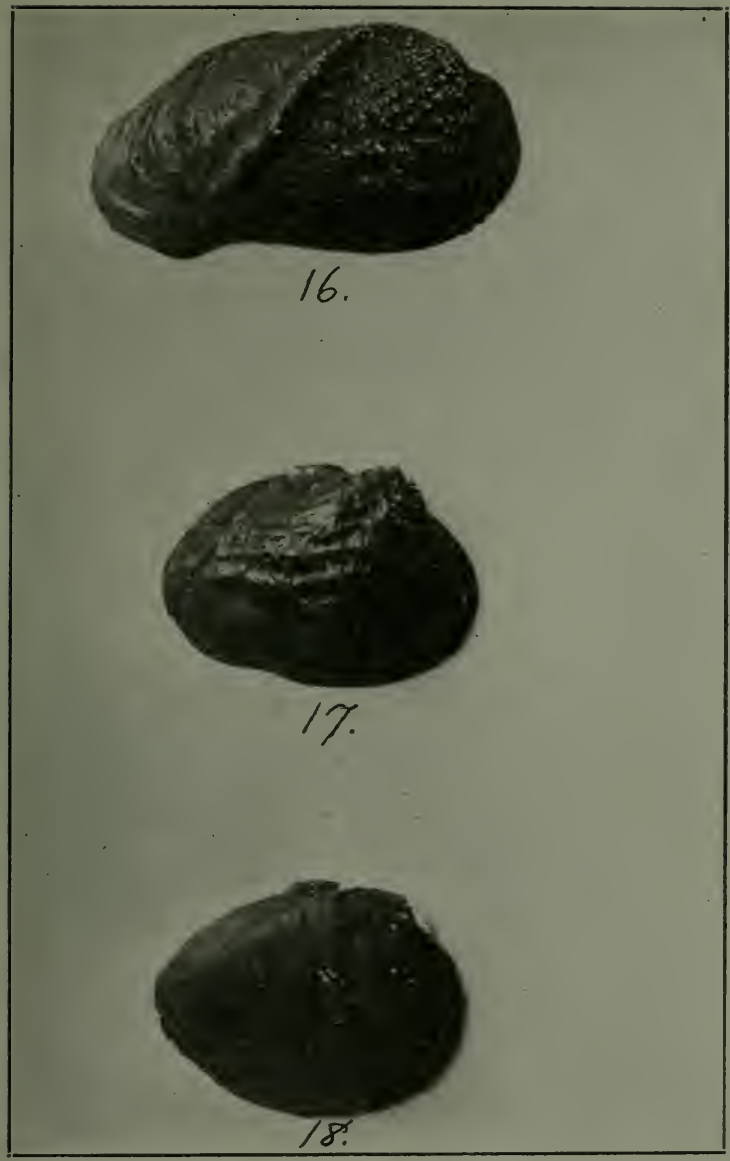

Fig. 16. The Tritogonia tuberculata, or "Buckhorn," or "Deerhorn."

Fig. 17. The Quadrula lachrymosa, or "Stranger," or "Maple-leaf."

Fig. 18. The Plagiola securis, or "Butter-fly." 
of the Mississippi River are usually white, with a pearly white nacre, and are excellent material for making buttons and knife handles. They are not always valuable, however, for in some rivers in Tennessee these are pink and in some Arkansas streams they are purple, and in some of the rivers in Texas they are a deep purple color. The "buck-horns" do not usually grow in colonies, but are distributed among other shells. Some very valuable pearls are occasionally found in them.

The Quadrula lachrymosa, or "stranger," or "mapleleaf," is illustrated in Fig I7, about one-third natural size. This is very scarce in some rivers, and is not usually abundant in any of the rivers. It is similar to the "three-rilge." It is used in the manufacture of buttons, but the irregular surface of this shell slightly reduces its value as button material. These also prorluce nice pearls.

The Plagiola securis, or "butterfly," is a very pretty shell, with pearly white nacre. This shell is shown in Fig. I8, one-third natural size. A pair of these shells open, and when viewed from the outside, have the appearance of a butterfly, and for this reason, their common name is used very appropriately.

This variety is one of the most valuable ones for making buttons. In some rivers the "butterfly" attains a large size. It is not abunclant in most rivers, although there are some places where it is quite common. Some very lustrous and valuable pearls are occasionally found in this variety.

The Lampsilis i'cntricosus, or "pocketbook," is shown in Fig. 19, atout one-third natural size. This variety 


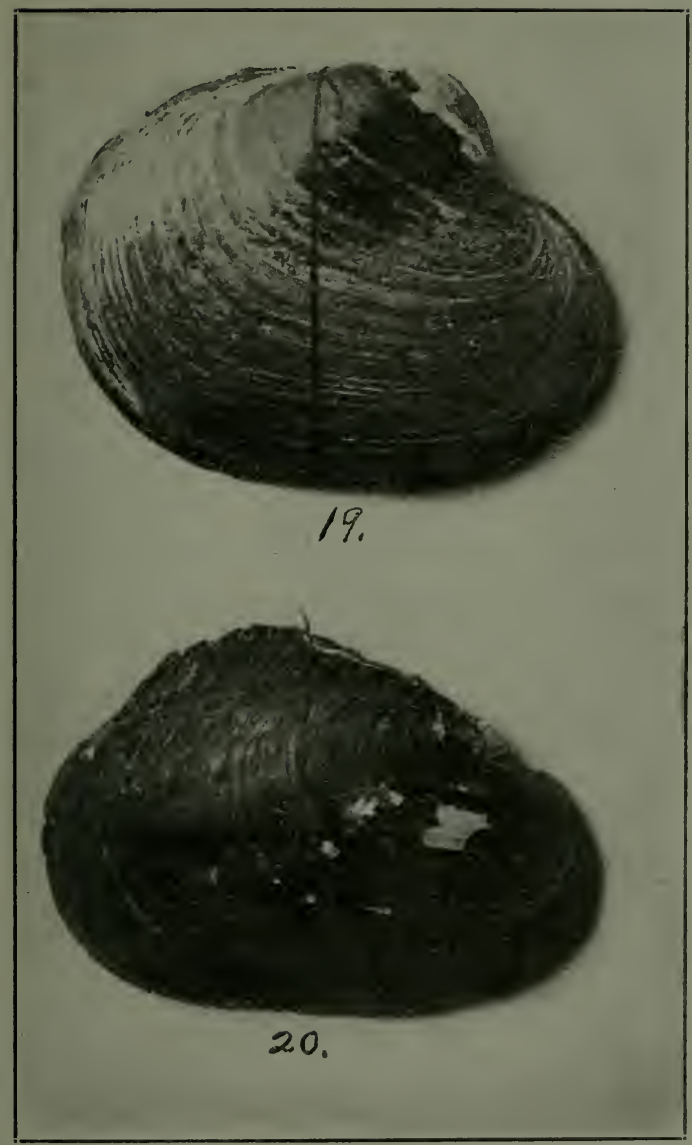

Fig. 19. The Lampsilis i'entricosus, or "Pocketbook."

Fig. 20. The Symphonota complanata, or "Razorback," or "Hatchet-back." 
grows sparingly in both lakes and rivers, and is known throughout most of the States. In some instances the shell is too thin for button material, but usually it is a good shell for the purpose. The nacre is generally white and lustrous, although some times a few pink ones are found. They are some times used in the manufacture of pocketbooks and novelties. Slugs, baroques and pearls are occasionally found in these shells.

The Symphonota complanata, or "razor-back," or "hatchet-back," or "heel-splitter," or "hackle-back," is shown in Fig. 20, about one-third natural size. This variety is common in most rivers, but is not a valuable shell, unless it is thick and has a white nacre. As a rule, however, the shells are thin and colored. They do not grow in beds by themselves, but are usually scattered among other varieties of shells. Pearls are not often found in the "razor-backs," but when they are found in these shells they are very brilliant and valuable.

The Quadrula obliqua, or "pig-toe." is shown in Fig. $2 \mathrm{I}$, one-third natural size. This shell is white, with a good luster and is a good shell for making small buttons. It is a very common variety and in some rivers they are very plentiful. Its small size reduces its value somewhat as a button shell. Occasionally nice small pearls are found in the "pig-toes."

The Quadrula metanevra, or "monkey-face," is illustrated in Fig. 22, one-third natural size. This shell also has a pearly white nacre, but is small and for that reason is not quite so valuable as many larger shells. It has 


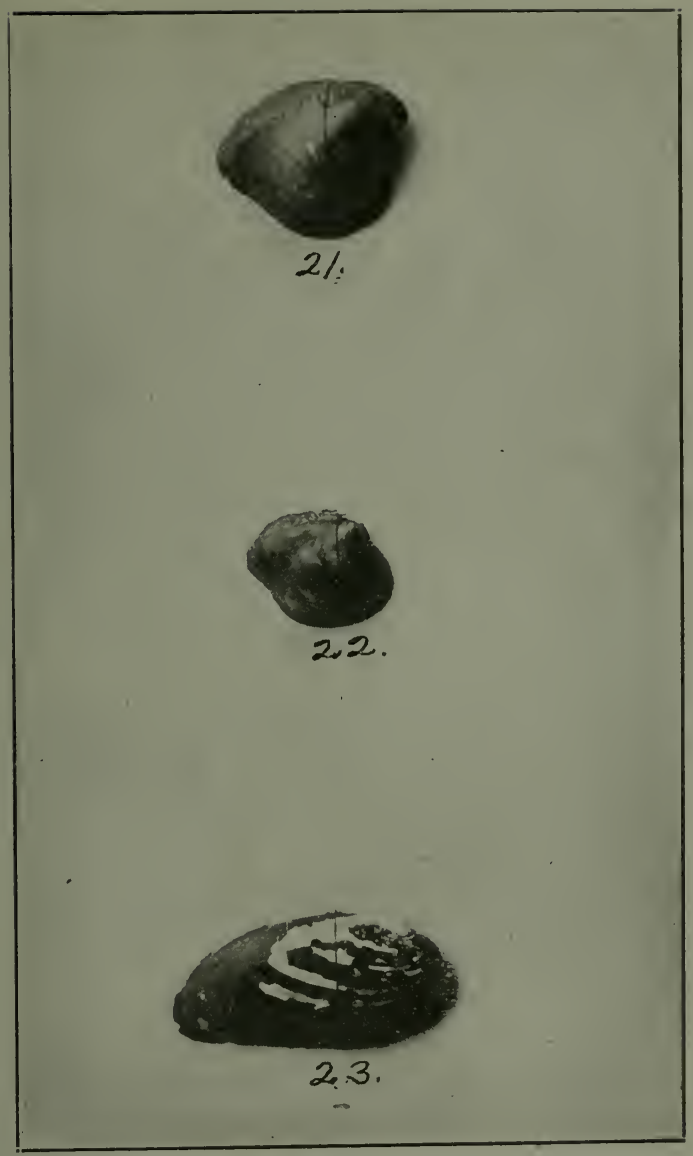

Fig. 21. The Quadrula obliqua, or "Pigtoe." Fig. 22. The Quadrula metanevra, or "Monkey Face."

Fig. 23. The Unio gibbosus, or "Ladyfinger," or "Spectacle-case." 
about the same value as the "pig-toe" shells. Small pearls are some times found in the "monkey faces."

The Unio gibbosus, or "lady-finger," or "spectaclecase," is shown in Fig. 23, one-third natural size. It is usually an unsalable shell on account of its color. It is not often found with white nacre, but in such cases it is usually of commercial value. They are very widely distributed and are found in both lakes and rivers, and are especially plentiful in the headwaters of the rivers. They are some times infected with the marginal cy'st distomid, and occasionally contain slugs, baroques and pearls.

There are some other shells which occasionally are of commercial value, but the ones illustrated and described are practically all of the valuable fresh-water shells of the United States.

If the present styles should change, and a demand be created for colored buttons, then the colored shells would become valuable. It is not likely, however, that there will be a change from the present styles of buttons.

Amateur pearl hunters should remember that while some varieties of shells do not have a commercial value, all varieties of shells occasionally yield pearls. 


\section{CHAPTER IX. \\ Value and Uses of Shells.}

7 IVENTY-FIVE years ago the shells in the United States did not have a commercial value. Such a thing as a button made from a shell of a freshwater mussel was unknown. All the pearl buttons that were used here then were imported. About that time a man named J. F. Boepple, who had learned the trade of button making and who was then making buttons at Otensia, near Hamburg, Germany, began to take an interest in American fresh-water shells. He received a small box of them and was so successful in his experiments with them that he sold his factory there within a short time and came to America to enter the button business. In 1892 he established a factory in Muscatine, Iowa, and was the first to manufacture buttons from our Unio shells.

This pioneer in the button business had the advantage of a favorable tariff and an unlimited supply of mussels in the rivers near, yet the first venture was a failure. financially. Mr. Boepple was an expert in his work. yet he seemed to lack some business qualities which are necessary to succeed.

This founder of the button industry was later con nected with the Fairport biological station and in his 
service for the Government, devoted his time to the work of perpetuating the supply of the fresh-water mussels. $H$ is vast experience and special talent for the work made him one of the most valuable men in that department of the government service.

At the time of his death a little over a year ago at Davenport, Iowa, the city of Muscatine, Iowa, paid a special tribute to the pioneer button manufacturer by suspending all business and industrial activities on the day of the funeral.

The people who are connected with the great button industry of our country are very much indebted to him for the interest he manifested in the advancement of the pearl button business in the United States.

The manufacture of buttons is the main industry in a number of thriving cities along the Mississippi, the Illinois, the Ohio, the Wabash and other-rivers.

One of the latest census reports gives an idea of the importance of the industry.

It shows a total of 6,400 people employed in the button business. The total wages per week were $\$ 69,000.00$, and the total wages for the year were $\$ 3,450,000.00$. In one year $25,200,000$ gross of buttons were made, the average price per gross being $2 \mathrm{I} 3 / 4$ cents. The amount paid for shells reached a high figure. The amounts of shells shipped from the various rivers were as follows: Wabash River, I4.400 tons: Ohio River, I3.440 tons: Arkansas River, 9.I20 tons; Mississippi River, 8.640 tons; other rivers, 2.400 tons; making a total of 48,000 tons from all the rivers. The average price of shells 
from the Mississippi River was $\$ 17.00$ per ton. The average price per ton from all the other rivers was \$15.00. The total value of the shells from all the rivers was $\$ 737,280.00$. Since this report the prices of shells from the Mississippi River have averaged $\$ 20.00$ per ton, while the average prices of the shells of other rivers has been reduced.

At the present time, April IO, I9I3, there is a strong advance at Rapids City, Illinois, on the Mississippi River: shells are now worth $\$ 28.00$ per ton. The price of shells at Pearl, Illinois, is $\$ 16.00$ per ton, and they are about the same price at Peoria, Illinois.

The Illinois River, in the vicinity of Peoria, has been the scene of great activity in the pearl hunting and shell fishing industries. Many fine pearls were found there last year and about one hundred cars of shells were shipped out of Peoria.

Fig. 24 is a view of "Gatlin's Landing," Peoria, Illinois, showing pearl hunters, cooking vats, shells, etc. The large pile of shells in the upper lefthand corner of the picture belong to Mr. Henry Gatlin, who sold them for $\$ 1,500.00$. This is just one of hundreds of such landings to be found in various parts of the country.

In addition to the large number of people employed in the manufacture of buttons there are also several thousand pearl hunters or "clammers." The amount they receive for their work depends upon their skill and industry and many other conditions; such as the supply of shells in the water where they work, and the market 


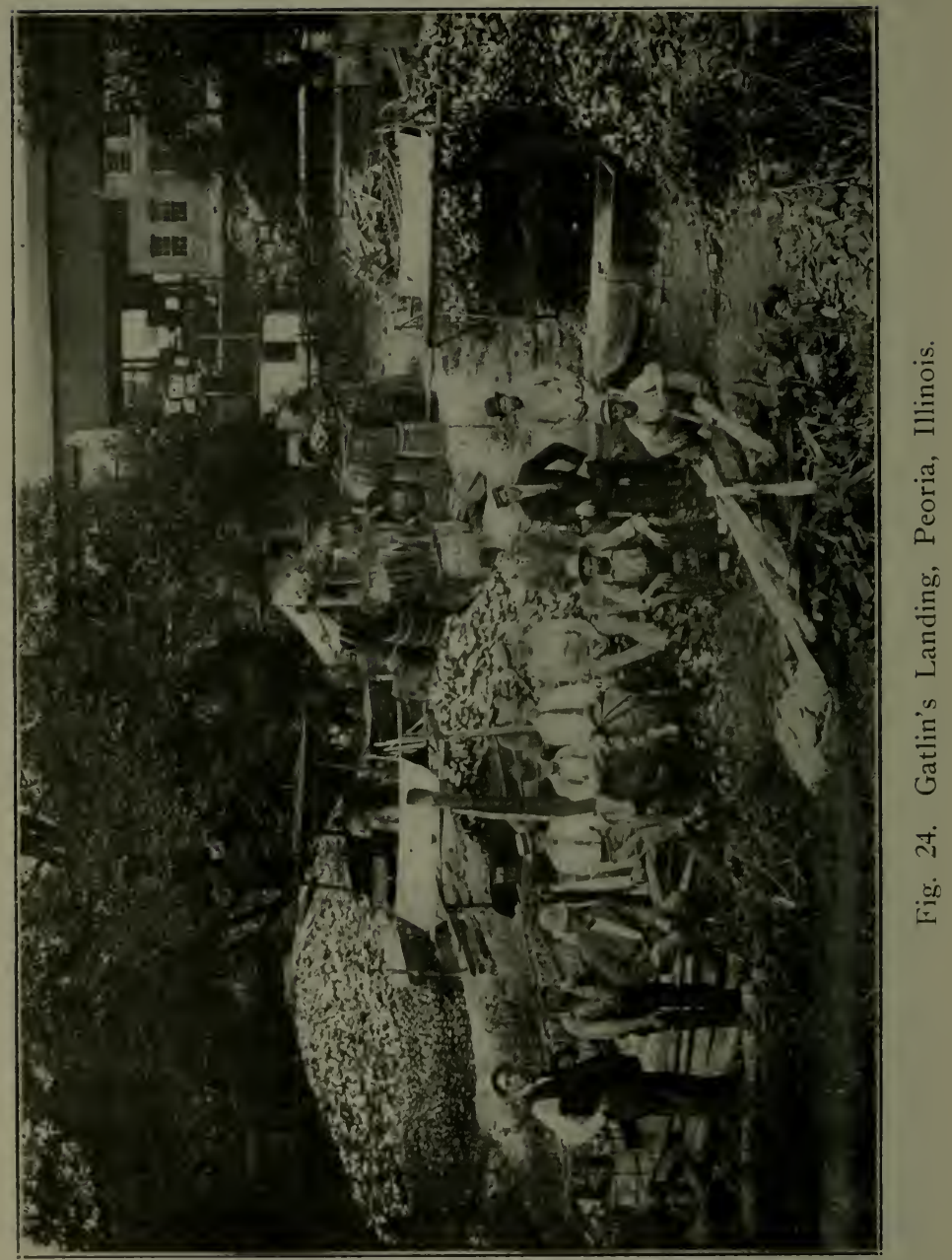


value of the shells they gather and the weather, and their luck in finding slugs, baroques and pearls.

There is quite a difference in the values of shells. In rivers near the Iowa markets, the freight rate is lower than in the more remote districts. Some rivers have fine shells, but are too far away from the market to be worked profitably. In some instances this difficulty can be overcome by building a barge and installing machines for cutting blanks. In this way the shells are workerl up into blanks, while the small floating blank factory gradually drifts toward a favorable shipping point, where the blanks are shipped to the nearest button finishing plant. The plan is a good one.

It is important to know just what the button manufacturers need for button material. The requirements are a white shell with the whiteness uniform throughout the various strata of the shell; a bright pearly nacre; a degree of toughness that will allow the shell to be worked up without cracking or splitting: and a size and shape and smoothness that will allow the shell to be used without much waste.

As the principal use of shells is in the manufacture of buttons, a brief description of the evolution of pearl buttons will probably be of interest to pearl hunters and shell gatherers.

The mussels are first cooked and then the meat is removed. The cleaned shells are then shipped to the factory and stored in sheds. They are then sorted into different sizes and soaked in water from three to six days 
so they will not be brittle. They are worked up while wet, otherwise they would crumble. The first machines used are the blank cutters, which are hollow cylinders of steel and with diameters corresponding to the sizes of the buttons. One end of the cylinders have fine teeth which saw out the blanks. The cylinders are adjusted to the lathes in which they revolve. The shells are held against the saws with pliers, although some blank cutters prefer to hold the shells with their hands. As the blanks are cut they pass back through the saw and saw holder and drop into a receiver.

Fig. 25 shows a large Quadrula heros, or "washboard" shell, from which five large button blanks have been cut. The stains on this shell made it difficult to cut more of the large blanks, but some material could have been saved by cutting some smaller blanks from it. After the blanks are cut they are held against a revolving grinding wheel to remove the black epidermis and to make the blank smooth. After this they are turned and the buttons are given their proper shape. The holes are then drilled in them and they are complete, except for the polishing. This is done by placing the buttons loose in large tumblers where they are subjected to the action of a chemical fluid and mutual contact while the tumblers revolve. They are then washed and dried and sorterl into various sizes and grades, and then sewed on cards and packed into cardboard boxes and are ready for the market. Many of the western factories just cut the hlanks and send them to eastern factories, where they are finished. Some of the western companies, however, 


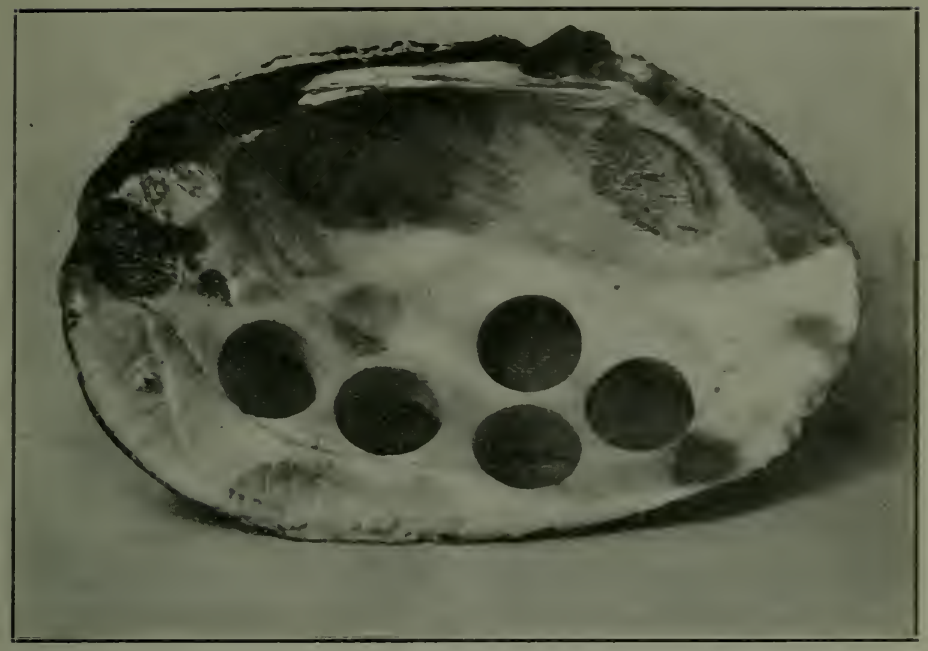

Fig. 25. Large Quadrula heros, or "Washboard" shell from which five large button blanks have been cut.

are well provided with the most approved finishing machines and finish their buttons in their own factories.

While the Unio mussel shells are used mostly for buttons, there are many other uses for them. A few of the articles of every day use which are made from them are as follows: Buckles, knife handles, umbrella handles, hat pins, pistol stocks, penholders, pocketbooks, trolling spoons, match safes, jewel cases, opera glasses, novelties and souvenirs. There are some other uses which require large quantities of shells. One of them is the manufacture of crushed shell for poultry food. During one year 30,726 tons of chicken grits were made from the waste 
material of the button factories. This was sold for \$I69,000.00 , or at the rate of about $\$ \mathbf{5 . 5 0}$ per ton.

Another common use for shells is in road making. It is estimated that there are about 3.000 miles of roads in the eastern States that have been surfaced with shells of oysters and clams. The localities which use shells for this purpose are: Connecticut, Long Island, New Jersey, Delaware, Maryland, Virginia, North Carolina, Florida and Louisiana. The shells cost three cents a bushel and to cover a road sixteen feet wide to a depth of fifteen inches in the middle, and eight inches on the sides requires about 30,000 bushels of shells per mile, making an expense of $\$ 900.00$ per mile. In order to keep the road in repair, 2,500 bushels of shells are required annually at a cost of about $\$ 75.00$. It is the cheapest road material in those sections, but it is not entirely satisfactory as roarl material on account of the rapid wear and the objectionable lime dust. The shells are also used for railroad ballast. They are not so clurable as rock, but are cheaper in some localities and answer the purpose fairly well.

Shells are often used for sidewalks, and are well adapted for that purpose.

In Colonial times shells were used for making lime and most of the brick buildings that were built then were solidified with the shell lime. It was not very satisfactory though, on account of its tendency to absorb moisture, and its use was discontinued as soon as limestone was discovered.

Shells are userl in large quantities for spreading on private oyster grounds for the purpose of obtaining a 
"set" of young oysters. It is estimated that $4,000,000$ bushels of oyster shells are used annually for this purpose in the waters of New York, Connecticut and Yirginia.

Another peculiar use for shells is in the manufacture of certain special grades of steel.

Personal adornment is probably the oldest use of shells : and they are still used for that purpose in many countries. One of the most artistic articles for adornment is the shell cameo. The cameos are carved to represent historical scenes such as the landing of Columbus; or, a medallion of the head of some historical character. The king-conch shell has generally been used for this purpose. In earlier times this branch of art attained a high standard of perfection. Recently, however, it has been, very unfortunately, neglected; and it is to be hoped that this valuable art will soon receive the attention which it deserves.

Shells have also been used extensively in the decoration of buildings. Their principal use in architecture is in the form of mosaic decorations. A splendid example of this artistic work may be seen in the magnificent stairway of the Chicago Public Library.

The great variety of colors of the fresh-water shells of the United States make them very valuable material for use in this art.

There is a firm in Brooklyn, New York, which makes a specialty of pearl inlaying. The art products which they make from shells of various colors are very fancy and attractive. The colored shells of our rivers are very 
well suited to this use. There is room for many more artists in the pearl inlaying business.

Some of the uses of shells are very odd. A recent issue of a popular scientific magazine contains a description of the Kapas sea shells which are used as generally for window panes in the Phillipine Islands as we use glass in this country. The publication shows a view of the windows of the main entrance of the Phillipine General Hospital in Manila. They are a fine example of the modern use of shells. The old churches there also have magnificent windows made from the Kapas shells. The shells are also used in windows of stores, offices, homes, and in many other buildings. In Manila alone, 5,000,000 of these shells are used annually for windows. The shells are almost flat bivalves six or eight inches long. The largest will square four inches and sell at $\$ 4.00$ to $\$ 5.00$ per thousand. The smaller shells are sold anywhere from $\$ 1.50$ to $\$ 3.00$ per thousand, and are used for ordinary purposes in dwellings and stores. The shell panes have been tested and prove to be much stronger than glass. The inside of the shell is glazed and has a subdued luster. The shells are so thin and transparent that print can be read through. As the tropical sunlight filters through the silvery greyness of the shells, it becomes more gentle, mellow and magnificent. The value of shells for the purpose of making windows in the Phillipines, suggests that perhaps some of the shells in the United States might possibly be used for the purpose. The Symphonota complanata, or "razor-back," is large and thin and nearly flat. It is found in many tints and colors and should 
answer for use in windows very beautifully. It would be necessary to grind away the epidermis and polish them on the outside, but windows of such material would be very novel and valuable.

Shells were used for currency by the Indians in the early history of the United States, and were known as "wampum." Even yet shells are used as currency in certain parts of Africa.

The giant clam, Tridacna, is found in tropical waters and often on the oriental pearl beds. It yields the largest shells in existence. In some cases a single pair of these weigh over 500 pounds. A diver who accidentally places a hand or foot in an open shell is imprisoned and must sever the limb to save his life. These shells are often used as benetiers. A pair of them were given by the Republic of Venice to Francis I., and are now used as benetiers in the Church of St. Sulpice, in Paris.

The descriptions of some of the shells of foreign waters were taken from a paper on foreign shells and will probably be of interest to pearl hunters in general. 


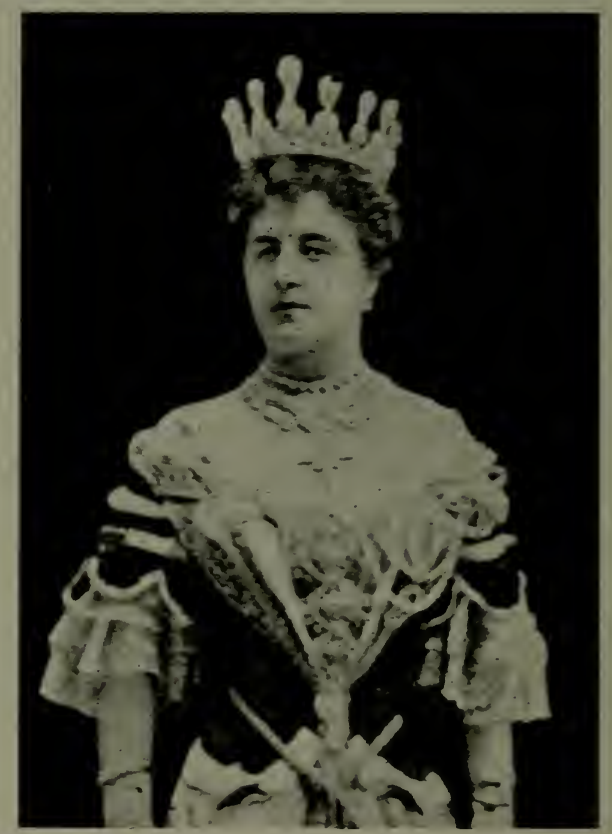

THE MARCHIONESS OF LONDONDERRY 


\section{CHAPTER $\mathrm{X}$.}

\section{How to Prospect For PeARls.}

7 HE investigation of a part or all of a certain river is now known as "prospecting for pearls.'

In many occupations which are dependent upon the natural resources of a country, it has been found that there is a great diversity in the natural resources in various places. In this respect, what is true in regard to the various kinds of mineral resources is also true of pearls. In order to do successful prospecting for gold, silver, copper, lead, etc., it is first necessary to secure a knowledge of the circumstances and conditions under which the various minerals are found, and it is equally necesessary to have good preparatory knowledge in order to be successful in prospecting for pearls.

In many instances there has been a total lack of system in the manner of selecting pearl fisheries.

The purpose of this chapter is to assist beginners in the very important task of selecting the most profitable place for their work.

As pearls are only found in the mollusks it is very necessary to know just what conditions are most favorable for the growth of the fresh-water mussels. These are found in nearly all of our streams, yet they are more plentiful in some places than in others. The streams 
which contain the largest numbers of mussels are those which contain pure water running over beds of limestone rock in some places along their course.

Rocks of various kinds and gravel and sand are good signs of both shells and pearls. Limestone is very valuable in the formation of the shells, yet they grow well in rivers where sandstone, slate, shale, marble or flint are commonly found. As the water flows over the stones, the process of erosion wears very fine particles away from the rocks and this becomes mixed with the water, making it calcareous, and is just what is needed for the formation of shells and pearls.

Some rivers have very little rock or gravel in them, and their beds are muddy, yet if there are rocky bluffs nearby, the smaller streams carry sufficient quantities of lime water into the river to provide for the growth of shells and so the muddy river also produces some shells and pearls.

Some varieties of mussels do not form beds, but are distributed over a large area and scattered among other shells.

Other varieties live in colonies or beds. The beds are of various sizes; some are rather small, while others are a mile or more long. In some narrow rivers the beds may cover the entire river bottom, while in the larger streams they are often in very narrow beds. The position of the beds depends upon a number of conditions such as the nature of the river bottom, the strength of the river current, the depth of water, the position of islands and sand-bars, and other influences. Some beds 
are in the centers of large rivers, but more often are upon shoals or connected with islands or bars. Very often the beds are in a portion of the river where they are somewhat protected from the full force of strong currents in the swift rivers, and in the quiet rivers they are often found in the parts where the current is strongest. They seem to thrive best where the river bottom is sandy and gravelly, and where the water is moderately deep and the flow is free and gentle.

In swift rivers the islands are a good protection for the mussels. They may be found on all sides of an island, but are more likely to thrive in the rather quiet water between the island and the nearest shore, and below the island. This is a very favorable condition which makes an excellent pearl fishery in many instances.

The beds that are located in rocky or sandy places are the most likely to produce pearls, baroques and slugs.

The size and color of the shells are an indication as to the size and color of the pearls, baroques and slugs. The very largest shells produce the largest pearls, while the smallest shells produce small pearls and never yield large ones. The color of the pearl is the same as that portion of the shell nearest to it when found. Practically all fine pearls are found in the posterior or thin end of the shell, and as that portion of the shell is often brilliant, the pearl has a better luster than the other parts of the shell.

In some instances it is desirable to know if a portion of a river has a sandy bottom. Some pearl hunters use a convenient method of getting this information. A 
cake of laundry soap is tied to a weight on the end of a line and dragged a few feet on the bed of the river. If the soap gathers sand it is a proof that the river bed is sandy at that place.

When small shells are found open upon the bank of rivers or lakes it is an indication that there are shells in the water. Muskrats, raccoons and other predacious animals bring out the small mussels for food.

- The distorted shells known as "cripples" are the ones which generally contain the fine pearls, yet only certain ones of these contain pearls. They are described fully in another chapter.

The appearance of the shores often indicate the amount of labor that will be involved in pearl hunting in a certain locality.

A large number of old trees, logs and brush in the water along the shores, indicate a great many snags, or "hang ups," on the bottom of the river, which will cause unlimited trouble when the crow-foot dredge or dip net is used. The logs and stumps have been especially troublesome in the Illinois River.

The parasites should receive special consideration in prospecting for pearls. These are the causes of the formation of most pearls, baroques and slugs, so it is very important to select a pearl fishery where these are most abundant. Among the parasites that are found in the mussels there are several that are especially prominent. The Cotylaspis insignis, Leidy, can be seen with the naker eye and some of them resemble a small pale leech. An- 
other, The Aspidogaster conchicola, is very similar to the one just mentioned.

The common leech is not so numerous, but is also a parasite which affects the mussels. There are several others, but these three are especially noticeable, and pearl hunters should examine the shells to see if these small parasites are plentiful.

The parasites prefer to live in shallow, warm and quiet pools rather than in the deep, cool, swift currents of rivers.

The placid shallow water between an island and the nearest shore is an excellent location for them to get a start, and, a little farther down the stream on the same side, if deeper water can be found, it will be one of the best places to hunt for fine pearls, for the reason that the mussels seem to gradually move down stream into deeper water as they grow older and larger.

The author has hunted for pearls in places of this kind. An excellent example of such a pearl fishery is to be found near the east shore of the Mississippi River. a little more than a mile south of Rapids City. Illinois. Mr. Gumber, an expert pearl hunter who lives near there, has been very fortunate in hunting for pearls in that pearl fishery. He has found a number of very fine pearls, besides large quantities of baroques and slugs. His favorite method of fishing for shells is to use the long handled fork from a boat in the summer, and from the ice in the winter. In taking less than four tons of shells while fishing through the ice he found $\$ 400.00$ worth of pearls. Since he first began pearl hunting in 
that locality he has saved considerable money from the sale of shells, pearls, baroques and slugs, and has bought a small farm and built a pretty home. In mentioning the good fortune of Mr. Gumber, it should be stated that he has been far more successful than the average pearl hunter, and amateurs must not infer that they may be sure of doing as well.

Other favorable places for pearl hunting may be found just below sand or gravel bars, and especially below the bars which are found at the mouth of a creek or smaller stream which comes through a rocky district. These bars protect the mussel beds from the strong currents, and, as the water is rather shallow just below them, it is warmer and large numbers of parasites thrive and affect the mussels. The deeper water just a little below such places is one of the best places to look for fine pearls.

Many fine pearls have been found in locations where the river bed often contains deposits of blue mud.

While the places that have been described are the ones most likely to yield pearls, they are also found in other places which do not appear to be so favorable.

Where beds are located near steamboat landings, occasionally shells can be found that have been injured by the steamboats, and these shells sometimes contain slugs and baroques, and in rare cases pearls have been found in them. The importance of the steamboat landing, however, has been greatly overestimated.

In prospecting for pearls, it is very important to mark every new place that is especially favorable. At any particular spot where an unusually large number of 


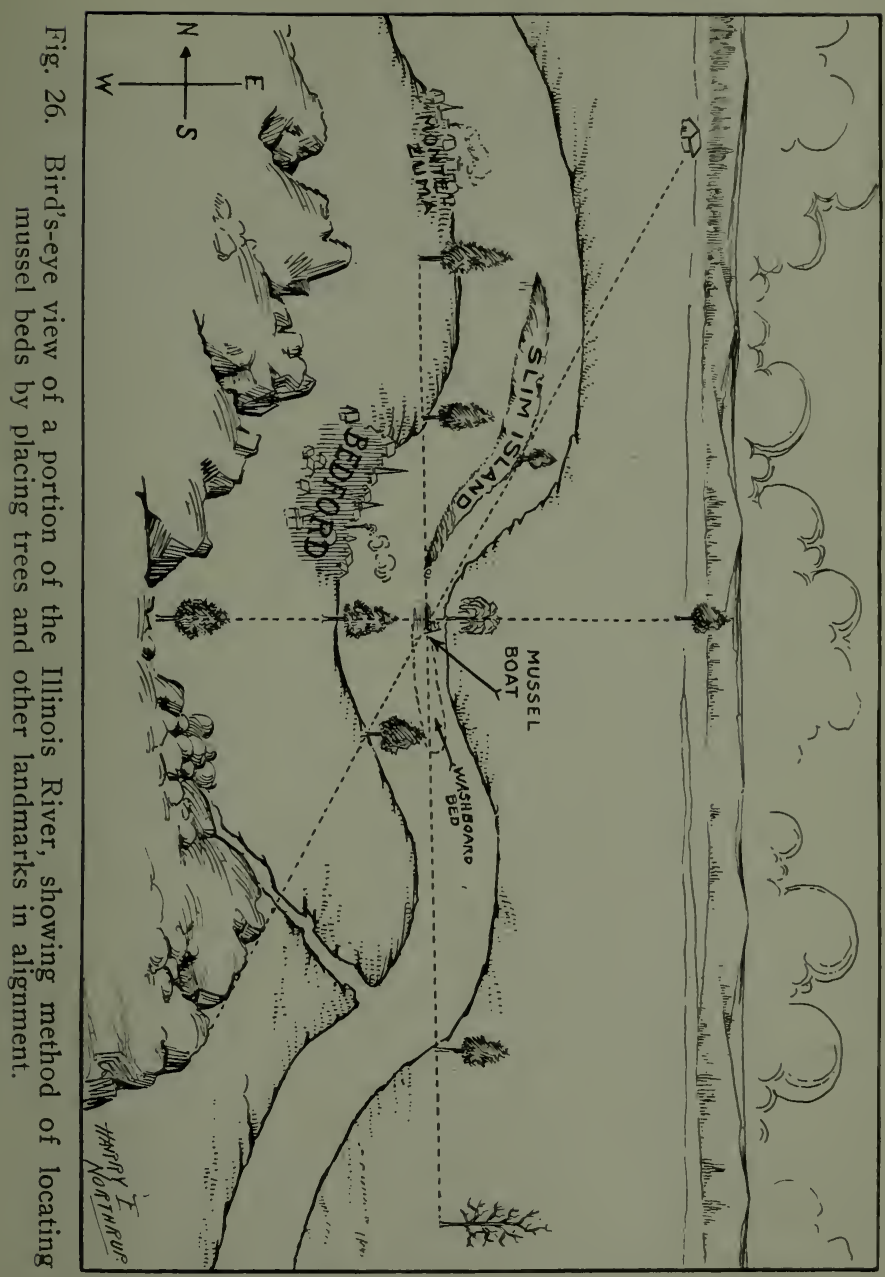


shells have been taken, or where a pearl has been found, or when, for other reasons it is desirable to return to the very same location, it is necessary to use some reliable plan which will help to find the place again. Water is very deceptive, and it is impossible to estimate the distance between various objects or the distance from the shore.

If the pearl hunter is in a boat, as is usually the case, he should anchor the boat immediately before it is moved by the river current or the wind. He will then have time to note his position carefully and the best plan for marking such a place is illustrated in Fig. 26. This is a view of the Illinois River, near Bedford, and shows a system of marking a certain location by getting trees and other objects on the shore in alignment. By a careful study of the illustration, the amateur will understand this very effective system of locating mussel beds. It is a good plan to carry a small note-book and a pencil while at work and make a rough sketch of any position to which it is desirable to return. In this method it is best to sight in several different directions, getting two widely separated objects in line with each other in each direction, and remembering the various objects that were placed in alignment. The system is so perfect that an experienced pearl hunter can return to the exact location of any place which he may mark.

Some beds of mussels do not run straight, so they may require several marks to enable the pearl hunter to follow them accurately and without loss of time. The men who know every turn in the mussel becls are the ones 


\section{How to Prospect for Pearls}

who can get the most shells in a day. In some places an anchored float or a long stake driven into the mud is used to mark a location, but neither are satisfactory as they point out the place to every one and cannot remain long where pearl hunting appliances are used.

The methods of prospecting for pearls which have been described have been proved to be very reliable, and pearl hunters may profit by their use. 


\section{CHAPTER XI.}

How to Make A Crow-Foot Dredge Outfit.

$7 \mathrm{HE}$ most common appliance that is used by pearl hunters for the purpose of catchirig mussels is 1. the "Crow-foot Dredge." In the spring of 1897 this very ingenious and practical device came into use and has been very popular. A view of several complete outfits may be seen in Fig. 27. The dredge consists of two pieces of iron gas pipe to which are attached large numbers of lines. Several hooks, each having four prongs, are attached to each line. A bridle rope is attached to each bar near both ends of the pipe. A larger long rope is fastened to both bridles, thus connecting the two dredges. The hoat is usually eighteen or twenty feet long, with a flat bottom and square ends. It is, therefore, safe to use, and will carry a good load. Four upright pieces of wood, two for each side, are fastened to the gunwales of the boat and serve as standards to hold the bars when they are not being dragged over the bottom of the river. The standards should be notched on the top end and should lean slightly toward the center of the boat so that any mussels that drop off the hooks will fall into the boat, rather than into the water. At the bottom of the standards and near the top of the gunwales short notched pieces of wood are attached, which 


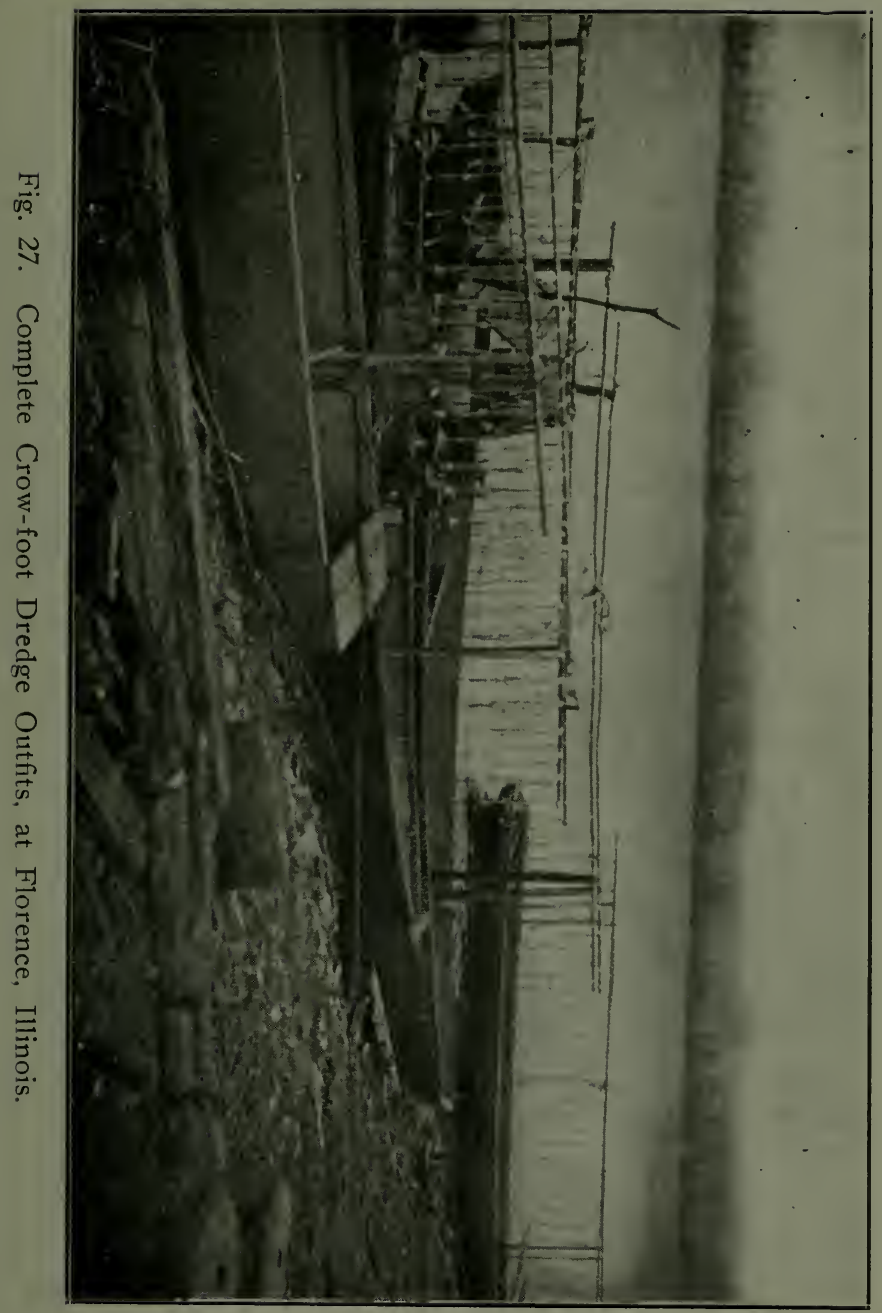


also serve as rests to hold the bars. These are called half rests, and the bar is first placed on them after being raised out of the water. Then it is raised one end at a time, and placed on the high standards. There is another part of the outfit known as the "mule," which consists of a wooden frame with a heavy cloth tacked over it, with small guide ropes tied to it.

After the dredge is placed in the water and anchored to the front end of the boat, the "mule" is placed in the water on its edge at the back end of the boat, and attached to the boat by the guide ropes. The current of water strikes the broad surface of the "mule," which causes it to pull the boat and dredge. As the dreilge is gradually pulled down stream the hooks catch the mussels. The usefulness of the appliance depends upon the labits of the mussels. They rest on the bottom, often partly buried in sand or mud, with the posterior end of their shells facing upstream and partly open to admit the water which contains both oxygen and food. As soon as they are touched they close their shells quickly, and any foreign object which happens to be in the shell is tightly grasped and held. As the dredge is dragged over the mussels the prongs of the hooks enter the open shell and the mussel shells close and grip them tightly. After a sufficient number have become attached, the dredge is raised to the boat.

Now that a general description of the entire outfit has been given, the parts of the crow-foot dredge will be rescribed separately. Fig. 28 shows the "mule."

The size of the mule needed will depend upon the 
How to Make a Crow-foot Dredge Outfit. i i I

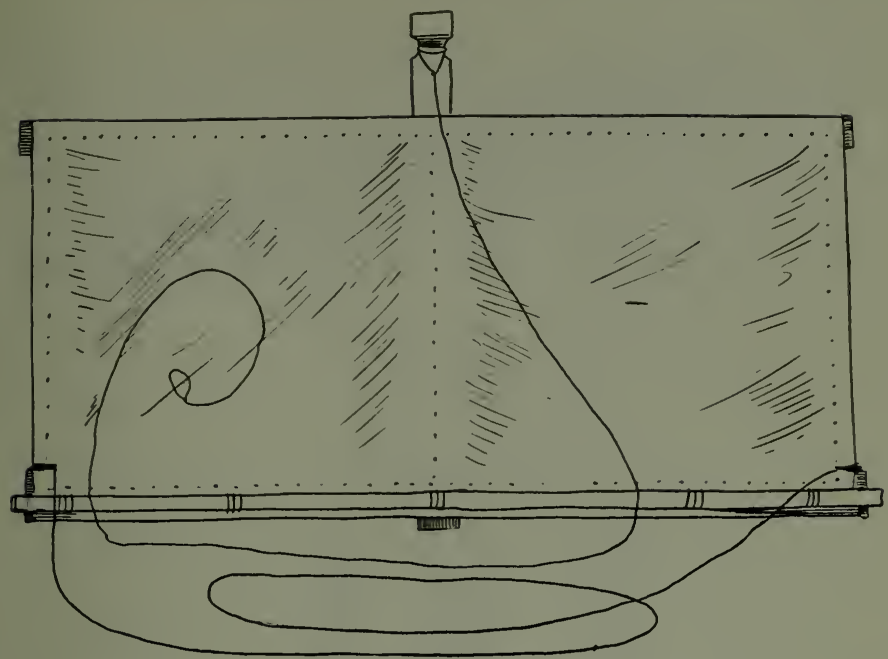

Fig. 28. The "Mule."

strength of the current in the river where the dredge is to be used, and will also depend upon the number of hooks to each dredge and the, nature of the river bottom. Usually during the spring months when the current is strong a mule $2 \frac{1}{2}$ feet by 5 feet will be large enough, but later in the summer when the water is lower and the current is not so strong it will require a larger mule to pull a large dredge. A strong but light wooden frame is made and covered with a heavy cloth. The cloth should be tacked on rather loosely so the water can fill in like the wind in a sail. This will make it pull better. Some use a piece of gas pipe or other iron along the bottom of the mule to help sink it, although it is not really neces- 
sary to use a weight. The center wooden piece should extend a little above the rest of the mule and be sharpened so a small rope can be attached to it. The other end is attached to the boat. This rope is tightened to bring the mule out of the water or by giving the mule more rope it sinks deeper into the water and pulls

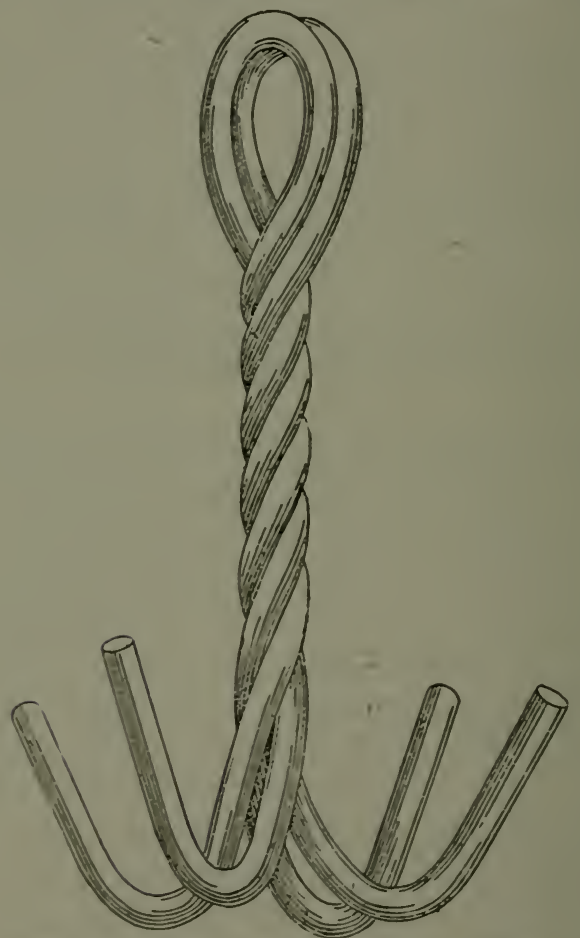

"CROW FOOT" HOOK, ACTUAL SIZE.

Courtesy of $I$. Willard Son \& Co. 
How to Make a Crow-Font Dredge Outfit. i i 3

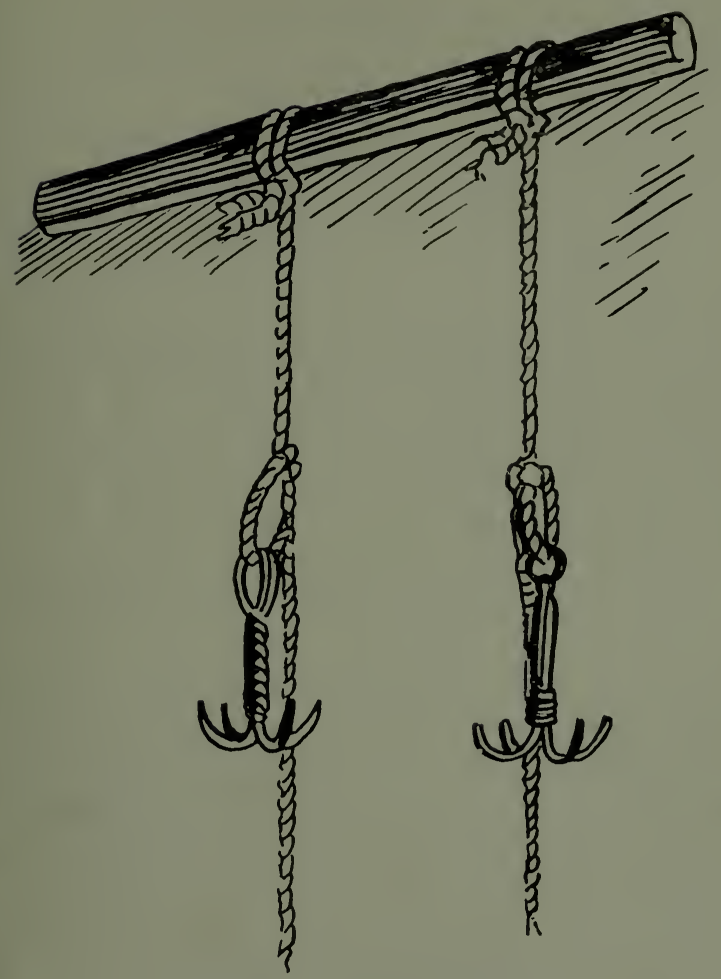

Fig. 29. Hooks and Lines.

stronger. There is another rope which is known as a guide rope and each end of it is attached to a lower corner of the mule. When the mule is in use the guide rope is passed over some nails or other projections in the back end of the boat and can be slipped to the right 


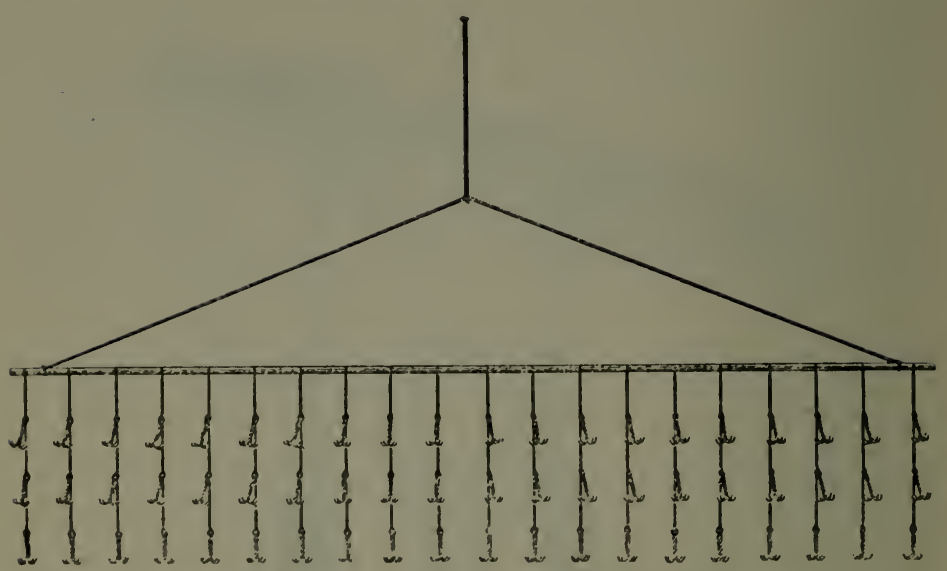

OUTIINE SHAPE OF A "CROW FOOT" DREDGE.

Courtesy of $H$. IIillard Son \& Co.

or left. If it is desirable to move the boat to the right, the guide rope on the right side is tightened, which also loosens the left rope. If it is desirable to move the boat farther to the left, the left guide rope is tightened and the right guide rope is loosened, if it is desirable to go straight ahead the guide ropes should be made equal.

Another very serviceable mule is made similar to the one illustrated except that no frame is used. The cloth is attached to a wooden strip above and an iron bar below. It is used in the same manner as the other mule. The large hauling rope which is used to drag and lift the dredges should be a strong one. A five-eighths incli new hemp rope is strong enougl, but is so small that it cuts the hands. A new one or one and one-quarter inch 
rope is very good for the purpose, as it is larger and easier to handle. Any new rope gradually gets larger after being used awhile. One objection to a new rope is that it twists and gets full of kinks which make the rope inconvenient to handle. A good, strong swivel at one end will allow the pearl hunter to get rid of the twists easily. Another plan is to use a ring on the bridle and a snap on the end of the rope. The snap can be loosened so the rope can be untwisted, but the snap is liable to come open while the dredge is on the river bottom in use, so it is not as reliable as a good swivel. After the rope has been used for awhile it will not give much trouble by twisting. The length of the rope needed will depend upon the depth of water. At Florence, Illinois, the ropes used are generally about sixty-five feet long. At some places more rope is required, while at other places less will do. There should be enough to reach the bottom of the river, letting the dredge drag back of the boat a sufficient distance to make sure that all the hooks are scratching the bottom of the river, and, in addition, there should be about twenty-five feet left in the boat. Some is needed to anchor the dredge, while at least ten feet more is needed to reach back to the dredge. which rests on the standards, and there should also be an allowance made for the shrinkage of a new rope.

The river may raise some and more rope will be required on that account.

Some pearl hunters like to drag both bars at once on some occasions, which, of course, requires more rope.

The bars are usually twelve to sixteen feet long and 


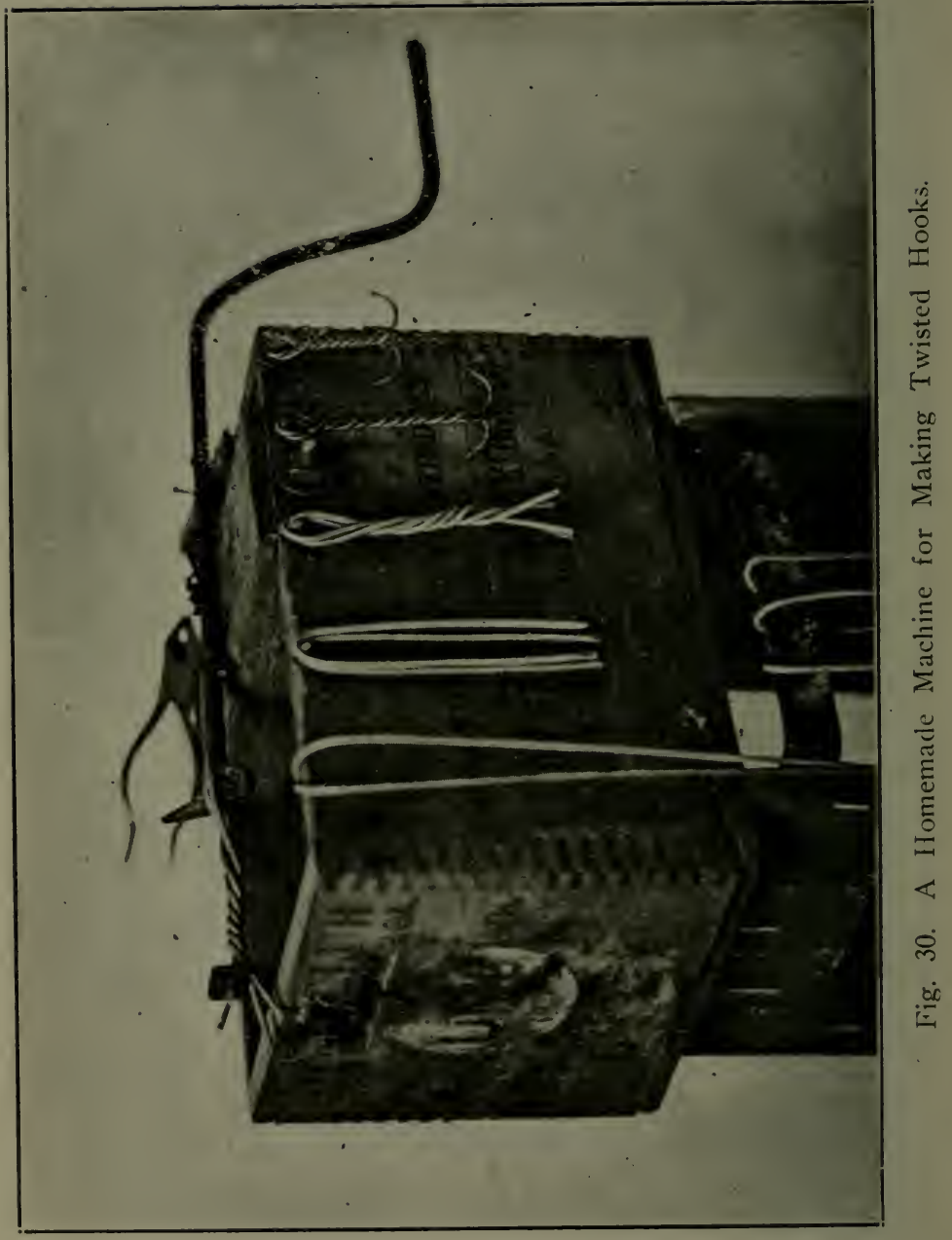


are about five-eighths to one inch in diameter. A strong wooden peg is driven into each end of the bar, and a wire is fastened to it and run along the bar several feet, where it is joined to the bridle rope at the place where it is tied to the bar. The bridle rope is fastened so that it is rather loose, and the hauling rope is tied to it in the center in such a manner as will keep it from slipping toward either end of the bar. The hauling rope is also tied to the middle of the bar.

The lines used to hold the hooks are strong, twisted cotton, known as marlin. The kind which is best adapted to the use is number 120 marlin. Number 96 will do, but it is not quite large enough to wear well. The number I2O is sometimes sold in two styles. One is a hard twisted cord and the other is softer and seems larger. The hard twisted cords do not last well as they soon become cut out on the sharp gravel. The softer cord wears much better. The lines are cut the proper length and tied to the bar about three or four inches apart. Three or four hooks are tied to each line. The manner of tying the lines to the bars and the hooks to the lines is illustrated in Fig. 29.

The amateur will find it to his advantage to tie the knots as they are shown in the illustration. In attaching the hooks he should be careful to allow a large loop where the hook is tied. The loops are a great advantage when the dredge is in use, as all dredges get tangled up in various ways and they can be untangled much more easily if the hooks are loose so they can swing free. The lines shrink considerably, so the loop should be a large 
one. If the knots are made just like the one in the drawing they will not slip down against the hooks. In the same illustration, two styles of hooks can be seen. One is the wrapped hook and the other is the twisted hook. The wrapped hook is a very good one, and is easy to keep in good condition. It is made by cutting wires into lengths of about ten inches. Then two are folded together and held in a clamp, while a baling wire is wrapped around them, after which the ends are cut even and bent properly with pliers.

The twisted hook is easier to make and does the work very well. Through a courtesy of Mr. C. N. Douglas, of Florence, Illinois, a photograph of a machine for making twisted hooks is shown in Fig. 30 .

The machine consists of a strong wooden box upon which is mounted a crank at one end and at the other end a metal plate, having four holes in it is attached to the box. In making this kind of a hook machine a piece of one-half inch iron about thirty inches long is used for the crank. It is bent to the proper form and, in making the hook part it should be left fully one-half inch in diameter so that it will make large eyes in the hooks. The hook part is pointed, but at the place where the hooks are held it should be the full thickness. The metal plate is perforated with four one-fourth inch holes. all within an area of one inch square. It is also a good plan to drill several other holes in it so as to bolt it to the bnx. Different sizes of wires are used in making hooks, the sizes depending upon sizes of mussels that are to be taken. For the smallest mussels a number 12 wire 
is occasionally used, but it will not catch the larger ones.

Number I I wire is the most popular. Number Io is used for the largest shells, and even number 9 is used occasionally. The strength of the heavy wire hooks does not allow them to let go of a snag, and if a drerlge containing a large number of number 9 wire hooks becomes entangled around a solid snag, the pearl hunter begins to wish for an ocean liner to help him pull loose. The number II wire hooks will straighten out somewhat under a strong pull, and thus the dredge becomes free again and is ready for use as soon as the hooks are bent to the proper angle with the pliers. In making the twisted hooks, the wire is first cut into lengths of ten inches, called needles. The needles are made into hair-pins and two hair-pins are placed on the hook end of the crank, and the ends of the hair-pins are passed through the holes in the plate. The crank is then turned several revolutions, and the hook is finished, except for cutting the ends even and bending the prongs properly.

The different stages in the development can be seen on the side of the machine in the illustration. The boats are propelled by the oars or by a small gasoline engine. In new pearl fisheries where the mussels are very plentiful and it is not necessary to go far, the oars are used and there is not much need for an engine, besides there is more room in the boat without it. In older pearl fisheries there are less shells and more drags are necessary to get a given number of shells, so the engine is a great advantage, and if it is desirable to tow other boats. a stronger engine is required. Most of the mussel boats 
on the Illinois River have engines in them. The sizes of the engines which are needed for the work depend upon the size of the boat, the number of boats to be towed and other conditions. Most of the boats contain twohorsepower engines, while some contain much larger ones, and are used to tow other boats. The author has had both the rowboat and engine-boats in his pearl hunting experiences, and knows the strain of rowing upstream as well as the aggravations of the gasoline motor. The outfits in the various localities differ slightly, yet the outfit that is described here is the most approved style, used with good results in practically all of our pearl fisheries. 


\section{CHAPTER XII.}

How to Use the Crow-Foot Dredge Outhit.

M

OST of the mussel shells that have been used in the manufacture of buttons have been taken from the water by the use of the Crow-foot Dredge. Its construction and use are based upon a thorough knowledge of the mussels and their mode of living. It has been so generally used and has proved so practical that its use will probably be continued for many years in various pearl fisheries.

In using the crow-foot dredge outfit it is necessry for the pearl hunter to keep an extra supply of line and hooks in the boat. The lines will wear and some hooks will come off the lines. Sometimes one can avoid the loss of hooks by noticing the lines and repairing them. Where a line is badly worn, it should be replaced before the hooks are lost. The hooks often straighten out while being used and should be kept in good condition with the pliers as the prongs will not catch the mussels if they are not bent to the proper angle.

In old pearl fisheries the pearl hunter finds about as many hooks as he loses. In fact he finds many things. and it is surprising how many different articles can be caught on the mussel hooks. Old shoes, over-shoes, rubber boots, cans, bottles, shot-guns, jugs, knives, cinders, 
purses, traps, wires and pieces of harness are only a few of the hundreds of articles that are brought out of the water in the work of "crow-footing." The hooks get practically everything which happens to be on the bottom of the river.

One part of the boat should be cleared to allow a space to throw the mussels as they are taken from the hooks. Some old dead shells are caught and should not be thrown back into the water, but should be put in one end of the boat and later emptiel on the shore.

Where a number of crow-foot mussel boats are at work the mussels are disturbed so often that they close their shells and are therefore not ready to "bite," and so there are less taken for awhile. In such cases the best time to catch them is very early in the morning after they have had a quiet rest and are feeding again. The first ones who drag their dredges over them get the most shells.

In using the dredges the boat should be moved to the upper portion of the mussel bed and turned crosswise with the river, and the dredge should be placed slowly into the water parallel with the gunwales of the boat, then lowered to the river bottom. This method causes the bar to drag properly. Then let out a sufficient amount of rope to allow all the hooks to drag freely on the bottom and tie the rope to the front of the boat, and put the mule to work at the rear of the boat.

It is sometimes possible to ascertain as to whether the hooks are dragging over the mussel bed by reaching over the end of the boat and holding the hauling rope in one 
hand for a few minutes. If it seems to move ratlier unevenly it is a good sign it is catching the mussels, but if it drags very smoothly and evenly it is an indication that the boat is not over the mussel bed. By using the guide ropes on the mule the boat can be guided to the right or left so as to move to a more favorable position. The top rope of the mule is to regulate the speed of the boat. The deeper the mule sets in the water, the faster it moves the boat. By a little practice one can soon tell just about the time required to get a loaded dredge bar in a certain river. They should be taken from the water at regular intervals, however, as when they are left to drag too long, the mussels that have been caught on the hooks will gradually let loose. In raising the dredge bar the first thing to do is to take the mule out of the water. Then loosen the rope at the front and stand in the center of the boat and pull in the rope and lift the dredge and set it on the half rests. Then turn around and place the other dredge into the water and let out sufficient rope and tie the hauling rope to the front of the boat again. The next thing is to place the mule to work again and raise the loaded bar, one end at a time, upon the high standard where the mussels can be pulled from the hooks, and if some hooks are bent straight they may be bent properly. The pearl hunter should stand in the center of the boat while drawing in the dredge for the reason that this plan will make the boat lie crosswise with the stream and will therefore be in the proper position when he turns around to place the other dredge into the water. By the time the mussels are taken from the 
hooks it is usually time to take up the other bar. The workman must also watch to keep the boat over the mussel bed.

There are some men who sometimes drag both bars on the mussel beds at the same time. In some places where the current is strong enough to pull both bars it is a good plan to use this method over the portion of the bed which contains the most mussels. The amateur will have enough to do in dragging one bar successfully, but later when he has learned the position of the bed better and can handle the boat and dredges with more ease it will be possible for him to use both bars to advantage in some places.

In using both bars the first bar is placed a long distance from the boat and the rope is tied to the front of the boat, while the second bar is placed nearer to the boat, and the rope is tied to one of the rear standards. Then the mule is placed in the water deeply to pull well, and the pearl hunter can give his entire attention to guiding his boat. When the time comes to raise the bars, the mule should remain at work until one bar is raised, and it must be remembered that the one which was placed in the water last and which is nearest the boat should be raised first and placed on the standards. By this time the other dredge has also been dragged far enough so the muie can be raised and the dredge in the water anchors the boat while the mussels are being taken from the hooks of the dredge which has been raised. In new pearl fisheries where the mussels are very plentiful it is not often desirable to use both bars at once, as enough shells 
can be secured by dragging one dredge at a time. In guiding the boat to keep it in the proper position it will be advisable to use the method illustrated in Fig. 26 and described in Chapter X.

Where a number of these boats are in use on one mussel bed the pearl hunters will need to be careful or their dredge bars will get close together and become entangled. There is really no occasion for such an accident, yet sometimes the men become busy and do not notice that the boats are drifting too close to each other. The work of separating the bars is very tedious and uraprofitable.

Very often small logs and pieces of wood and other trash are brought up with the dredge. It is a good rule, and well followed in most pearl fisheries, to place all such inside the boat and take it to the shore at the time or later. Where the logs are large, other men near should assist in loading the log. By such care and co-operation the mussel bed is soon cleared of all trash and can be worked with more ease and profit.

It is a common thing to get the dredge caught upon a snag from which it is difficult to loosen it. In such a predicament the first thing to do is to mark the location carefully so it will not cause trouble again. If the boat contains an engine like the one belonging to $\mathrm{Mr}$. C. Davis, of Florence, Illinois, which is shown in Fig. 3I, it is much easier to pull the bar loose from the snag. The best way is to let out as much rope as possible and tie the rope to the bow of the boat. Then start the engine and run straight up stream at full speed. The sudden jerk is 
almost sure to loosen the dredge, and, if the bar is removed from the snag, it should be raised to the boat before it is caught again. If the first attempt results in a failure it will be neecssary to keep trying until the bar is loosened. If the boat does not have an engine in it and it is possible to secure the assistance of an engineboat the two should be lashed together at the bows and placed side by side and moved upstream in the same manner as has been described. When oars alone are used it is much more difficult to loosen a bar from a large snag. In this case it is a good plan to go to the front of the boat and try to pull up the bar, either with the snag or without it. Some snags can be brought up in this way, yet if it is a large one it will be necessary to use other methods. One plan is to draw the rope as tight as possible and tie it to the bow of the boat and go to the rear of the boat and jump up and down or shake the boat from one side to the other. The agitation will often dislodge the dredge.

Another method is to let out all the loose rope and tie the rope to the bow of the boat, and then row up stream rapidly. The sudden strain on the dredge is very likely to loosen it from the snag. Sometimes it is necessary to cut the rope and leave the bar with the snag, which, of course, makes the snag worse than it was, and the lost bar must be replaced in order to proceed with the pearl hunting. There are many bars lost on snags, but in most cases they pull loose from the snag as a part of the snag breaks or the hooks straighten in the efforts to dislodge them. Pearl hunters should keep each other informed 


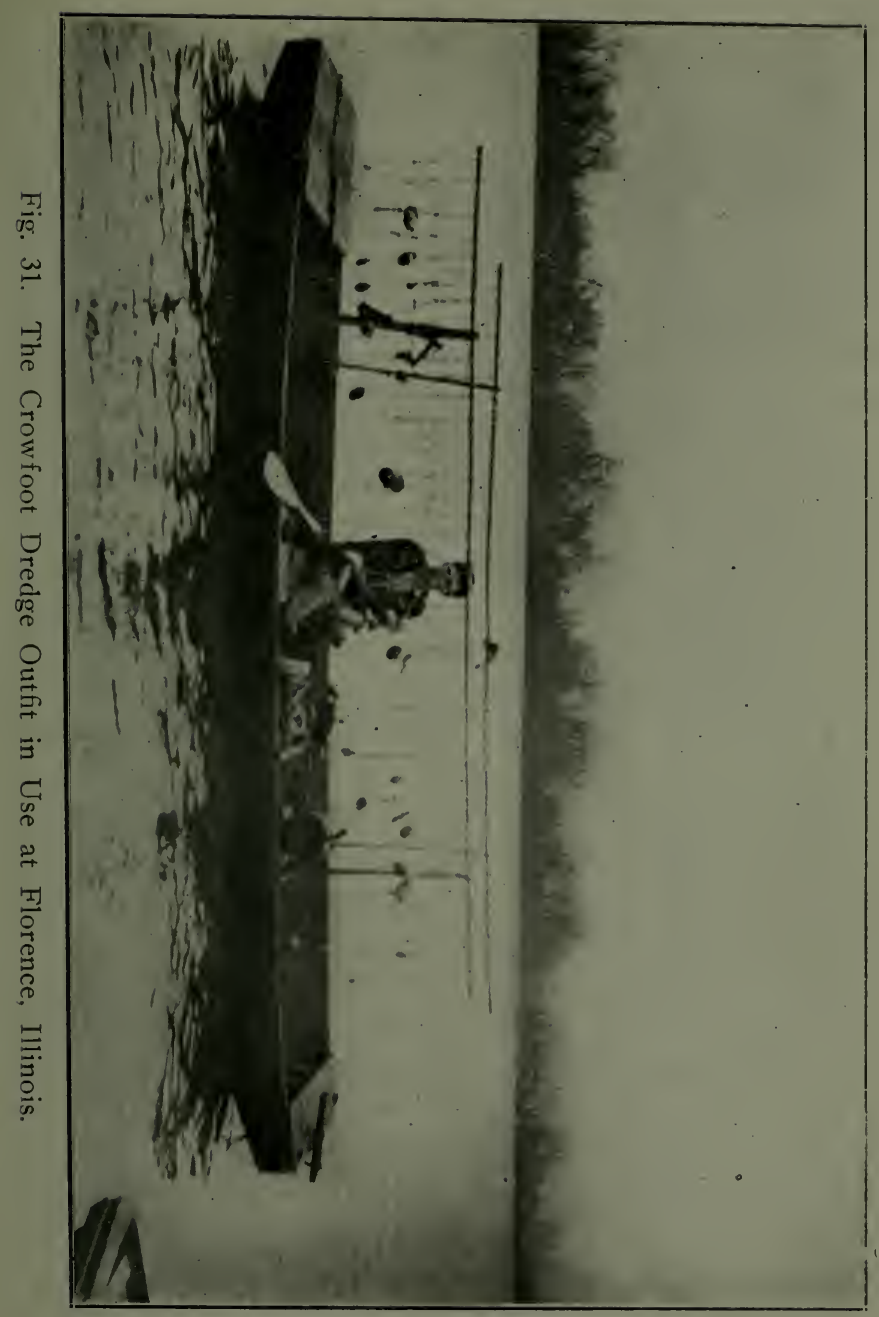


as to the exact location of the snags, or "hang-ups," as they are often called.

Winds are a great hindrance to the use of the crowfoot dredge, especially where the mussel beds are very narrow and difficult to follow. Winds that blow parallel to the course of the rivers are not very troublesome, but the cross winds are very troublesome and it is often necessary to quit work until the wind ceases.

Another difficulty on some rivers is the steam-boat waves. It is usually a good plan to take the mussel boat to the shore and stand on the bank until the large boat goes by. It is disagreeable and sometimes dangerous to remain in a mussel boat when the waves are high. The rocking of the boat causes the lines and hooks to swing in all directions and often strike one in the face or catch in the clothing. It is best to avoid all such dangers.

When the outfit is not in use, the large hauling rope should be taken out of the bottom of the boat and stretched over the bars so it will dry. The ropes last longer when they have proper care.

There is another way in which the crow-foot dredge is sometimes used. There are some lakes in which there is no current and it would be impossible to use the mussel boats as they are used on the rivers. In such lakes the windlass dredge is sometimes used to a good advantage. A windlass similar to a well windlass, only larger, is built upon a large boat, and the boat should be anchored at the lower end of the mussel bed. The dredge bar is attached to the windlass by a long rope. Then a small boat takes 


\section{Using the Crow-Foot Dredge}

the dredge up stream and lets it down upon the mussel bed, and a man winds the rope upon the windlass, thus bringing the dredge bar over the mussel bed back to the boat. While this method is not used generally it is of special value in some places.

The information in regard to the crow-foot dredge will be of service and value to all pearl hunters who wish to use the methods which are recommended. 


\section{CHAPTER XIII.}

\section{The Dip Net and Its Úse.}

\ HEN the dip net was introduced in Peoria Lake in I9I I, a valuable appliance was aclded to the pearl hunter's equipment. The other appliances were failures in Peoria Lake, and as soon as the usefulnes of the dip net was demonstrated, all other implements were thrown away and are now rusting on the shore of the Illinois River, north of Peoria. The dip nets have become very popular there and will probably come into general use in many other localities as soon as their merits become known. The new appliance has some very good features. It will gather all of the shells, regardless as to whether they are opened or closed, while the crow-foot dredge can only catch the ones that are opened. Then, too, it is probable that a dredge hook may sometimes pull a pearl from the posterior portion of the shell and lose it in the mud without even catching the mussel. The dip net works on another principle and is not liable to such a fault. If a mussel contains a pearl it is very likely to be taken whether the shells are closed or not. Another good thing in favor of the dip net is that it can be used where there is no current. Some very fine shells and pearls are found in the quiet lakes 


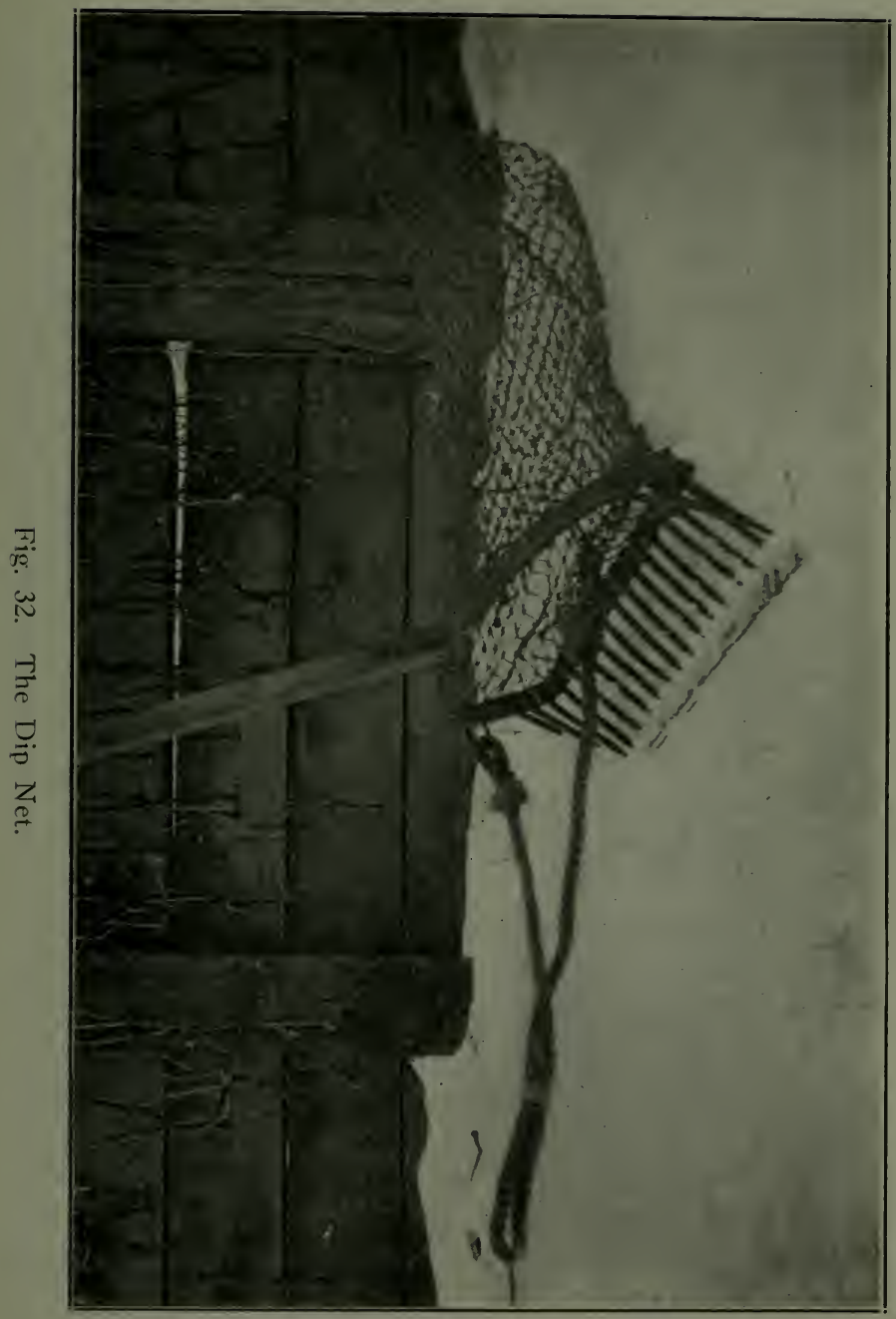


where the conditions are especially favorable for the use of the dip net.

Through the courtesy of Mr. Henry Gatlin two views were supplied. One of these is the good view of the dip net shown in Fig. 32.

The dip net consists of a steel hoop which is flat below and with a rather round top. The lower part of the hoop is bent slightly downward, and a number of pointed steel teeth are riveted to it. The bridle rope is fastened to the dip net by some iron rings on the sides of the hoop. The teeth of this dip net are six inches long. The hoop is twenty-four inches wide and the net is about one yard long, and is made of number 96 marlin. The size of the meshes in the net are two inches to comply with the fish laws of the State of Illinois. The steel frame of the dip net is bolted to a strong wooden pole, eighteen feet long. The dip nets are of various sizes. The sizes depend upon the size of the engine in the boat, which is to pull the dip net. There is no set rule as to the sizes. Some of the boats have three and one-half or four horsepower engines in them and pull small dip nets, but most of the boats have engines of more than seven horsepower, and even that much power is considered small for the work. Many of the engines are ten and twelve, while some have eighteen or twenty horsepower motors in them. The larger are much better as they can draw a larger load and go faster and collect more shells. Another advantage of speed is that the mussels roll into the back part of the net, thus making the appliance work more perfectly. 
The pearl hunter who uses the smallest engine cannot go so fast or gather so many shells as the ones who use large engines, yet he may be the lucky one and bring up a shell which contains a very valuable pearl.

There is a slight difference in the points of the steel teeth. Some have round points, while other are flat. Some men prefer the flat pointed teeth and say the shells do not become wedged between the teeth so much as when the points are round. The style of the points does not make any difference in the cost of the work. The cost of the dip nets depends upon the size needed. The steel frames with three-inch teeth, cost about \$2.50 for the fourteen-inch size. The eighteen-inch frames, with three-inch teeth, cost about $\$ 3.25$. The twenty-four-inch frames, with three-inch teeth, cost about $\$ 4.00$. The thirty-inch frames, with three-inch teeth, cost about $\$ 4.50$. Any of these sizes can be made with six-inch teeth by adding fifty cents to the prices mentioned.

A photograph of the dip net in use is shown in Fig. 33, and was very kindly loaned by Mr. and Mrs. John Stockfleth, of Peoria, Illinois. The man who is guiding the boat is Mr. George Stockfleth, and Mr. C. I. Ragan is holding the dip net. Both men live in Peoria.

This view shows how the dip net is used. The net is connected with the bow of the boat by a strong rope. In this case the rope is long enough to reach to the back of the boat and is to be set on the bottom of the river directly back of the boat, while the outfit is intended to run in a line directly over and following the mussel bed. When pearl hunters know the position of the mussel beds thor- 
oughly this plan is a good one, but one has to be very careful to keep the net from getting caught in the propeller.

There is another method which is more commonly used in which the rope does not allow the net to go back as far as the propeller wheel. The boat is first placed over the mussel bed, and the rudder is set to keep the boat in a circle. The dip net is places in the water on the side of the boat that will put it inside of the circle and the engine is started. In using either method the operator must press the dip net downward so the teeth will dig into the mud in orcler to catch the mussels. When the net is full it is lifted to the surface and splashed into the water a few times to wash out the mud and then the mussels are emptied into the boat.

One man can run an outfit by arranging a guiding lever where he stands so he can guide the boat with one knee. Many of the boats have two men, though.

Where "shelling" is good two men, or one man and a boy, can gather nearly a ton of shells in half a day, with a boat containing a strong engine.

Some boats are rather short for this work and a boom is placerl on the bow of the boat. An old wagon tongue costs twenty-five cents and answers for this purpose very nicely. The heavy end of the tongue is bolted to heavy timbers at the bow of the boat and the rope is attacherl to the pole cap iron at the end of the tongue. The outfit is then long enough to allow the use of a longer rope which will reach to the bottom of the river.

The dip net is very practical where the water is not 


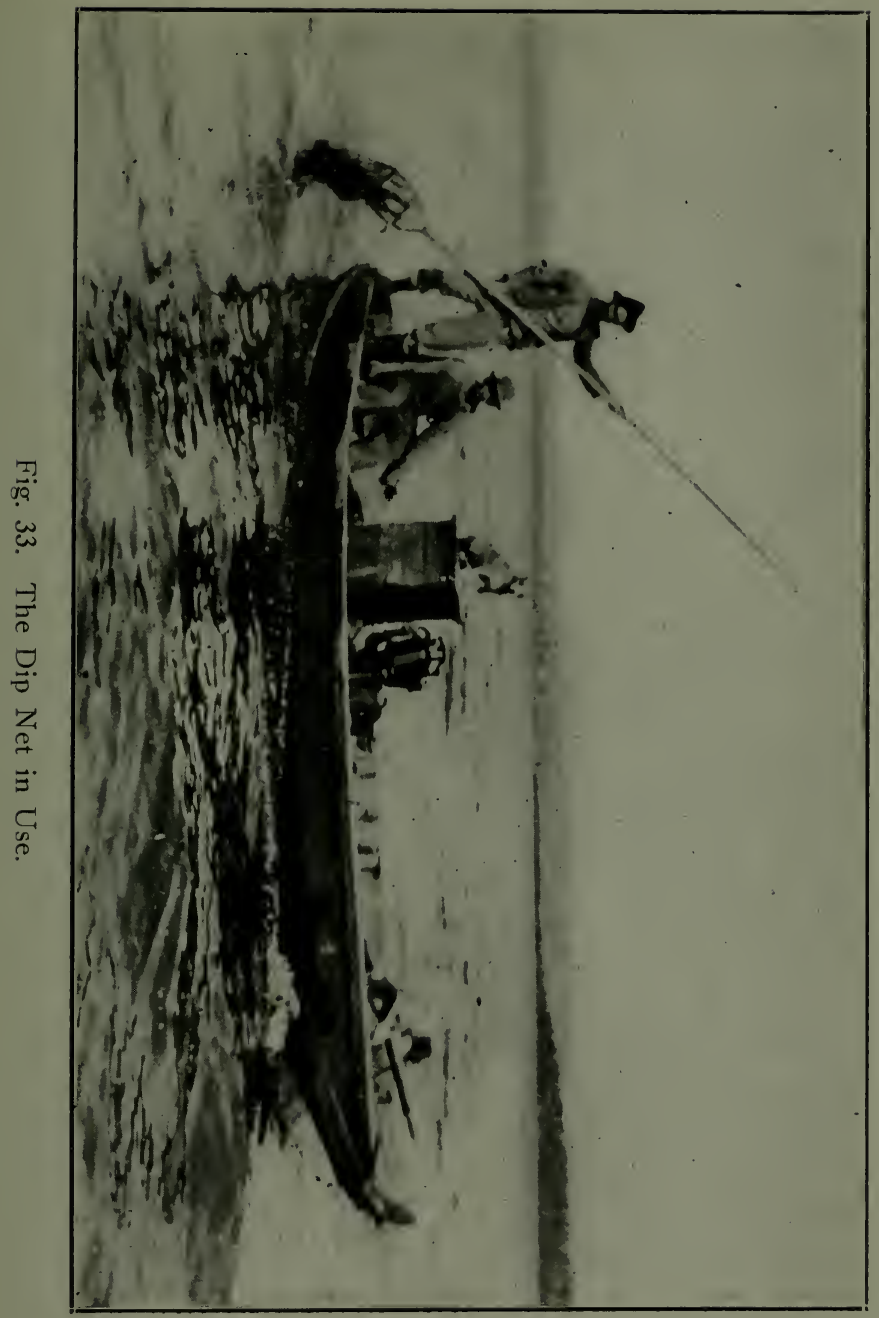


too deep, and where the river bed is free from snags; but it cannot be used in very deep water or where there are snags and "hang-ups."

The operation of the dip net is easy to learn and after a little practice, amateurs become very successful in their use of it. 


\section{CHAPTER XIV.}

Other Methods of Pearl Fishing.

$7 \mathrm{HE}$ appliances and methods which have been described in the preceding chapters can be used in rather deep water, but the implements and methods described here can only be used in the more shallow waters. They might properly be classified as shoal fishing appliances and methods.

One of the most important tools for use in pearl hunting in shallow water is the shell tongs. The most approved style are the Coke Fork Tongs, which are made from two coke forks. The points of the tines are cut off a few inches from the ends, and the forks are ironed and riveted together something like scissors are joined, and they are mounted on poles of any length desired. Vegetable forks may also be used in making shell tongs, but their tines are farther apart so they are not quite so serviceable in gathering smaller shells.

There is another implement known as the "Scissor Rake," which is similar to the tongs, except that rakes are used in making them instead of forks. They are not so popular as the tongs. A view of the shell tongs may be seen in Fig. 34 .

In using the tongs, the pearl hunter moves his boat directly over a portion of the mussel bed where the 
water is shallow and the mussels are most abundant, and anchors the boat. Next he places the tongs in the water and with one handle in each hand he works the tongs around the mussels until he has gathered some into the implement, and then raises them into the boat. There is nothing certain about the catch being all mussels. Sometimes the tongs contain rocks, or mussels mixed with rocks. The tongs are profitable tools when used in suitable places. Some pearl hunters have made as much as $\$$ I $_{5} .00$ in one day working in some of the northern rivers.

They have also been in very popular use in the south. In some parts of the IVhite River, in Arkansas, large numbers of boats have been collected together in a very small space, where the pearl hunters used the tongs to collect the shells.

Another good use for tongs is in fishing for mussels through holes cut in the ice. A great many fine pearls have been secured by using this method. A pair of tongs usually costs about $\$ 3.50$, and many of them have been made by the blacksmiths of Muscatine, Iowa. The usefulness of the tongs in shallow water has been so thoroughly demonstrated in so many localities it will continue to be a very popular implement among the pearl hunters.

The fork is used more than any other implement. The one shown in Fig. 35 has a remarkable history and has probably handled more shells than any other fork in existence.

Mr. George Platt, of Camanche, Iowa, bought this fork in 1898 in Linxville, Wisconsin, where he lived at that time. About three years ago Mr. Charles Newton, of 


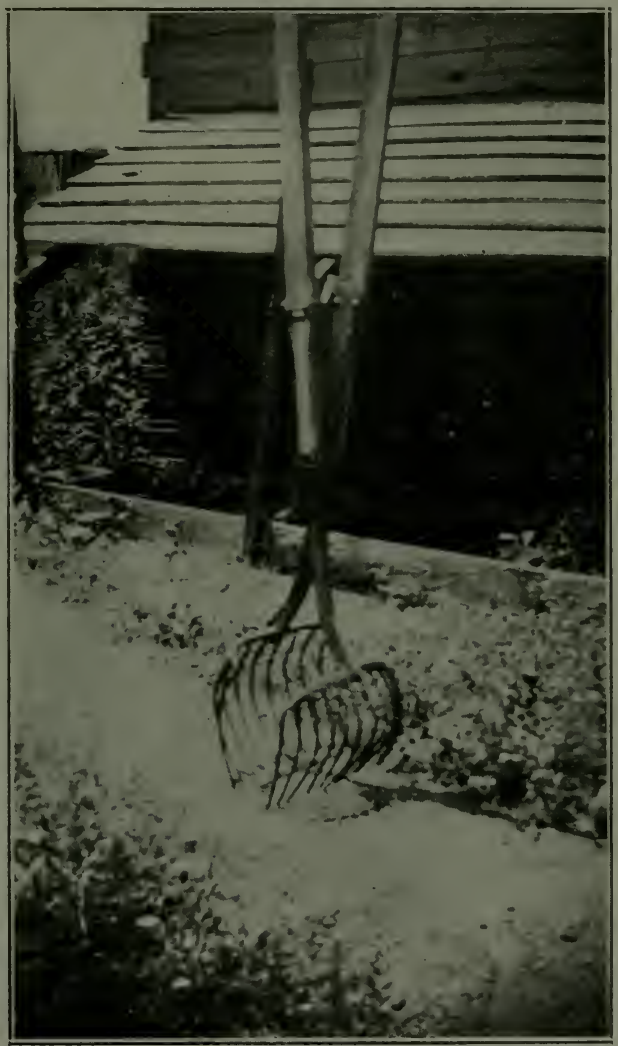

Fig. 34. Shell tongs. Only a part of the handles are shown in the photo. 
I'eoria, Illinois, bought the fork from Mr. Platt and has been using it on the Wabash and Illinois Rivers.

It has been used continuously since it was purchased in Linxville, and the tines are now badly worn under the basket part of the fork.

The forks are used generally to load or move shells, but in times of low water they are used in a method of slell gathering which is commonly known as "short forking." In this method the pearl hunter stands in the warm water, which is usually up to his waist, and uses the fork in almost the same manner a spade is used, unless the rocks are too great a hindrance. As soon as the fork contains some shells they are lifted out of the water and the stones and trash are taken out of the fork, and the mussels are thrown into the boat. "Short-forking" is generally done in July and August, or in the early part of September, and although the season for this work is very short in almost any locality, it is a very profitable method. In new beds it is possible to load a boat in a very short time. Occasionally in the older fisheries a pearl hunter finds a new mussel bed and is able to load several boats and hide them by sinking them in the shallow water by the side of a good mark near the shore before the others have learned that a new mussel bed has been discovered. As a rule, however, the men find the new places without much delay. If a pearl hunter stays very long in a new location, some one will stop to see if shells are plentiful.

Another use of the fork is in the method known as "long-forking," which is also called "shoulder-forking" in some localities. In this method the fork is attached 


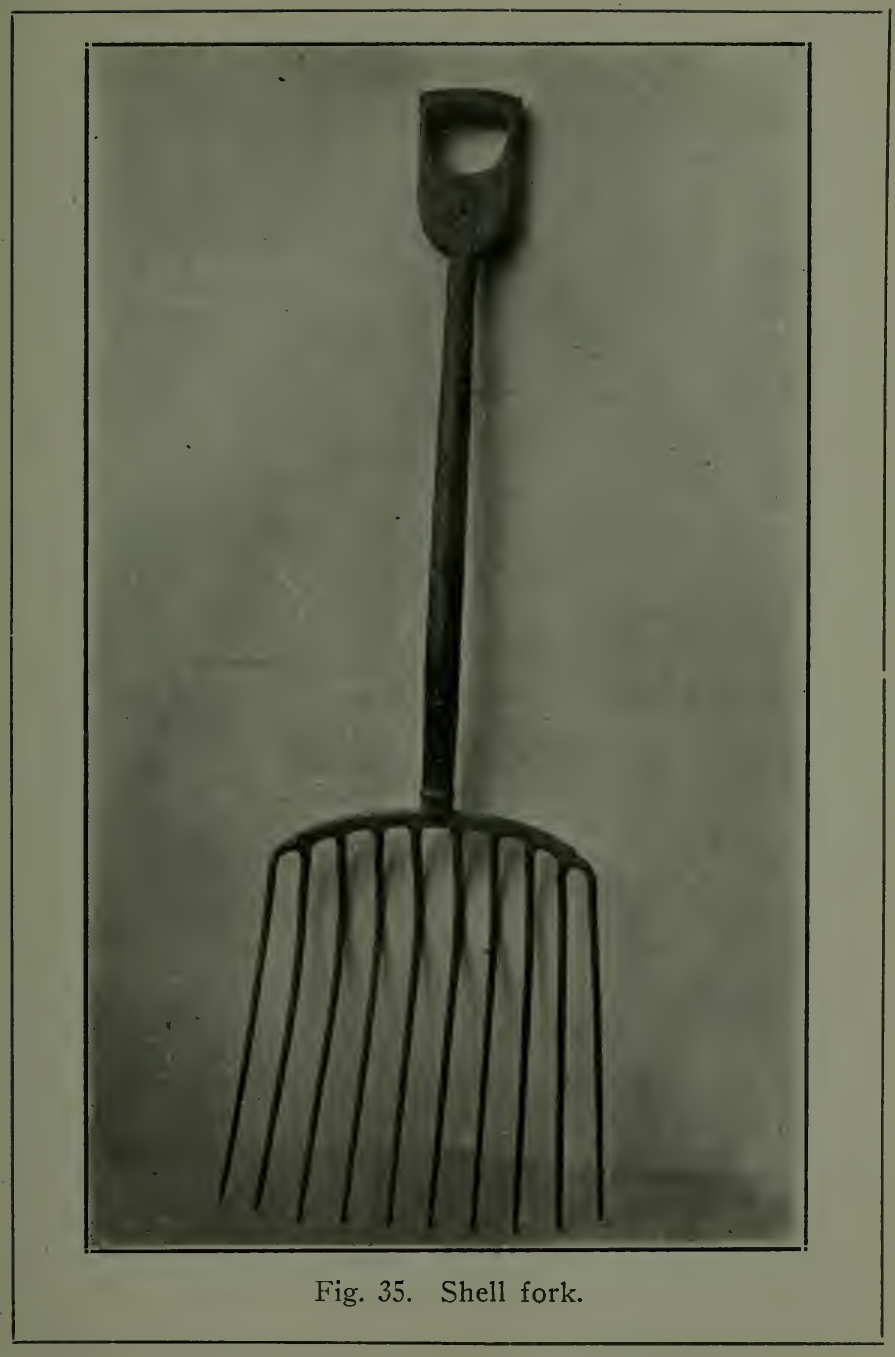


to a long pole and the pearl hunter stands in an anchored boat and presses the fork down among the mussels, often using the side of the boat as a fulcrum to force the fork under the shells. By loosening the shells and shaking them into the basket part of the fork he is then able to raise them and throw them into the boat. The long fork is also used in fishing for mussels through holes in the ice, in which case the ice is used as a fulcrum. In using the fork for "long-forking" some men use wire and build a net a few inches above the fork, which adds to the capacity of the basket of the fork. The fact is the best forks for this use do not have the proper sliape to do this kind of work as well and as easily as they should. It is too easy for the mussels to roll off the forks. It is to be hoped that some manufacturer of forks will make one which will be more efficient and easier to use. The "long-fork" method is a very successful one in many places, and some men prefer it to any other for all seasons of the year.

There is another appliance that is used occasionally which is known as the shoulder rake. These are often a plain garden rake with a coarse wire net attached back of the teeth. Others are larger and are made by a blacksmith. In using the shoulder rakes a boat is anchored and the pearl hunter places the rakes in the water and gradually pulls it toward the boat, where the basket is emptied. The shoulder rake is also used to fish through the ice. It is not an important appliance, yet there are some places where it can be used fairly well.

The eagle-claw clam rake is very popular among the 


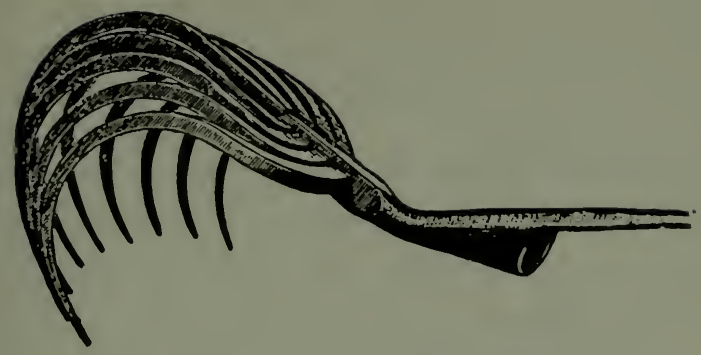

Fig. 36. Eagle Claw Clam Rake.

clam diggers of Long Island. The rake, which is illustrated in Fig. 36, has nine teeth: they are bent to form a large, roomy basket. This is a very convenient appliance to catch fresh-water mussels in some shallow pools.

The rake must be mounted on long handles. In using this rake the mussels are loosened and shaken into the basket part of the rake, then lifted ont of the water.

A very common method is that of wading into the water and picking up the mussels. This, of course, must be done in the summer while the rivers are low and the water is warmest. Under some conditions it is one of the most profitable methods. The men sometimes make \$10.00 to \$12.00 per day of about five hours. It is necessary to wear considerable clothing as a protection against the cool water. A rubber coat is needed as a protection against the wind, which is nearly always blowing on a river. The mussels are picked up and placed in a wire basket, or an old bucket. which has been perforated. and when it is filled it is emptied into the boat, which is anchored near. 
In places like the rapids, near Rapids City, Illinois, where the author used this method of pearl hunting the running water is rather dangerous, and it is customary for the pearl hunters to use a small rope about thirty feet long, one end of which is tied around the man's waist. and the other end is tied to the bow of the boat. There are many deep places there and it would be impossible to swim back to the anchored boat against the force of the water, so the rope is a good safeguard, and especially so when one is working alone. Four or five hours is a a good day's work in the water and the work should be done during the hottest part of the day. When the water is cold enough to make one's teeth begin to strike against each other it is not safe to remain in the water. The method is not a very desirable one and not used much, except where fine shells are found near the factories where they bring the highest prices, or in other places where pearls are more frequently found, such as Carldo Lake, Texas. The methods that are used differ accorcling to the local conditions. A method that is good in one locality will often be worthless in another place. It is a good plan therefore to know them all so if one method fails another can be used successfully. 


\section{CHAPTER XV.}

Methods of Opening Shells and Extricting Pearls.

NE who has never seen a mussel opened, and who tries for the first time to open the shells of a mollusk, finds that the animal holds its shells together so tightly, he is liable to give up the task.

Most animals are provided with some special means of protecting themselves from their enemies. In this instance the animal lives in a strong stone house and is provided with two strong muscles known as adductor muscles which contract and close the doors in all times of danger.

The methods which are employed for the purpose of opening the shells of the mussels are not the same in all localities. In Scotland, Germany and some of the other foreign countries the pearl hunters use an instrument made especially for the purpose. This appliance has sharp flat points which are inserted between the shells of the mussel and then a lever is turned which causes the shells to open far enough to see if they contain a pearl. As the pearls are found near the edge at the posterior end of the shells, it is easy to ascertain as to whether the shell contains a pearl.

The method is said to be of great value in conserving the supply of mussels, as those which do not contain 
pearls are thrown back into the water. The system is not of value in places where shells are gathered in large quantities for the button industry. The most modern methorl of examining shells to see if they contain pearls is in the use of the X-ray in the Tuticorin Fishery, Ceylon. Iiy the use of this strong light the pearls can be located in the oysters and those which do not contain pearls are returned to the water. The use of the $\mathrm{X}$-ray for this purpose has only been experimental. It is not likely that it will be used to any extent in the United States unless pearl hunting can be developed, through scientific methods, to such a high state of perfection that the proportion of shells containing pearls, baroques and slugs, might be large enough to warrant the use of the electrical machine. A very common method used by most pearl hunters in opening shells which have the appearance of containing pearls is that of inserting a thin blade between the shells and cutting the adluctor muscles of the mollusk.

Nearly all of the "crippled" shells are openerl with a knife and it is a very pleasant experience to open a "cripplecl" mussel and find a valuable pearl inside of it.

While a few are opened with knives, practically all of the shells which are gathered in our northern rivers are opened by "cooking out." or "boiling out," as it is called in some places. The large quantities of shells which are required for the manufacture of pearl buttons makes it necessary to use a method by which the shells can be openerl without the loss of time. While the large quantity of buttons are a necessity to the people, the killing of such large numbers of mussels is a cause for regret. 
When the mussels are brought from the fisheries, the pearl hunter uses the fork and forks them out of the boat into a shell box. These shell boxes are usually sixteen inches square inside, and hold one hunclred pounds. or more, of the mussels. They are strong but light and are carried between two poles about five feet in lengtin which are securely fastened to the sides of the boxes.

When the box is filled two men carry it and empty the mussels into the cooking vat which is illustrated in Fig. 37. The vat is built of broad heavy boards made into a box about five feet long and about two feet wide and one foot deep. The bottom is a large piece of galvanizer! sheet iron, which is nailed to the boards and which is longer than the box at both ends so that the projecting ends of the sheet iron protects the ends of the vat from the fire which burns in the furnace under it. The vat is placed on the bank on an elevation which is not liable to the overflow of the river and is mounted on two low. level walls of bricks or stones, and afterward dirt is thrown around to fill in any open places in the walls.

The chimney is made at the upper end, the lower end of the chimney being set on the edges of some stones and other rocks and dirt filled in around it.

Several joints of stove pipe make a good chimney. and if an elbow is placed loosely on it is a good thing to use in windy weather, as the elbow can be turned away from the wind, thus increasing the draft of the furnace.

When the vat is filled with shells, about two buckets of water are thrown into the vat and the mussels are covered with a piece of old carpet or some other cover, then 
a fire is built under the vat. The fuel used is generally dried drift-wood. In a short time the shells open and the fork is used to throw them upon the shell sorting table, shown in Fig. 37. The water which remains in the vat is usually strained through a piece of wire screen to secure any pearls or slugs, that might happen to be in the water. During the process of "cooking out," the vat should not get dry as it would ruin any pearls, baroques or slugs that may be in it. It is not desirable to use much water, however, as it requires a longer time to "cook out" when too much water is used, although there should always be enough to cover the bottom of the vat. The shells must be allowed to cool gradually. Throwing cold water on the hot mussels is liable to crack auy pearl that may be among them.

The sorting table is usually about five or six feet long by two and a half feet wide, with boards at the back and ends to keep the mussels from falling off the table. They are usually made of cheap material and are high enough to sort the shells conveniently.

Experienced pearl hunters often find pearls before the mussels are "cooked out," but some escape their notice, so the cooked mussels are likely to contain pearls, baroques and slugs. Great care is exercised in searching the meats in order to save all valuable pieces. The cleaned shells are thrown over the table on the shell pile. In examining the meat for pearls, the senses of sight and feeling are used. Many valuable pieces may be seen, but it is necessary to feel of the meats in order to find all of the pearls, baroques and slugs. Nearly all pieces found 


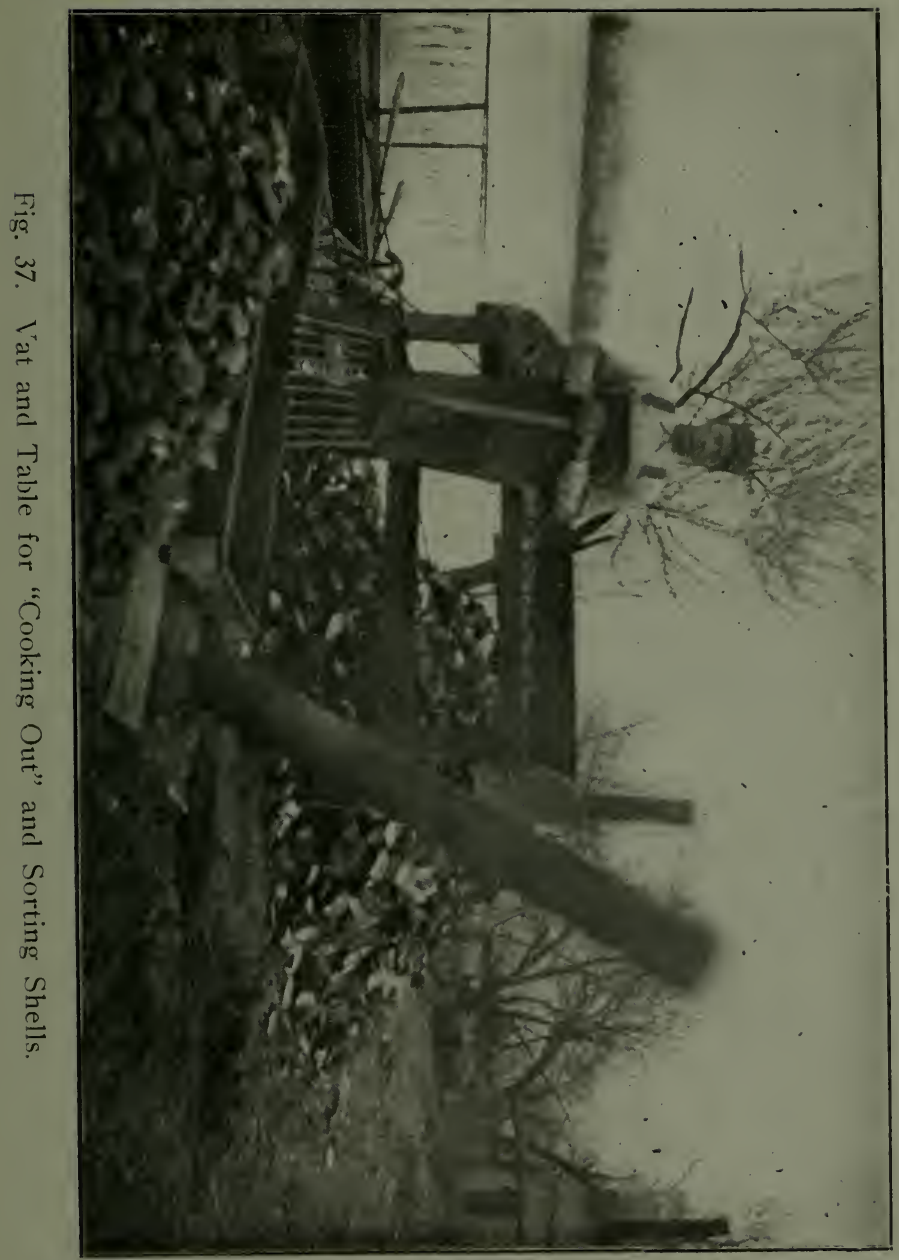


in shells have some value, yet the very smallest pieces which are not much larger than a grain of sand are not of sufficient value to bother with. Many people spend too much time in trying to separate these tiny pieces from the meats. Searching for these smaller pieces is often the cause of eye-strain, which is the cause of many diseases of the nervous system. While it is not profitable to collect the very smallest pieces, great care should be exercised to secure all pearls, baroques and slugse:

The meats should be kept wet in order to find all the pearl pieces easily.

There is one very offensive method that consists of placing meats in barrels and allowing them to decompose in the sun. The mixture is usually stirred about once a day until it is sufficiently rotten to be passed through a seive, which holds the pearls, baroques or slugs that were in the meats. The strong odor from the decayed mussels is very loathsome. It is an old Oriental method which should not have been introduced in the United States. Fortunately, however, there are only a few who use the system here.

Of the various plans for opening shells, the most popular one is the "cooking out" method. 


\section{CHAP'TER XVI.}

Wh Tr.upleks Make Good Peirl. Hunteks.

$W^{1}$

HENEVER pearls are found, and especially when they are found in rivers that have not been known as pearl streams, the newspaper reporters usually write exaggerated and sensational accounts of the "finds."

The occupation of pearl hunting is pictured in glowing colors and many people leave valuable positions to enter the new work, which appears to be so fascinating and full of promise. The fact is that many people become disappointed in the work of pearl hunting. Some men work for years in some locations without finding a pearl. If the newspapers would only print the things which are absolutely true in regard to the work, there would be less disappointment among those who enter the new profession of pearl hunting. The editors are not to blame in most cases as they are not familiar with pearls and the conditions of the shell business and have to depend upon others for their news items.

Among the many people who engage in pearl hunting are: Farmers, stockmen, farm hands, hunters, trappers, fishermen, tradesmen, saw-mill hands, mechanics and boys. Of course, some are more successful than others, 
their success depending considerably upon their industry and their qualifications for the work.

The pearl hunter's occupation is unlike many other kinds of employment. The selection of a pearl fishery and the examination of the shells for pearls, baroques and slugs are the two most important parts of the work, and in order to do these things properly, it requires goor? eyes, close observation and quick perception.

Of the men who engage in pearl hunting, none have such good qualifications as the hunter and trapper.

The successful hunter or trapper who enters the work has the advantage of his previous training to help him in the new enterprise. It is very natural for a hunter or trapper to be a careful observer. As he goes along nothing can escape his observation and what he sees and hears he accounts for immediately. The faculty of observation is very highly developed in some hunters and trappers. An instance which shows the ability of hunters and trappers has been told of a Western hunter who was acting as a guide for a hunting party. At one time they came across the track of an Indian pony, which the guide followed for a short time and then said: "It is a stray black horse with a long bushy tail. It is nearly starved to death, has a split hoof of the left fore-foot, and goes very lame, and he passed here early this morning." The hunting party were very much astonished and asked him his reasons for knowing these particulars by the tracks of the animal, when he replied: "It was a stray horse because it did not go in a clirect line; his tail was long for he dragged it over the snow; in brushing against 
a bush, he left some of his hair, which shows its color. He was very hungry, for, in going along, he has nipped at these high, dry weeds, which horses seldom eat. The fissure of the left fore-foot, also, left its track, and the depth of the indentations shows the degree of his lameness; and his tracks show he was here this morning when the snow was hard with frost." Many people notice the things they see or hear, although none have attained such a high degree of proficiency in observing as the hunters and trappers, with the possible exception of detectives, who have had long training and experience in their work, and they are also much more efficient if they have had experience as hunters or trappers when they were young. Hunters and trappers are also very familiar with the nature of the streams in the vicinity. where they live. There is scarcely a foot of land which they do not know thoroughly; and they have set their traps in the edges of the pearl streams. They can remember just where the muskrats or raccoons have carried mussels for food and left the small empty shells lying on the bank.

A large per cent. of the pearls that have been found in the United States were found by hunters and trappers. As an illustration of the success of hunters and trappers the case of Mr. Charles Newton, of Peoria, Illinois, is given. Mr. Newton has hunted and trapped all his life and spends his winters on a good trap line. During the pearl fishing season in the Peoria District last summer he found five valuable pearls, which were sold at the following prices: First, $\$ 80.00$; second, $\$ 100.00$; third, $\$ 450: 00$; fourth, $\$ 1,100,00$; fifth, $\$ 65.00$; the total being 
\$1.795.00 for pearls, and in addition to this sum he received money for the shells which he gathered, and also some for the slugs, which he found. He used the dip net which is so popular in the Peoria District. These five pearls were found within one-half mile of Mossville, which is ten miles north of Peoria, Illinois. Many of the pearl hunters who worked in the Peoria District found pearls, but Mr. Newton's experience is an exception. Amateur pearl hunters should not base their expectations upon his fortunate experience as it does not represent the average results from pearl hunter's efforts.

One reason why the occupation of pearl hunting should appeal to trappers is because it can be followed when trapping is out of season.

In referring to the hunters and trappers and their especial qualifications for pearl hunting it should be stater that while they are favored in various ways, there are many others who are very successful in the work. Fishermen are often very fortunate in the work. They too have valuable river experiences which are a help to them. Every one has an opportunity to find valuable pearls if they hunt for them industriously. 


\section{CHAPTER XV'II.}

The P'akticla.ik Kind of "Crippled" Shell thit Yields the PE.ARL.

DARLS are found in various molluscan shells, but the ones of the greatest beauty and value are found in shells which have irridescent interior layers. Of the shells which have the pearly interior the most important are the Ariculadac, Mytilidac, and the Unionidae.

The first two groups are marine shells, while the last is the fresh-water group which are found in the rivers of many lands and are most abundant in our country.

In the marine mollusks, or oysters, the two valves are not of the same size and shape. The normal valves of fresh-water mussels, however, are of the same size and shape and very seldom contain pearls of value, although in rare instances very fine perfect pearls have been found in them.

The fine pearls are usually" found in what are known as "crippled" shells. There are no two "cripples" that are precisely the same in size and shape, yet there are two distinct classes of them, which may be termed as the worthless "cripples" and the valuable "cripples."

The "crippled" shells have an abnormal appearance. Such mussels have a long convex elevation on the ex- 


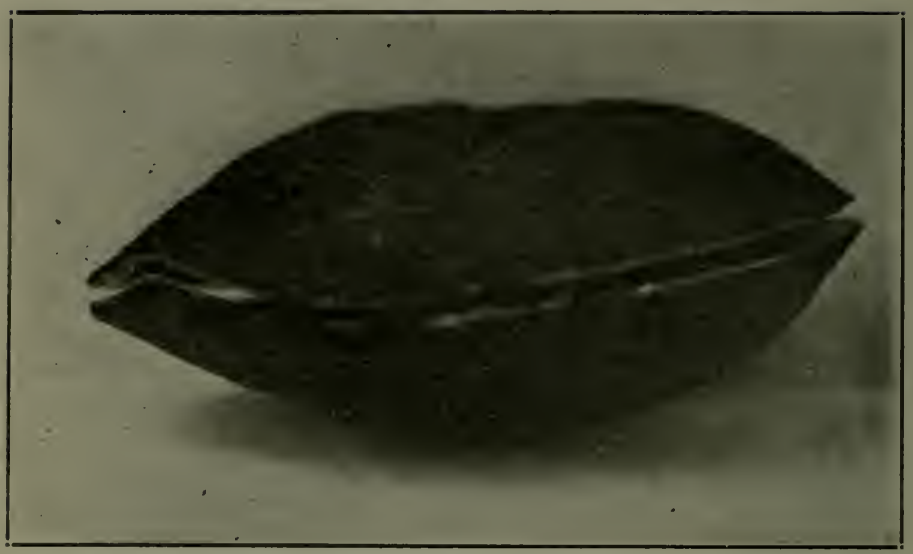

Fig. 38. Exterior View of the Worthless "Cripple."

terior of one valve and a corresponding long concave depression on the exterior of the other valve. These peculiar distortions are the largest and most distinct at the outside edge of the posterior or thin end of the shell. Both marks lead across the shells toward the umboes, or beaks, gradually becoming smaller and less distinct as they reach the older parts of the valves. The elevation is sometimes called a "deerhorn." These misshaped, or distorted shells are scarce, the valuable "cripples" being much rarer than the worthless ones.

It is rather difficult to give a description of the two rlifferent classes of "cripples." which will be sufficiently plain to show the difference between them.

For this reason four photographs are supplied, which illustrate the two classes of "cripples." These are shown 
"Crippled" Shells thit Yield Pearls i $5 T$

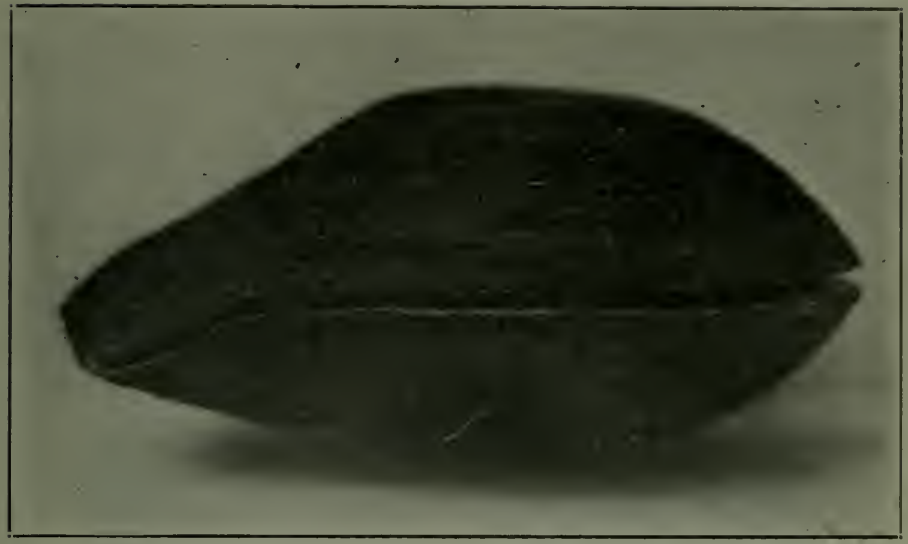

Fig. 39. Exterior View of the Valuable "Cripple," which Yields the Pearl.

in two sets. One set illustrates the exterior of the shells, while the other set shows the interior of the same shells.

The shells which are illustrated are taken from the author's collection of "cripples," which he has gathered in his work as a pearl hunter in various localities. The valuable one was found by him in the Illinois River, about one mile south of Florence, Illinois, and contained a beautiful low-button pearl, which weighed eleven grains. In Fig. 4I, the arrow indicates the socket in which the pearl was found. The shells which contain sockets are very rare. Most pearls rest in the folds of the mantle or against the smooth surface of the nacre.

In the views which show the exterior of the shells, the two parts of each shell are in juxtaposition, while the 
anterior or heary ends of the shells are at the right sicle of the illustration and the posterior or thin ends of the shells are at the left.

Fig. $3^{8}$ shows the exterior of the worthless "cripple." It will be observed that the elevation, or "deerhorn," is on the upper shell, while in the case of the valuable "cripple," shown in Fig. 39, the "deerhorn" is on the lower shell.

Amateurs should study these photographs very care-

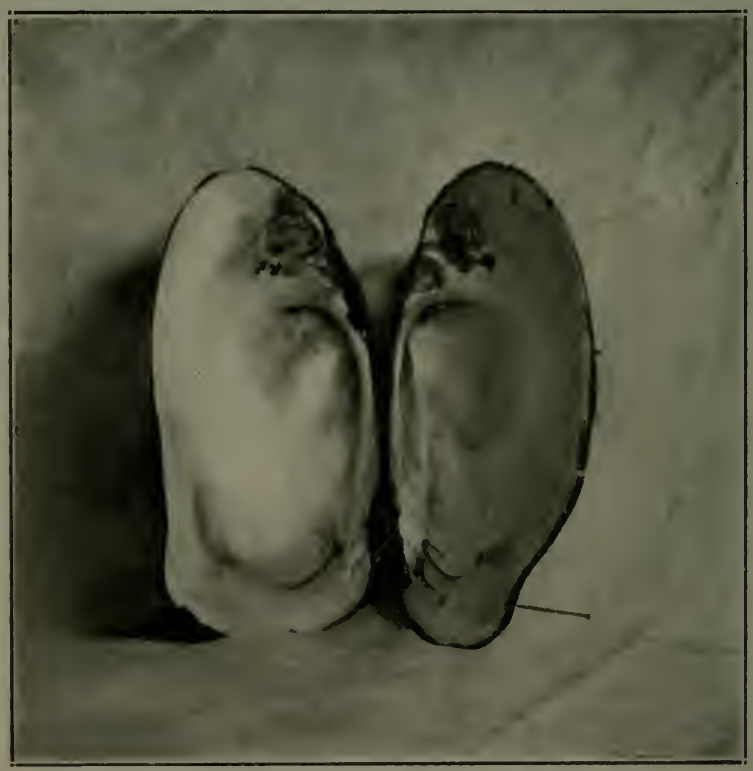

Fig. 40. Interior View of the Worthless "Cripple." 
“Crippled" Shells that Yield Peirls

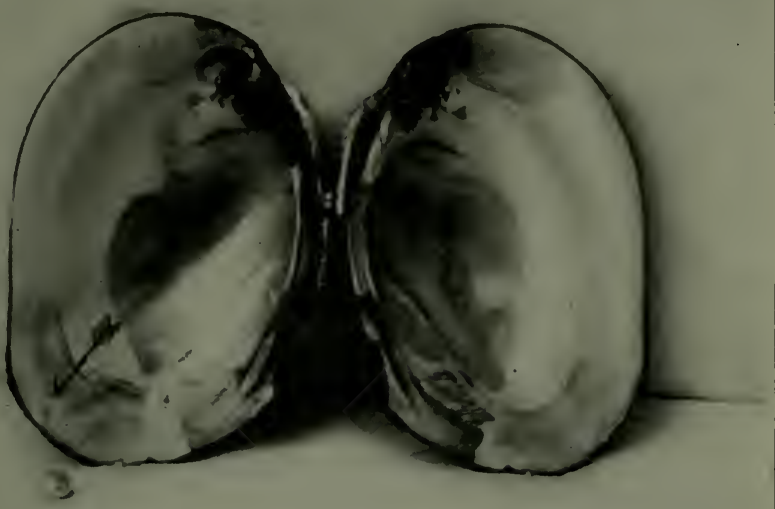

Fig. 41. Interior View of the Valuable "Cripple," which Yields the Pearl.

fully as they may get valuable information from them which might otherwise require years of experience in pearl hunting to secure.

The interior of the worthless "cripple" is shown in Fig. 40. The interior of this shell should be compared with the interior of the valuable "cripple," which is illustrated in Fig. 4I.

The fine pearls which are taken from fresh-water mussels are usually found in that portion of the shell which is indicated by the arrow in Fig. 4I. This portion of the 
Shell has a brighter color and irridescence than the rest of the shell and the pearls have the same color and briiliancy as the portion of the shell nearest to them when found.

Large valuable "cripples" contain large pearls, unless these have been lost. The small valuable "cripples" do not contain large pearls, although they often contain valuable small ones.

The pearls which are found are not always valuable Sometimes a large distorted shell will yield a very imperfect pearl. While the valuable "cripple" evidently contains a pearl, and the size of the shell and the distorted condition are indications of the size of the pearl, there are no other outward indications of its value.

Often a small distorted shell will yield a pearl of great value. In extremely rare instances the worthless "cripples" have yielded pearls, but they were small and of little value. It seems that the worthless "cripple" is unable to hold the pearl in its shells, and a pearl that happens to start growing on the wrong side of the animal. becomes lost, although the irregular growth of the shell must necessarily continue, grarlually decreasing in ruggedness and distinctness after the pearl has been lost.

The winter rest lines and the irregularities of the exterior of the "crippled" shells often tell an interesting story of the mussel's life. The worthless "cripple," which is illustrated, probably held a pearl for awhile. The deerhorn on the exterior of the original shell becomes very prominent and irregular until it has passed the fifth winter rest line, while from there to the edge 
of the shell it is comparatively smooth. These conditions indicate that the pearl was lost from the shell during the sixth year of the mussel's life. As additional evidence there is a mark on each shell at the same place between the fifth and sixth winter rest lines. The marks indicate that the mussel sustained a slight injury during its sixth year. This was possibly caused by the momentary intrusion of a dredge hook which may have assisted in removing the pearl at the time it was pulled from the shell. While the winter rest periods are not plainly marked after the sixth year, it is probable that about five more years elapsed before the mussel was taken from the water, making the age of the mollusk eleven years.

The two shells illustrated are about the same size, yet the reader will observe that the distortion is much greater in the valuable "cripple" than in the worthless one. There is much variation in the "cripples" which are found by pearl hunters, and it is a good plan to examine and study all of them carefully.

The irregular shapes of the crippled shells are probably caused primarily by the presence of some parasite inside of the shell which interferes with the normal secretions of shell forming material.

The mantle supplies material for the epidermis, the middle portion of the shell and the nacreous lining. A portion of the mantle may be wrapped around the parasite, or otherwise removed from its proper position, which would interfere with the normal secretion of one or more of the three shell forming materials. It is probable that a part of the material which should be used to build 
the shell is used to envelop the foreign object. This being true, the part of the shell nearest the object would not receive its full share of building material and would therefore become dwarfed, while the other portions of the shell receiving their full shares of building material must be distorted to meet the portion which has not received the normal amount of material. The fine pearls are found in a number of different shapes, the most valuable one being the perfectly round pearl. This shape appears to be the most difficult for the mussel to develop.

Another desirable kind is the pear pearl. These are nearly always found well formed and it appears to be much easier for the mollusk to roll and coat them properly than the round or ball pearls. The high button and low button pearls are usually pressed against the nacre of the shell in such a manner as to prevent perfect coatings of nacre from being applied to all parts of the pearls.

It is probable that some of the larger button pearls were once ball pearls, but on account of their increasing size they finally became pressed against the shell in a manner which prevented a perfect coating of nacre so they became some what flattened on one side, and in some instances two sides became flattened on account of the pearl touching both shells of the mussel.

There are also other pearls which resemble eggs, barrels and other objects.

Most of the pearls which are found in the "crippled" 
“Crippled” Shells that Yield Pearls i63

shells have some imperfections. The faults are mostly caused by pressure of the shells against the pearls.

While the "crippled" shells produce most of the pearls. it should be remembered that perfect ball pearls of fine luster are occasionally found in shells that are normal. The pearls which are found in perfectly normal shells do not touch either shell and are therefore perfectly rouncl and have a fine luster. Such pearls are often found in a sort of sack hanging inside of the palaal line near the gills.

Mr. Noah McFadden found one of this kind in the Illinois River, near Meredosia. He sold the pearl for $\$ 1,000.00$. The pearl was perfectly round with a fine luster and weighed twenty-seven grains. The shells which contained the pearl were perfectly normal.

While the perfectly normal shells do not often contain pearls, the gems which are found in them are very likely to be perfect.

There is another kind of "cripple" which produces baroques and slugs. These "cripples" are often the result of some kind of accident, in which the shells have received some injury. Occasionally a mussel becomes injured in a manner which moves one valve farther forward and the teeth are broken off. Such shells often produce a large number of slugs.

Other shells become wedged between solid rocks and grow into peculiar shapes, but are not so likely to yield slugs.

There are many ways in which the mussels may be in- 
jured in accidents but such "cripples" are easily distinguished from the valuable "cripples."

Some shells which do not appear to be injured contain nice pearls, baroques and slugs. 


\section{CHAPTER XVIII.}

The Influence of Local Conditions Utpon tile Color of Shelis axd Pearis.

7 HE American fresh-water pearls have gained international fame for their great variety of fancy colors. The crowns of many kingdoms are adorned with one or more of these precious gems.

The cause of the various colors is something which scientists are unable to explain. The subject has been very sadly neglected and probably there has not been a real need fcr the knowledge.

The time has arrived, however, when it is very desirable to know the exact causes of the various colors.

Great progress has been made in the science and art of perpetuating the supply of valuable mussels. The growing demand for fresh-water pearls, or, sweet-water pearls as they are often called, will make scientific pearl farming a profitable occupation.

It is, therefore, very important to know the influences which are the causes of different colors in pearls.

A single fresh-water pearl which has a brilliant fancy color is a valuable gem, but such a pearl is usually set alone because it cannot be duplicated. If such a gem could be matched perfectly, the value of both pearls would be greatly enhanced. 
The pearl fisheries of our rivers are very extensive, yet it would be very difficult to find two colored pearls which are alike in every particular.

The pearls from tic Ceylon fishery are nearly alike in color, and therefore jewelers depend upon them when they wish to make a large necklace. This is a valuable advantage which our colored pearls do not have; yet scientific management may help to overcome this difficulty by supplying a system whereby pearls of any color may be artificially cultivated. These colors are not a mere matter of chance. There is a real cause for every effect, and while we may not know the reason why some pearls are white, while others are green and pink, there is a good reason for it.

Shells which are white in one river are pink in another stream; while some which are pink or purple in the headwaters of a river may be white a hundred miles down the stream. All must agree that there are some local conditions which influence the color of the shells and pearls.

In the summer of I9Io the author gathered shells in the Mississippi River, near Port Byron, Illinois, where he sold his shells to Mr. J. F. Normand.

While working there he noticed that the nigger-heads and several other mussels with shells having white nacre were at rest, while the lady fingers and several others having pink nacre were always feeding. At that time the Mississippi River was lower than it had been for many years. The Northern States and Canada were suffering from a very prolonged drought. All the creeks and 
ponds were dry, and as there were no rains it is manifest that the river was made up largely of spring water then. It is very probable that a chemical analysis of the river water at that time would have shown a larger per cent. of minerals than could be found at other times. This condition suggests that the colors of the shells and pearls may possibly be caused by the minerals which are in the running water.

The colored shells are also smaller and lighter than the white ones and probably do not grow so quickly.

Investigations of the pearl fisheries of the various rivers of this country and some of the ocean fisheries seem to justify the theory of the mineral origin of the colors of the pearls and shells.

Illinois is a prairie State. The rivers are fed by creeks and other streams. There are large coal deposits, but they do not influence the colors of pearls, except where the deposits are near the surface and exposed to the action of the running water. The Spoon River, in Fulton County, has this unfavorable condition, and many of the pearls have a dead yellow color, which is very detrimental to their value.

Minerals are scarce in Illinois, and the shells with white nacre predominate.

The rivers of the State of Tennessee have yielded many fine colored pearls. A large number of these were pink and red.

Tennesse produces gold, iron, copper and marble. The great iron belt extends 5,400 square miles along the Tennessee River. 
M)
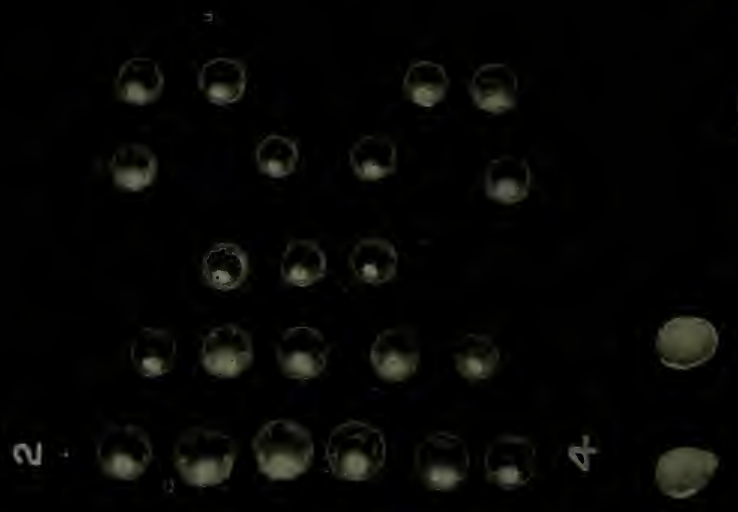

$$
\begin{aligned}
& -\phi \sigma \theta \\
& 00
\end{aligned}
$$
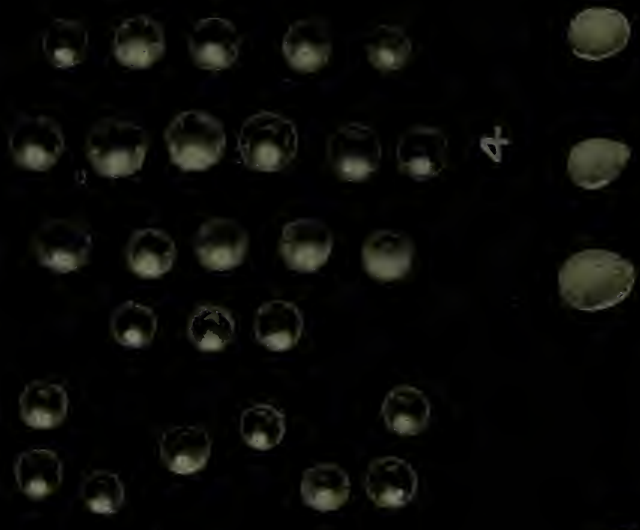

0

$-$ 
Some nice rose colored pearls were found in the Tennessee River in Alabama, which is a great iron district.

The Cumberland River in Kentucky has produced some very fine pink pearls. Above Cumberland Falls, The Unio gibbosus, or lady-finger, is about the only variety found, and the shells are pink. Farther down the river the color of the shells gradually becomes lighter, but shells are not taken in the first 175 miles of the river.

From Celina down, the shells are whiter and larger and "clamming" is carried on in many places.

Kentucky contains deposits of iron, gold and silver. Mineral springs are abundant in the hills. Salt is also found there.

Some very fine lavender pearls have been found in Kansas. This State produces lead, zinc and salt.

Some very large pink pearls were found in the northeastern part of Arkansas, in the Black River, which drains the Iron Mountain region of Missouri.

Other pink pearls were found in Murphy and Walker Lakes, both of which are known to contain iron.

The pearl fisheries of Wisconsin have produced a large variety of colored pearls. Among them are pink, red, bronze, purple, lavender, and peacock green. This State ranks high among the iron producing States, while lead, zinc and copper are also found. The State also has valuable mineral springs.

A careful comparison of the colors of the pearls found in the various localities and the kinds of minerals which are also found in the same places, leads to the conclusion that the colors of pearls depend upon the kind of min- 
erals which are deposited near the rivers. The evidence is only circumstantial, but is very much in favor of the mineral origin of the colors of pearls. From the information which has been gathered it seems as though the presence of iron is conducive to pink, or various shades of red. Green seems to come from copper, while the blue or lavender may be derived from lead or zinc or from a combination of these minerals. Possibly the mussels which live in a certain stream where a certain kind of mineral is abundant gradually become accustomed to it and feed at times when the water contains a large per cent. of the mineral.

In this manner the dissolved mineral may become assimilated like the carbonate of lime and used with it in the construction of the shells and pearls. Farther down the streams the shells grow whiter, which seems to indicate that the minerals which were in the water near the source of the river have been gradually reduced by the addition of water from other streams and to some extent by settling. As the river becomes larger the erosion is gradually reduced.

The size of the shells seems to depend upon the amount of carbonate of lime in the water. This is illustrated by the sizes of the shells found in different parts of the Illinois River.

The river north of Peoria is enlarged by the waters from smaller rivers, which carry a large quantity of carbonate of lime into it, and the shells in that district are very large. The southern portion of the river is much 
wider and leeper and the erosion is reduced so the shells are much smaller.

A.n investigation of some of the ocean pearl fisheries also furnishes some information relating to the color of pearls.

The pearls from the Ceylon fishery in the Gulf of Manaar, off the east coast of the island, are of a rather uniform creamy yellow color. The sea-coast there is even with a low-land plain back of it. The only mountains are in the extreme southern part of the island, where plumbago and precious stones are found.

In the pearl fisheries of Lower California, where the most approved diving outfits are used, pearls are found in white, pink, blue, green, brown and black colors. The adjacent land is mountainous, while the mining region comprises eighty per cent. of the area of Mexico. The minerals found there are gold, silver, lead, copper, platinum, iron, mercury, tin and zinc.

The pearl fisheries of Costa Rica, Panama and Colombia are famous for their black, blue, pink and green tinted pearls. These countries are rich in minerals and produce gold, silver, iron, copper, lead, platinum, mercury and zinc. These circumstances seem to indicate that local mineral deposits also have something to do with the colors of the ocean pearls. 


\section{CHAPTER XIX.}

The Luster of the Pearl-Its Cause Explained.

INCE the earliest records of the pearls's history, its magic charm has won the admiration of the people of nearly every land. The earliest rulers and conquerers were captivated by its tender, silky luster and from their time to the present, pearls have been the most important gems of royalty. Their great popularity, lasting over 2,400 years, is the very strongest recommendation for the pearl. These beautiful gems have several attributes which make them valuable, but the one virtue which charms and wins the people of all times is their soft, velvety luster. While this remarkable silky sheen is so greatly admired, the cause of the unusual appearance is not immediately obvious. Fine pearls and the portions of the shells in which they are found have this Oriental radiance. The shells consist of thin layers of carbonate of lime, interstratified with animal membrane. The various layers of nacre follow the form of the shell and are slightly inclined toward the surface. This peculiar structure of the laminae is easily discerned in the posterior adductor scar of the shell, where the edges of the strata slightly overlap each other. The tender, delicate irridescence can be plainly seen, yet a microscope reveals the full glory of the wonderful creation, where the ar- 
rangement of the reflecting surfaces of the curved edge: presents an endless variety of beautiful tints and colors. The wealth of the colors in the arched edges artistically portrays a magnificent rain-bow or reminds one of the lavish display of rich colors often seen among small clouds at sunrise; and if the shell is moved slightly, a pretty representation of the aurora borealis may be seen in the unique arrangement of the laminae of the adductor scar.

Now the fact is that while the shell has the appearance of being composed of a series of richly colored layers of nacre, the various layers are about the same and the beautiful series of colors is an optical illusion, which is known as the phenomenon of interference. The word interference is the term employed to express the effect which rays of light, after being bent or diffracted, produce on each other. The large number of narrow, curved surfaces which are in the adductor scar furnish one of the best examples of the phenomenon of interference.

The pearl is also composed of a series of nacreous layers interstratified with animal membrane, but the pearl is made up of concentric layers, each new layer completely surrounding those already made. There is also another difference in their structure. While the shell is composed of three distinct parts, the conchioline epidermis, the inner prismatic formation, and the nacreous lining, only one of these three materials is used ordinarily in the formation of the pearl, this one being the nacreous material which is used in making the lining of the shell. This material is the finest that is used in the formation of 


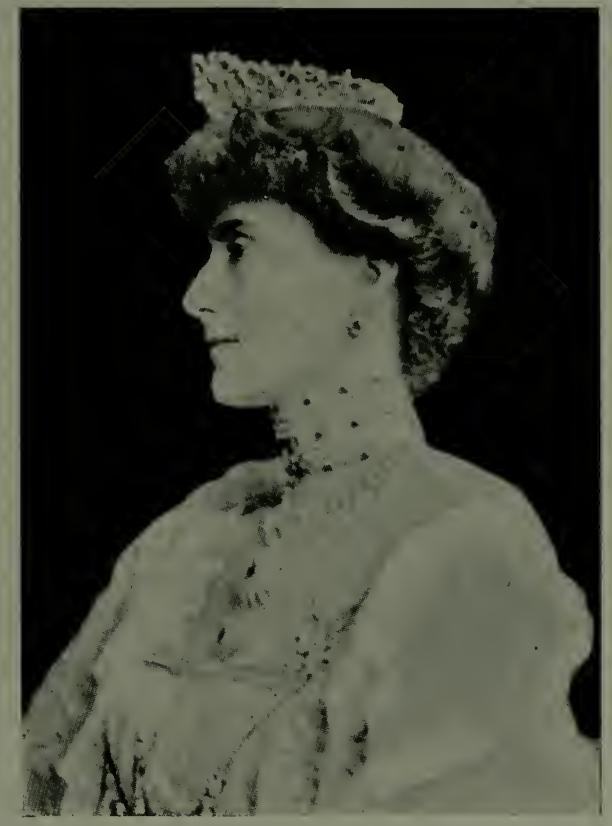

THE COUNTESS OF STRADBROKE. 
the shell and has the appearance of being composed of a large number of very thin wave plates slightly overlapping each other and set in animal membrane.

The layers or strata of the pearl are not always regular. Pearls are often found in which there is quite a variation in the stratification. Some layers are thicker than others or have a spiral formation as if they had been made by rolling the pearl in the nacreous material.

Pear pearls are often pearls that were once round, but which have become elongated by the irregular deposit of nacreous material. Button pearls are somewhat flattened on account of being pressed against the shell, but if these become loose in the mantle they gradually become round.

The normally formed ball pearl is composed of a series of layers very similar to the structure of an onion.

In Fig. 43 cross section views of an onion and a pearl are shown to illustrate their similarity.

The arrangement of the transluscent strata of the pearl are such as to cause the phenomenon of interference, but not in just the same manner as it is produced by the edges of the strata in the adductor scar of the shell.

In the drawing of the pearl, the vertical dotted line is intended to represent a ray of light entering the transluscent layers of the pearl.

There is a difference in the circumference of the various strata of the pearl, and, therefore, the ray of light falls more obliquely upon some layers than others. As the light strikes the strata at various angles, it becomes bent or diffracted, and, if the rays meet after diffraction, 

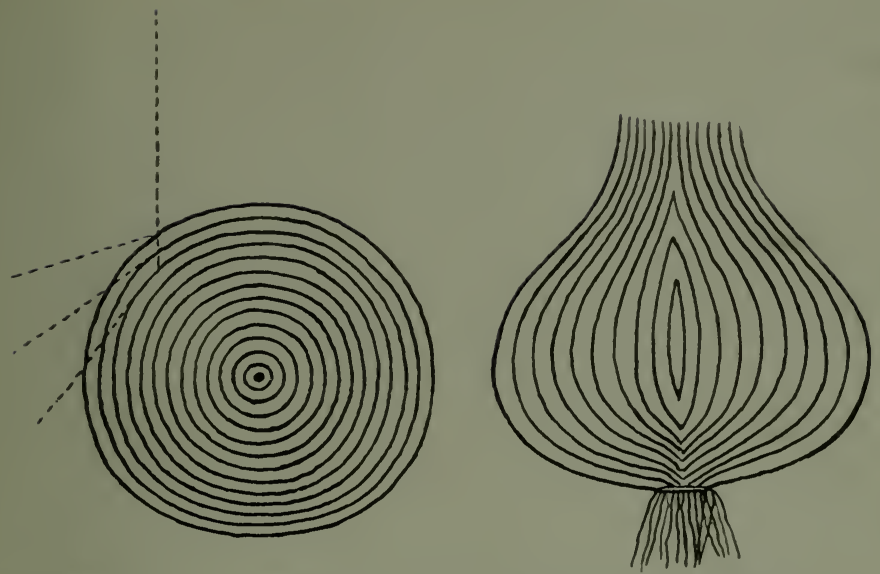

Fig. 43. This illustrates the similarity in the structure of the the pearl and the onion, and shows the manner in which rays of light are inflected from the strata of the pearl, thus causing the luster.

they will be divided. This peculiar inflection of the rays of light from the different strata of the pearl is another fine example of the phenomenon of interference.

Some pearls are so extremely translucent the light can almost pass through them, and these, of course, present the very finest degree of luster.

The perfectly round pearls have ilie host luster on account of their more perfect arrangement of strata for producing these phenomena, although the other forms are capable of inflecting the rays of light and have beautiful radiant lusters.

The soft velvety skin of the pearl increases and enriches its delicate sheen. 


\section{CHAPTER XX.}

The Care, Value and Sile of Pearls.

WHERE are some things which relate to the care, value and sale of pearls which many amateur pearl hunters desire to learn. The care of pearls when found is very important, as these gems are more liable to misfortune than the other jewels.

All the "crippled" shells should be opened without boiling, if convenient, as the boiling process sometimes ruins the pearls, especially when the vat becomes dry. The vat should be cleaned as soon as the mussels are opened, and if any pearls or slugs are found they should be allowed to cool gradually. The pearls should be cleaned by washing in water to remove any adhering substance.

When pearls are carried loosely among other objects they become injured or scratched. It is very necessary to prevent friction and protect the lustrous surface of the pearl.

Many pearl hunters wrap them in cotton to prevent friction. Pearls which are allowed to dry rapidly are liable to check or crack, and for this reason it is better to keep the cotton wrapper damp. Some men keep their pearls and slugs in cotton in a small box, with a glass 
cover, such as jewelers use to hold the works of a watch.

There are some commodities which are so regular in price and so continually and universally in demand that the price is uniform and all know the value of the articles.

The value of pearls, however, is influenced by such a large number of conditions and combinations it is impossible to establish a standard of value that can be relied upon in all cases. The value of pearls depends upon the luster, tint or color, shape, size and the degree of perfection.

These virtues furnish a great variety of intricate combinations, and the best connoiseur of gems is often confused as to the exact value of a pearl. The great variety of colors of our fresh-water pearls makes the problem of value even more complex.

In addition to these circumstances the fact that there is no other pearl just like the one to be valued, makes it impossible to be guided by precedent, and then as a final result, the buyer and seller must agree on a price.

Pearls that are absolutely perfect are very rare and bring a high price. Those which are imperfect do not command a high price unless they are nearly perfect or of an unusually large size.

Pearls are classified as pearls, baroques and slugs.

The ones which are classed as pearls are: The Round or Ball Pearl, the Pear Pearl, the High Button Pearl, the Low Button Pearl, the Egg Pearl, the Barrel Pearl and the Seed Pearl. 


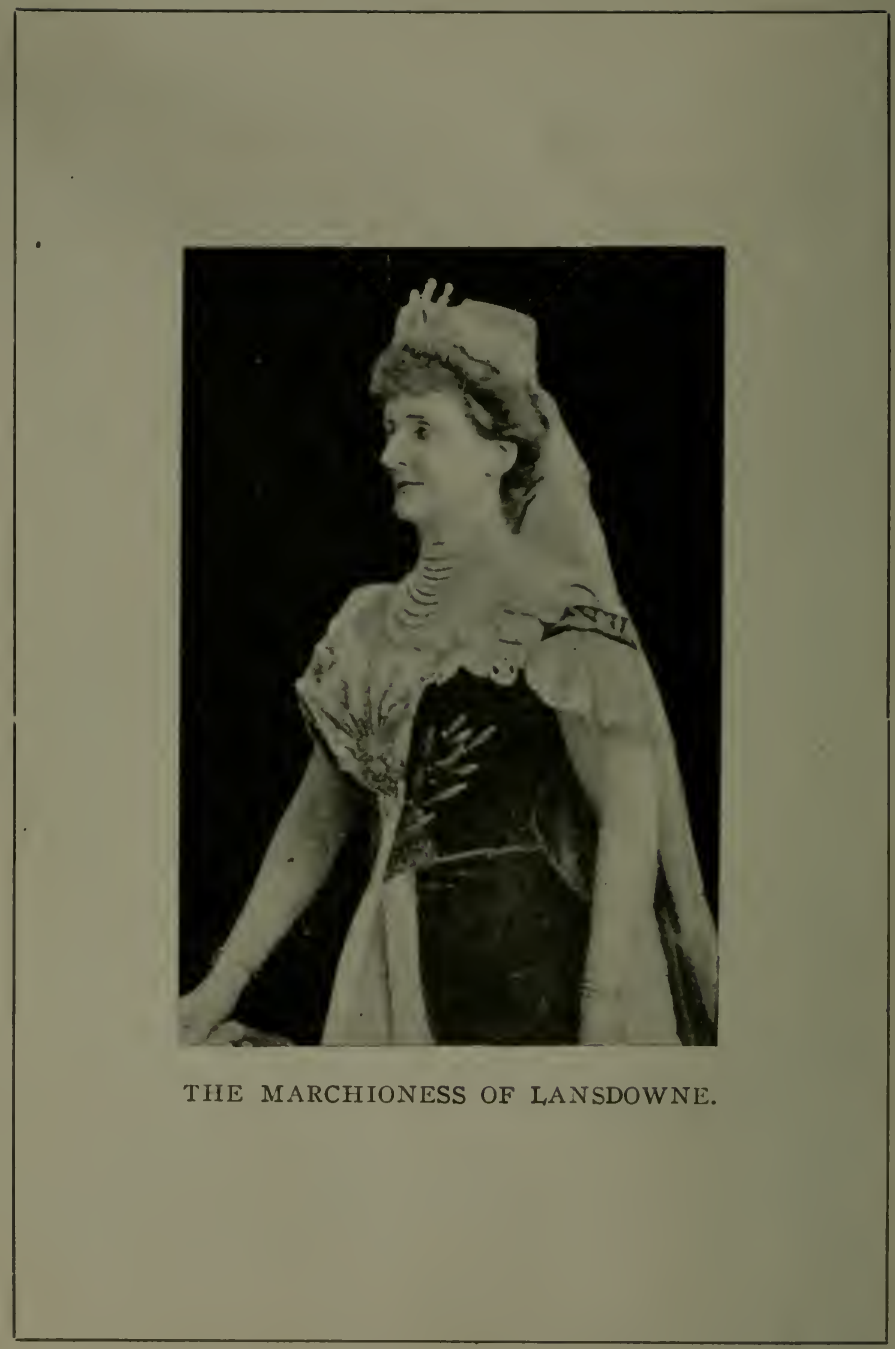


The Baroques are: The Rose-Bud or Strawberry Pearl, the Turtle-Back Pearl, the Biscuit Pearl and other valuable nuggets.

The Slugs include: The Spike, or Hinge Pearl, and the other ordinary formations, and the smaller pieces called Chicken Feed.

The various kinds of fine pearls are usually graded as large, medium and small pearls; a large pearl, weighing fifteen grains or more; medium, five to fifteen grains ; and the small, under five grains.

The sizes of the grades given here are not always used. some dealers using other gradations.

One buyer offered $\$ 30.00$ per grain for perfect large ball pearls, and $\$ 20.00$ per grain for perfect medium pearls. These prices are too low, although the price offered for the medium size of perfect ball pearl is about as good as buyers usually pay.

The most valuable one is the large perfect ball pearl, which is white and very translucent. The value of these is nearly always underestimated and pearl hunters do not demand enough for them. The large perfect ball pearls are in great demand for centers of necklaces and the value of pearls weighing more than ten grains increases very rapidly with the increase in size.

The other forms of large perfect pearls are often nearly as valuable, and as they are often used singly in jewelry it is not so important for them to be white. If they are perfect they may have any bright live color and be of great value, although light pink, sky blue, and peacock green are especially desirable. 
The egg pearls and pear pearls are generally used for pendants and for scarf pins.

The banded pearls do not command a high price. The band is usually of a dead color and generally extends through all the layers of nacre so nothing is gained by "peeling."

If the pearls are large and lustrous, however, they are good for some uses and have a value. The barrel pearls. when brilliant and perfect, are valuable, although the shape is not so desirable as the others.

The yellow fresh-water pearls are usually of little value, on account of their dull or dead appearance, although a pearl of a bright, butter cup yellow is very valuable.

All light, live colors permit a greater translucency and consequently have a better luster.

The dense colors are not so desirable, although perfect black pearls are very rare and valuable.

When two or more pearls are matched in size, form. luster and color or tint, their values are greatly enhanced.

The pearls forming a necklace should be of the same luster and tint. Very few realize what large quantities of pearls are necessary to match a long necklace of them perfectly. Besides, great skill is necessary to enable onc to detect slight differences in tints and textures.

Some pearls have imperfections which can be hirlden by the setting and while they are not worth as much as the perfect ones they liave a good value. 


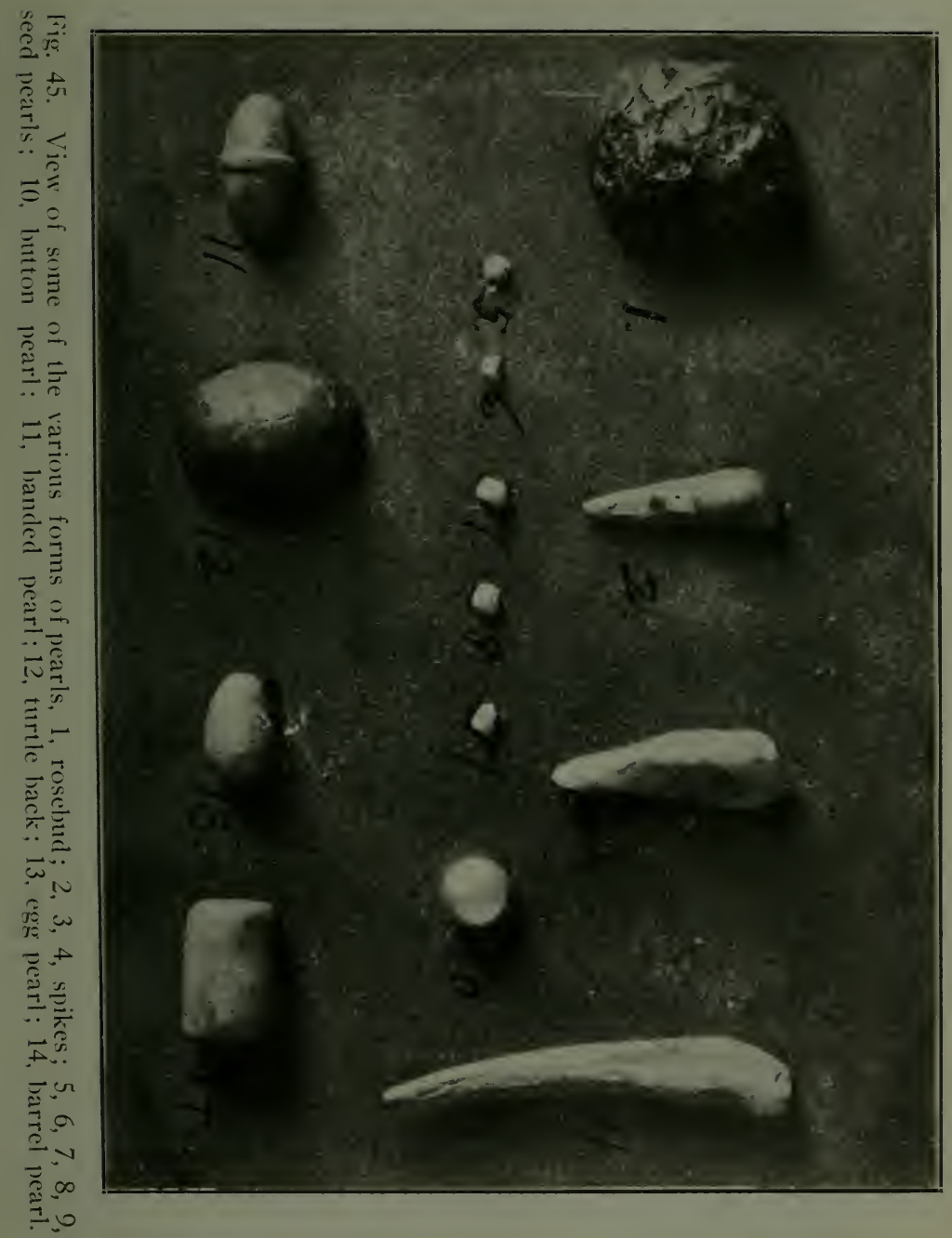




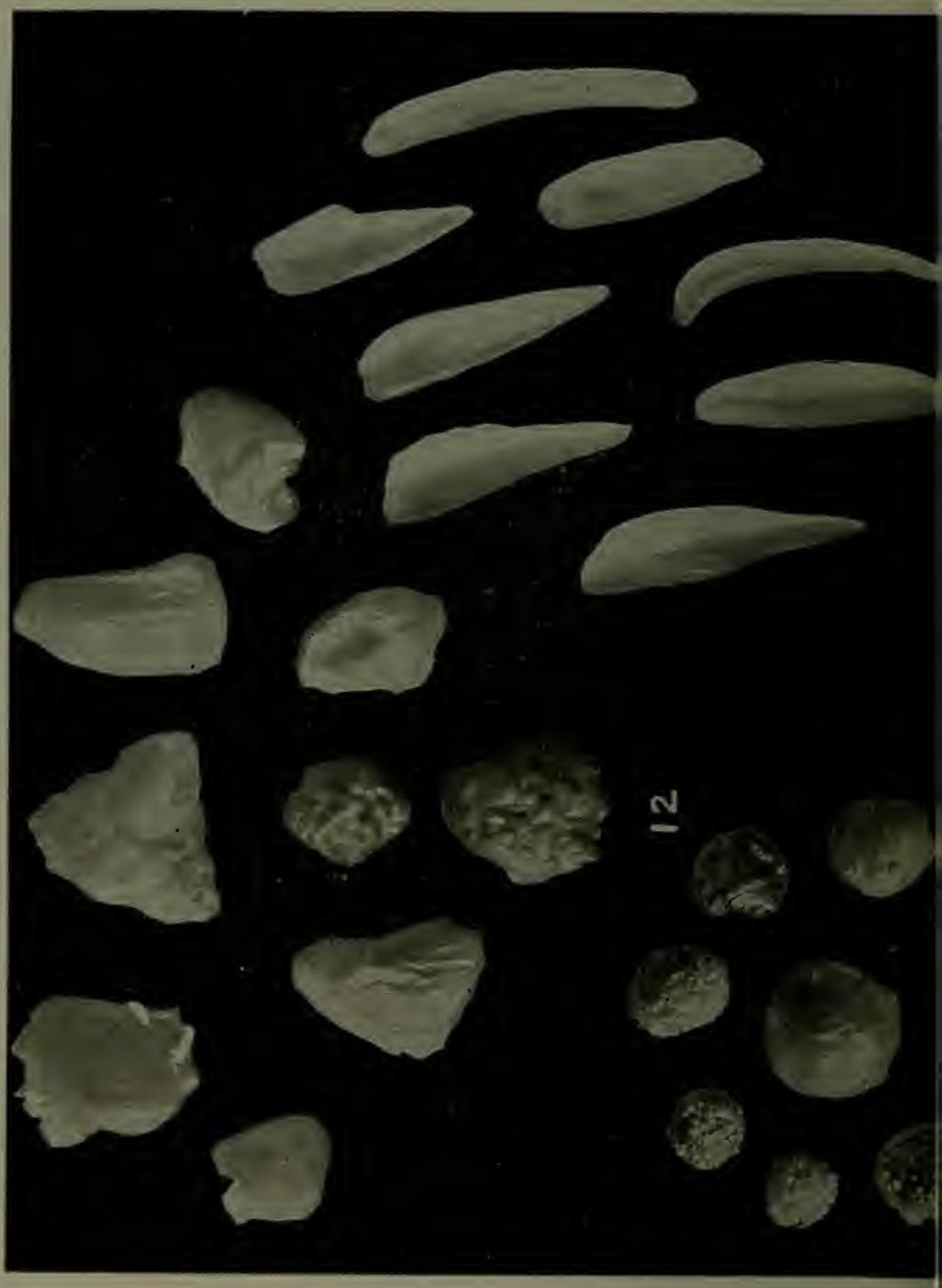



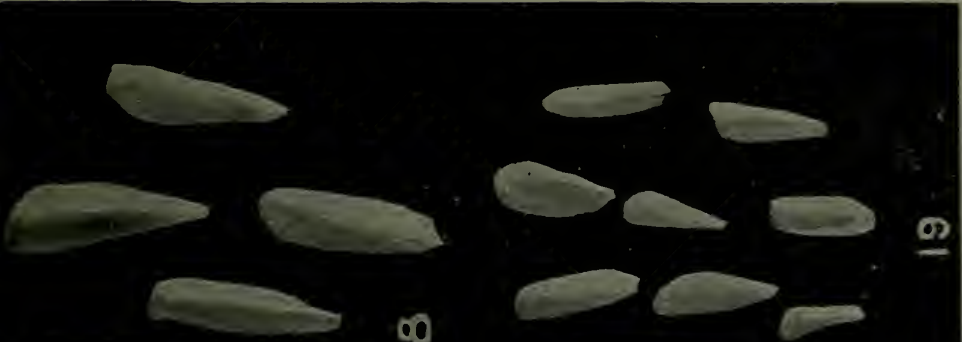

$\stackrel{\infty}{0}$
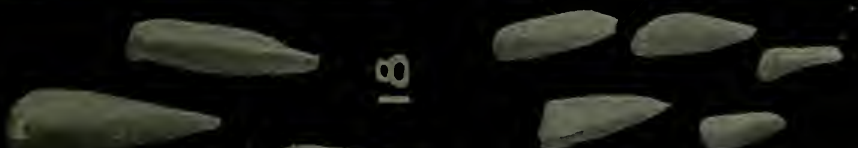

ก)
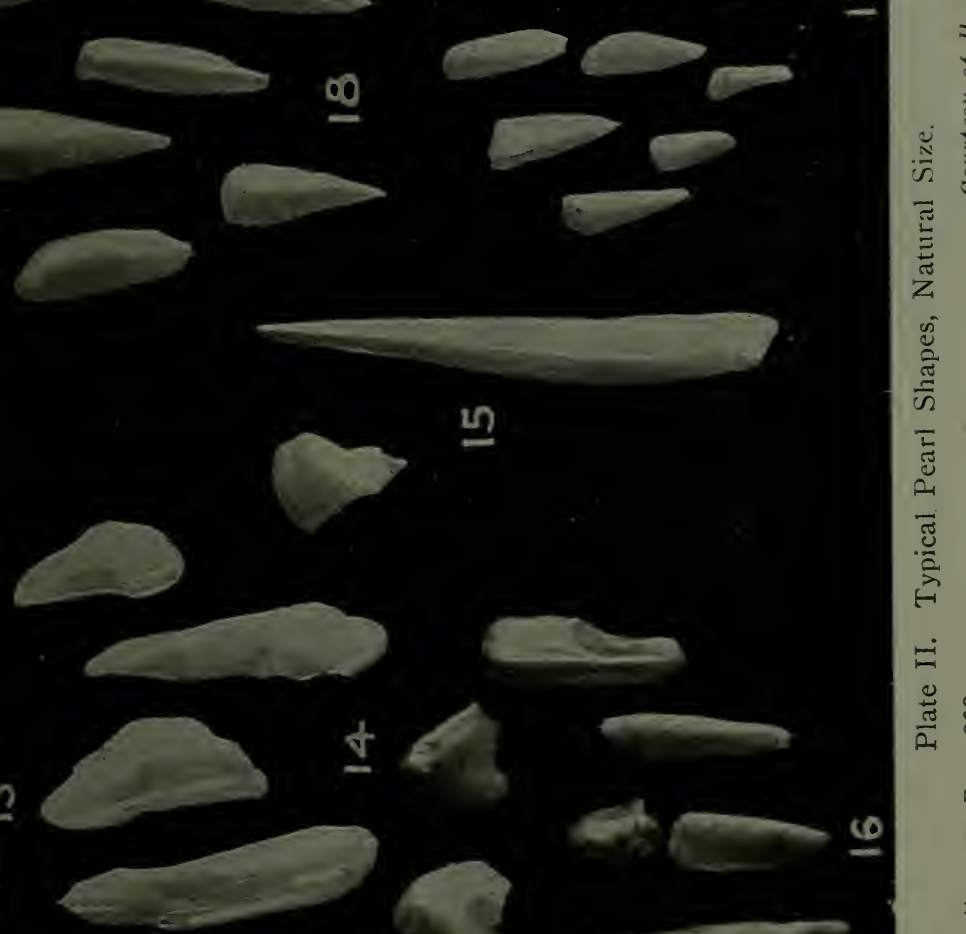

is

ह

$\approx$

$\Xi$

Е

च

造

苂

A

हु

v)
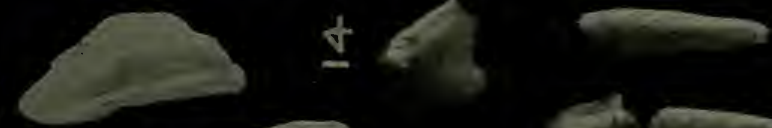

$\frac{\pi}{5}$

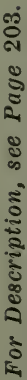


All kinds of pearls should be brilliant and lustrous to command the highest prices.

Pearls are always sold by the grain. This standard of weight is a very old one and originated in India. Small uniformly round seeds or grains were used in weighing pearls. Later, stanclards for this weight were established, so the grain is used exclusively.

Fig 45 illustrates an assortment which includes the Rose-Bud, Large Spikes, Seed Pearls, Button Pearl, Panded Pearl, Turtle-Back, Egg Pearl and Barrel Pearl.

The Rose-Buds, Biscuits, Turtle-Backs and other Baroques, when large and lustrous are in demand and sell as high as $\$ 4.00$ per grain, and sometimes even higher, although the poor grades have a much lower value.

All Slugs are sold by the avoirdupois ounce. The very large selected pieces that are clear and lustrous and nicely colored sometimes sell as high as $\$_{1} 5.00$ per ounce.

Fig. 46 shows a quantity of average run slugs which sell for \$3.00 per ounce on the Inlinois River. Such slugs are worth $\$ 2.50$ per ounce on the Mississippi River, and $\$ 2.00$ per ounce on the Maumee River. The quality of the slugs varies in the different fisheries. The color, luster and quality of the average run of some slugs in some localities are so good they occasionally sell for $\$ 5.00$ per ounce. The chicken feerl is not so valuable, but sometimes sells for $\$ 3.00$ per ounce.

The prices that have been mentioned are for freshwater Pearls, Baroques and Slugs.

The value of the pearls found in the various rivers, exceels the value of the shells. Most of the pearls are 


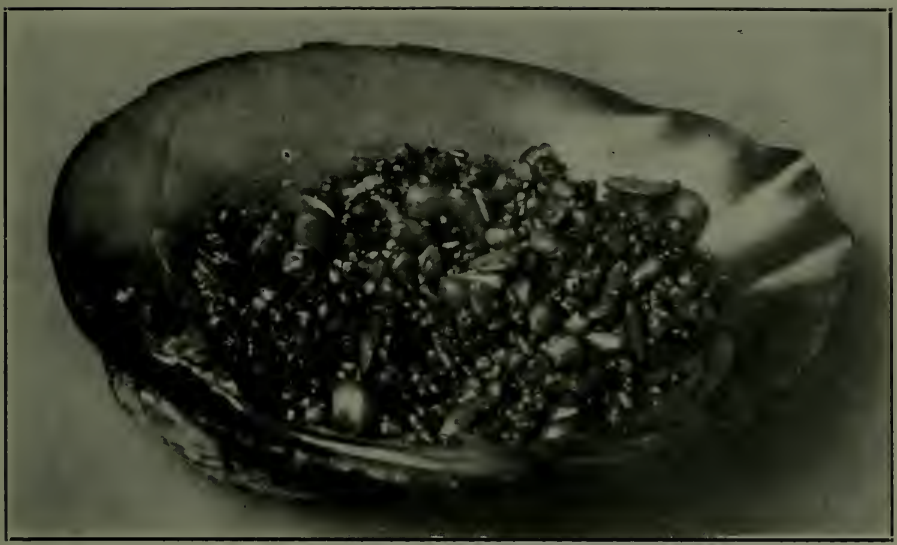

Fig. 46. Some “Average Run” Slugs.

sold to pearl dealers who are usually called pearl buyers on the rivers. They are usually shrewd men who are very skillful in buying pearls. Many of them use fast motor boats and make frequent trips up and down the rivers that are being worked.

The large jewelry companies do not often buy of pearl hunters, but get their pearls from regular dealers.

There has been some talk of a pearl trust. Some odd reports have been made which seem to indicate that such a monopoly exists, yet there is no real proof of it. Sensational newspaper items are not always to be truster. and it is to be hoped that there is no pearl trust.

There is a difference in buyers, though. Some men are more conscientious than others and have more sympathy for a poor man so they pay higher prices for the gems. 
There are some buyers who do not know much about pearls and their values. These men often buy for some other buyer and their lack of knowledge of pearl values limits their offers very much. Many buyers try to get a pearl hunter to promise to give them. the opportunity to make the first offer on any pearls they may be fortunate enough to find.

One should not make a promise of this kind as it places lim under obligations to the buyer, and although another buyer who is more liberal in his dealings may come along, the pearl hunter is in honor bound to withhold the pearl until he has fulfilled his obligation to the man who secured his promise.

One should study the buyers and decide which man is likely to pay the most for any pearl he may find, although it is not best to mention the decision to any one, as the. pearl buyer may learn of it.

When one finds a pearl, the less he says about it the better, and it is not a good plan to show the gem.

The man who pays the highest prices is the one who should have the first opportunity to make an offer, and if a satisfactory deal can be made it is all right to sell it then.

News of "finds" and the prices that have been offered for them travels very quickly along the pearl streams, so other buyers soon know of the pearls and the prices that have been offered for them.

After a price has been made on a pearl it is rather difficult to secure a higher price from another buyer. This seems strange, but there is at least one good reason 
for it. When an article has been offered for sale and a dealer refuses to pay more than a certain known price for it, other buyers who have learned of the offer naturally become somewhat conservative and do not care to offer a price which another dealer has refused to quote because of the business risk.

The financial condition of the one who finds a pearl has very much to do with the price. It is a deplorable fact that many pearl hunters are often in such a great need of money that they sell pearls far below their real value rather than hold them for a better price.

Under these circumstances perhaps it would be a good plan to secure the assistance of a storekeeper or banker. He could hold the pearl and supply some necessities and money and later the two could sell the pearl at a fair price and thus prevent a loss.

Pearl hunters are entitled to every consideration and should always receive the highest prices for their gems. 


\section{CHAPTER XXI.}

Imperfect Pearls and How to Improve Their.

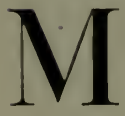

ANY of the fresh-water pearls are imperfect. Some of the imperfections are so serious the pearls cannot be improved sufficiently to bring much on the market.

Others can be greatly improved through easy methods, and can be sold for a much higher price than they could have been sold for without the improvement.

Pearl hunters often need information which will enable them to improve imperfect pearls, but are unable to secure it. Some buyers know of various ways of improving imperfect pearls, but they will not reveal their me thods to the pearl hunters.

Perfect pearls, of course, do not need any improvement and are the only jewels which do not require the services of skilled men to prepare them for use. The high value of pearls is an incentive to improve the imperfect ones and many are made more valuable by special treatment.

Round pearls which have a slight flatness or a flaw on one side may be improved by drilling through the defect, and when these pearls are placed in a necklace the imperfection cannot be detected easily.

Jewelers also conceal such faults by setting the pearl 
in a ring. Another method is to remove the outer layers, although this plan has the disadvantage of reducing the size and weight of the pearl. This method is known as "peeling," and is an important system of improving imperfect pearls by removing one or more of the outer layers of the pearl. This is usually done with a sharp knife, but it requires great skill to do the work nicely in all cases.

Some use acid for "peeling," but the difficulties accompanying its use are such as to make it rather impractical for those who have not had experience with it. The imperfect pearls which are to be treated by "peeling" are known as "peelers."

"Mud spots" are commonly found in fresh-water pearls of some fisheries. The pearls from the Illinois River are particularly liable to these defects. The "mud spots" are often very serious imperfections. The spots have a dark appearance and contain mud or sand and water. Such imperfections often cause pearls to crack unless they are removed.

Pearls containing "mud spots" are often improved by some jewelers by concealing the imperfection in the setting. It is, of course, very unfair to sell such a gen without telling the customer of the "nund spot" and its tendency to make the pearl crack. Responsible dealers will not permit a customer to make a purchase under the slightest misconception.

Some pearls have a rather dead yellow color when found. If this color extends through all the layers of the pearl it is practically worthless. Very often, however, 
only the outer layer or layers are dead and by removing them a beautiful pearl may be found. There is no telling what color of gem may be found under a dead outer stratum.

The cylindrical pearls, or egg pearls, which have chalky bands or rings around them should not be peeled as these imperfections are generally found throughout all the layers of the pearls.

The jewelers sometimes conceal these faults under gold bands in the jewelry settings; or cut the pearls in two parts and use them for ring sets.

The "peeling" of pearls often results in disaster. The imperfections often extend to the centers of pearls, so there is much uncertainty in this method of treatment.

There are some large pearls which have noticeable imperfections, particularly "mud spots," and it is a serious question as to the advisability of "peeling" them. Perhaps an examination of such pearls with the X-ray would enable one to decide the question. Sometimes pearls have a slight chalky appearance when taken from the shell. These can often be improved by allowing them to lie in olive oil for a few hours. There are other pure oils that are suitable for this purpose, but olive oil is preferable. This method is known as "feeding" pearls. In this plan of improvement the pearl absorbs a slight amount of the oil and becomes more lustrous, while the weight is also slightly increased.

Pearls that are worn by some invalids for a long time sometimes assume a dull color and are called "sick pearls." Long ago such gems were fed to fowls, which 
were soon killed, and then the pearls were removed from them. A plan which has become popular is to let servants wear them. This often improves the luster.

When the outer stratum is unusually bad, the pearl is improved by "peeling," although the next layer may also be imperfect. Some are greatly improved by experts who use secret preparations and methods.

Checked pearls are very common. The imperfections are often noticed under the outside strata and are generally caused by the drying out of the inner layers of the pearls. They are rather risky to keep as the check is a serious imperfection which is liable to grow worse. Such pearls do not command high prices.

Baroques are always imperfect pearls. They are often mounted in very attractive designs which represent various figures. Often these are made to represent the bust of some famous person or resemble. a bird or animal. The large number of the baroque designs are only limited by the imagination of the jewelers.

Many baroques are improved by scraping away dull or dead portions of the gems.

The improvement of imperfect pearls is sometimes done in an unfair manner. Such pearls should always be sold without misrepresentation. There are, however, honorable and legitimate methods and pearl hunters should use any fair system to increase the usefulness and value of any imperfect pearls they may find. 


\section{CHAPTER XXII.}

Imitations and Tests for Detecting Them.

T

IKE many other things of value, pearls have been imitated. Some of the imitations are very natuural in appearance, while others are very imperfect representations. For many years the Chinese have produced artificial pearl objects by introducing small flat metallic figures between the shell and mantle of the Dipsus plicatus, a large river mussel of that country. The figures are inserted carefully so as not to injure the mussel, which is returned to the water.

After a few months the mussels are again taken from the water and the figures are found to be covered with pearly nacre and are attached to the shell. They are then removed and used as ornaments.

The Japanese are more progressive in the art. They insert small porcelain domes inside of the Avicula Martensii, or Oriental pearl oyster. After four years the oysters are taken from the water and opened and the culture pearls and the natural pearls are gathered from them.

Through the courtesy of Mr. Fred Bahni, of Peoria, Illinois, a view of a Japanese culture pearl is shown in Fig. 47 .

The low domes become covered with layers of pearly 


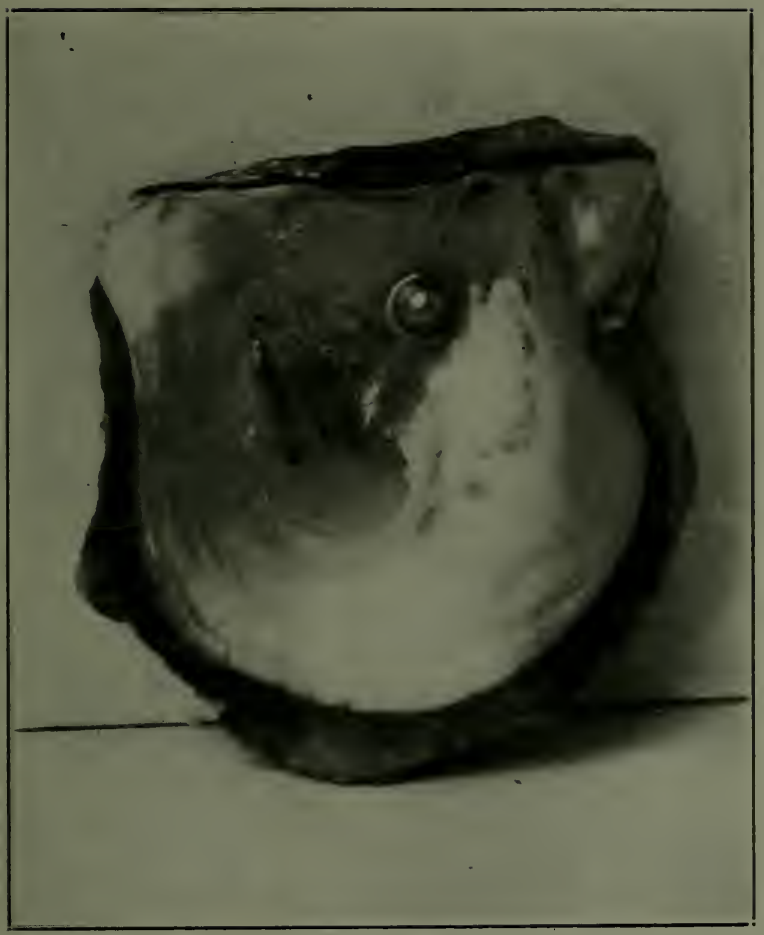

Fig. 47. Japanese Culture Pearl Attached to an Oyster Shell.

nacre and when the culture pearls are separated from the shells they are joined to other domes of mother of pearl of similar shape and size. They are then mounted in jewelry in such a manner as to conceal the lower mother of pearl portion. The Tapanese culture pearls have a 
fine tender luster, and except for the mother of pearl base they have the appearance of genuine Oriental pearls. Many of these are sold in this country to those who do not know their real quality.

The Japanese culture pearl is not entitled to the name of pearl because it is formed on an artificial base, and a portion of it is artificial. In case they should ever become "sick" they cannot be improved by "peeling," as the genuine pearls are improved, for the "peeling" process would expose the porcelain dome.

They are sold as Japanese culture pearls. The Japanese pearl industry is located in the Bay of Ago, Province of Shima, on the Pacific Coast of Central Japan. near the famous temple of Ise.

If a system of pearl culture can be developed in which pearls can be produced through the natural method, using parasites as nuclei for the pearls, such pearls would be genuine in every particular and should be sold as pearls, without discount or apology.

A very clever imitation has been recently placed upon the market. These are known as hard pearls and are made by coating a series of hard enamels over a suitable base. The system of building up the pearls from the inside with each strata of enamel completely enveloping the layers already formed is very similar to the natural growth of pearls.

The enamels which are used for this purpose are compounds of glass with different metallic oxides which produce the different colors. These are fused together at a very high temperature. The hard chunks of 
enamel are broken by a hammer and then ground to a fine powder. The powder is mixed with water and applied or "charged" to the object to be coated by means of a small spatula.

After each coating of the enamel the pearls are placed in a muffle and heated to a high temperature by electricity or gas.

The muffle is an oven made of fire clay. When the pearls are "fired" sufficiently the enamel fuses and they are ready to be taken from the muffle. When they are cool they are "stoned," in which process all rough parts are filed away with fine carborundum or emery stones.

When the pearls are "stoned" nicely another coat of enamel is applied to them and when they are dry they are "fired" again and "stoned," and so on until the pearls have been built up to required size. They are then stoned and polished and ready for use. They are very fine representations, but as far as colors are concerned the art has not reached the highest state of perfection. These can be distinguished from the genuine by their weight and texture, while their shiny surface suggests their glassy formation. They are, however, one of the best imitations. Another clever imitation is the fish-skin pearl. The method of making these was discovered in the seventeenth century. Hollow glass bulbs or beads are coated on the inside with a composition which contains a large per cent. of guanine, the mucus which lubricates the scales of the bleak fish. This was originally called "Oriental essence," and still goes by that name in Ecoufflians and Ponts-de-Ce. 
The bleak is the only river fish in France that is not used for food. They are very abundant in the Seine. Marne. Moselle and Escaut Rivers. The fishermen use nets and catch the fish by thousands as they travel in shoals in the current.

To obtain the "Oriental essence," the fish are scraped over a shallow tub containing a small amount of water. The scales are then washed and pressed and the essence settles to the bottom of the tub. It requires 20,000 bleak fish to furnish one pound of the essence. The essence is very brililant and if a drop of it is allowed to fall upon water the guanine floats and spreads, exhibiting many brilliant colors.

The "Oriental" essence is packed in tin boxes with ammonia and sent to Paris where it is used in manufacturing the fish-skin pearls. Many of these initations have a very delicate cream color and simulate the oriental pearls. They can be distinguished from genuine pearls by their weight and glassy shine.

Glass beads are very commonly used as imitation pearls. Some are made of opal glass and covered with several layers of isinglass with another coating of a mixture of turpentine and copal and oil and afterwards a thin layer of tinted soft enamel to give it oriency. Some opal glass beads are treated with fluoric acid. They have a ground glass appearance, however, which reveals their nature. Hollow glass pearls can be distinguished in several ways. They are usually coated on the inside and filled with wax. The ink spot test is a good one. If a small drop of ink is placed on one of these filled beads, 
two spots can be seen when the pearl is held between the eye and the light. One of these is the reflection of the ink spot and is on the inner wall of the bead resting against the wax. The reflected spot has a lighter color than the original. There would not be such a reflection in a genuine pearl. Hollow beads usually have one or two holes in them. These are smooth in the glass beads, while the holes in real pearls have a rough chalky appearance. Then, too, the glass beads which are filled with wax nearly always appear to have rings in the glass around the holes.

The hollow glass beads are much lighter than genuine pearls.

The solid glass beads are much heavier than real pearls and are not transluscent near the edge of the circumference like real pearls.

Black pearls are imitated by making balls from hematite and polishing them. They are, however, much heavier than real pearls.

Some very poor white pearls are drilled and temporarily colored by boiling them in a black color which penetrates through the strata of the pearls. These often have a bronze appearance and one should be suspicious of dark colored pearls that have been drilled.

Some gray pearls are simulated by making balls of mother of pearl and covering them with silver. Their weight and specific gravity are the same, but there is a difference in their luster. "Mock" pearls are those made from mother of pearl and polished. They have no luster and are otherwise easily detected. Another poor imitation is 
made by grinding mother of pearl to a powder and soaking it in vinegar and mixing it with gum tragacanth. This mixture is formed into balls and when partially dried they are placed in a loaf of bread and baked in an oven, after which they are coated with a fish scale solution to give them a luster.

Other poor imitations are balls made of plaster of Paris, which are afterward soaked in oil.

The most deceptive imitations are the Japanese culture pearls, the "hard," or enamel pearls and the best fish-skin pearls. 


\section{CHAPTER XXIII.}

\section{Ax Interesting Exhibit of Pearls.}

$1 \mathrm{~S}$ pearl hunters and others interested in pearls welcome information regarding these precious gems, the exhibit of pearls in the Field Museum of Natural History, Chicago, Illinois, is herein described. The collection of gems that during the World's Columbian Exposition drew so many to the Tiffany pavilion in the Manufactures Building, and to the gallery of the Mines and Mining Building, now occupies the central cases in Higinbotham Hall in the Field Museum.

The entire collection comprises a large variety of gems and precious stones, and is one of the most complete collections in existence. Many of the objects are of unusual interest and international reputation

The large variety of pearls in this collection is especially interesting. Here are found choice pearls from the various important pearl fisheries of the world carefully described so the visitor may make a thorough study of them. One case contains very valuable collections of pearls from Japan, Australia, Algiers, Singapore and California, and also pearl oyster shells, fresh-water mussels and other articles of interest.

Another case, which is divided into three sections, contains a valuable collection of Indian jewelry, illus- 
trating the remarkable variety of ornaments and jewelry used in India for more than 2,000 years. The first division contains many valuable gems including some beautiful pearls set in jewelry and embellished with rich red and green enamels peculiar to the Indian work.

The third division consists principally of necklaces and head ornaments. These are especially noted for the large number of pearls that are used in their construction.

A pair of ear-rings of red and green enamel and pearls from Goa add to the value of the collection of pearls in this division.

Other cases contain necklaces and other valuable jewrels from Brahma Amritsar, Jeypore, Kathiawar and Columbia.

All who visit this department of the museum will find the display of pearls and pearl jewelry of great interest. One of the very remarkable features of this collection of gems is the care that is taken of the collection. Probably no collection of European crown jewels is guarded more vigilently than the gems of the Field Museum. Day and night armed guards watch inside the room, while the outside is constantly protected by patrolmen. In addition the jewel cases are protected by a very ingenious and complicated electrical system. Any slight change in the cases causes alarm bells to ring in every part of the museum. Even the shelves which the jewels are mounted upon are balanced in such a delicate manner that the removal of even the smallest gem destroys the equilibrium of the shelf and sounds another 
set of burglar alarms. When the alarm is given, all entrances and exits in the building are locked and an emergency call is flashed to a nearby police station, and all the museum guards hurry to the jewel room.

This Museum is more accessible for the pearl hunters of the Middle West. Those in the East who wish to examine pearls in a public Museum should visit the American Museum of Natural History, New York City. This Museum has a collection of nearly 300 valuable pearls from the various pearl fisheries.

Another smaller collection may be seen in the Snithsonian Institution, United States National Museum, Washington. D. C.

DESCRIPTION OF PLATE I, PAGES r68 and I69, AND PLATE II, PAGES I84 AND I85.

Plate I. No. I, Large Round Pink Pearl, 64 grains; No. 2, Large Round White Pearl, 57 Grains; No. 3, Button Pearl, 29 grains; No. 4, Green and Purple Pearls, 3 to 8 grains; No. 5. Pink Pearls, 4 to I 2 grains; No. 5 , Pear or Drop Pearls; No. 7, Turtle Back Pearls; No. \&, White Pearls, 5 to I 5 grains; Nos. 9, Io and I I, Large. Medium and Small Nuggets, I to I8 grains.

Plate 2. No. I2, Large, Clear Slugs and odd pieces, 22 to 59 grains; No. I3, Rose Buds, or Strawberry Pearls, I2 to 72 grains; Nos. I4 and I5. Baroques, Points and Wings; No. I6, Nuggets and Slugs; Nos. I7, I8 and 19, Large. Medium and Small Points, or Dog Tooth Pearls. 
"The Best Beek fer Trappers Ever Published"

- THE -

Trappers' Companion

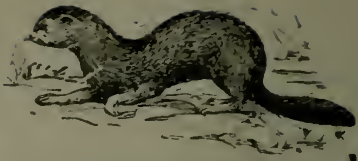

148 PAGES

NEARLY 100 ILLUSTRATIONS

The chapters which explain the trapping of the rarious animals give full particulars about traps, baits, scents. where and how to set traps for best results, etc. The methods and sets given are from the experience of the most successful American and Canadian Trappers. Every subject is treated by a man who writes from actual, extensive experience.

The articles treating on other subjects, such as grading raw furs, camp building, bee hunting, etc., etc., are all written by experts.

You would have to buy a Great Many Books, at an outlay of Several Dollars. to get Anywhere Near the amount of information contained in the Trappers' Companion, and then rou would not have it all. It is a necessary part of your outfit.

PRICE : FIFTY CENTS POSTPAID FUR NEWS PUBLISHING CO. ${ }^{71}{ }_{\text {NEW }}^{\text {W }}$ YoRK YoR

\section{Outdoor Pursuits for Profit and Pleasure}

ROOTS, BARKS, HERBS, LEAVES

Under this head 42 of the commoner botanical drugs are described, with 35 illustrations, showing how, when and where to find them, when to gather, how to handle for market, selling, etc. Invaluable for anyone interested in this subject.

Other chapters in this book are: GINSENG CULTIVATION GOLDEN SEAL CULTIVATION BEE HUNTING TURTLE TRAPPING FROG HUNTING $6+$ Pages-Illustrated

IF PRICE TWENTY-FIVE CENTS — POSTPAID FUR NEWS PUBLISHING CO. 71 WEST TWENTY.THIRD STREET NEW YORK 


\section{Mr. Pearl Fisherman!}

YOU SELL PEARLS

Do you always receive the full value of your find? Haven't you sent out goods and sold them at a figure far below their value because you haven't had another market to send them to? Haven't you had times when you wanted quick returns in cash for your pearls and still could feel that you were getting the best market prices?

You have been up against these conditions and that is why we state here that -

\section{W E B U Y PEARLS}

Are always in the market for high grade goods.

Always pay top notch prices.

Always report on shipments the same day we receive them and pay cash.

Always return goods, shipping charges prepaid if our offer is not accepted.

We have been buying pearls for twenty-four years.

We have hundreds of steady shippers and as to our reliability we refer you to any Banker or Jeweler or Dunn's or Bradstreet's Commercial Agencies.

\section{CONVINCE YOURSELF}

Send your next lot to us, packed securely in a sealed package, by Prepaid Express or registered mail and address to

\section{BUNDE \& UPMEYER CO M I L W A UKEE, WISCON I N}




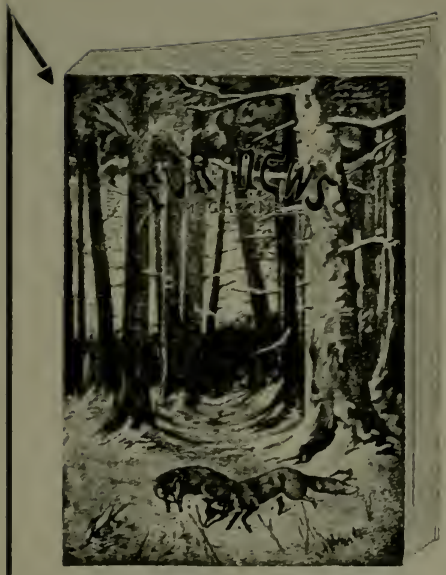

A Cover Design from F. N. M.

If you are interested in Trapping, Hunting, Fishing, Camping and Outdoor Life, you should read

\section{Fur News Magazine}

IT CONTAINS

Valuable information about trapping and hunting, giving methods and sets of the most successful American and Canadian trappers and hunters.

Reliable market reports and prices on raw furs, ginseng and other roots and herbs.

Good articles on outdoor life, camping, woodcraft and fur farming.

Gun department, of interest to all hunters and gun "cranks."

Articles on raising ginseng and golden seal.

Lots of good stories and letters about hunting, trapping,

fishing, bee hunting, turtle trapping and fur buying.

Valuable articles on the fur business and other interesting subjects.

Fine illustrations from photos and drawings.

If you want to get all your Raw Furs are worth, subscribe for

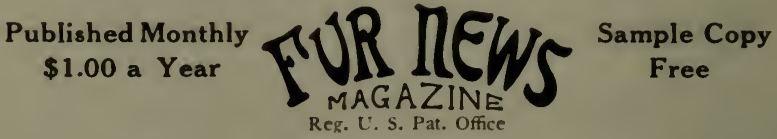

FUR NEWS PUBLISHING CO.

71 WEST TWENTY-THIRD STREET NEW YORK 


\section{PEARLS \\ SLUGS \\ NUGGETS}

H. WILLARD, SON \& COMPANY pay the Highest Market Value and they are large handlers of nice goods.

T Send them in by registered mail or express and they promptly make you a price by return mail, and if not entirely satisfactory they will be promptly returned.

I All goods held 10 days subject to approval.

\section{H. WILLARD, SON \& COMPANY}

Pearl Dealers

Marshalltown, lowa

MEYER JEWELRY CO.

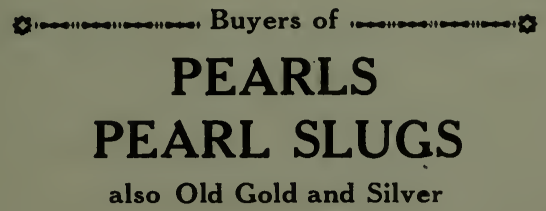

(D)

BOLEY BLDG. :: KANSAS CITY, MO. Reference: All Banks 


\section{Fur Farming for Profit}

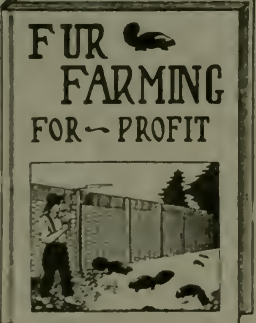

A Practical Book for those who wish to take up Fur Farming as a profitable occupation, or conduct it as a side line with other stock raising.

Fur Farming for Profit is written from the knowledge of various breeders who have learned the business by actual experience. It is Complete, Correct and Authenic.

192 Pages 60 Illustrations Cloth Bound PRICE 75 CENTS

\section{FUR NEWS PUBLISHING CO.}

\section{WEST TWENTY-THIRD STREET}

NEW YORK

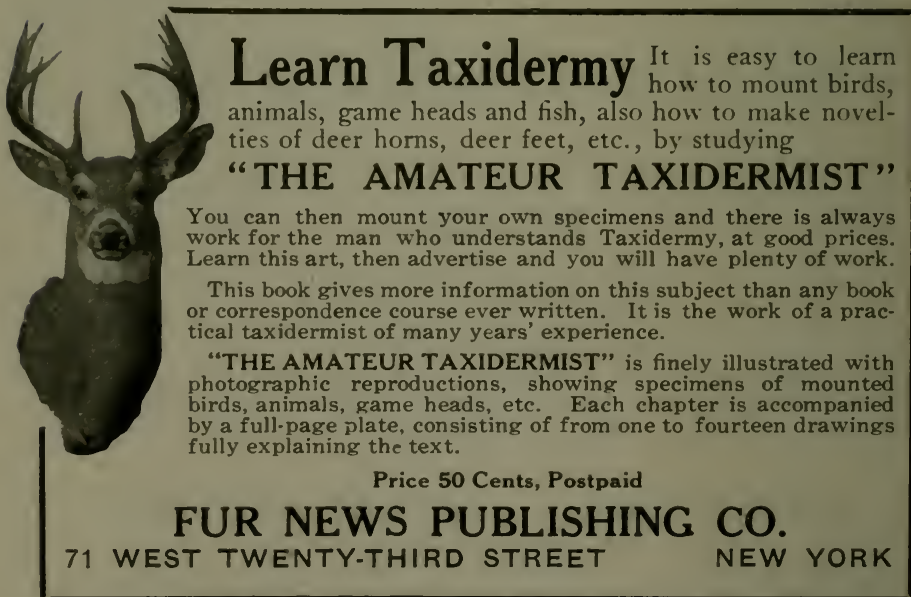





